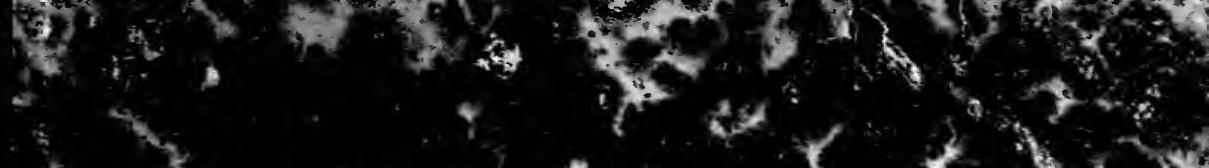

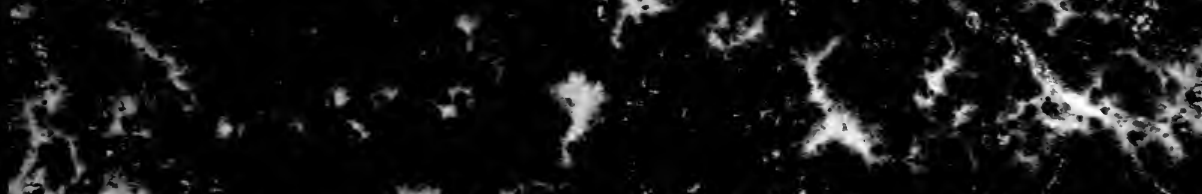
(3.)

$$
\begin{aligned}
& +2 \\
& 1: A \\
& \text { *.., } \rightarrow,+4
\end{aligned}
$$

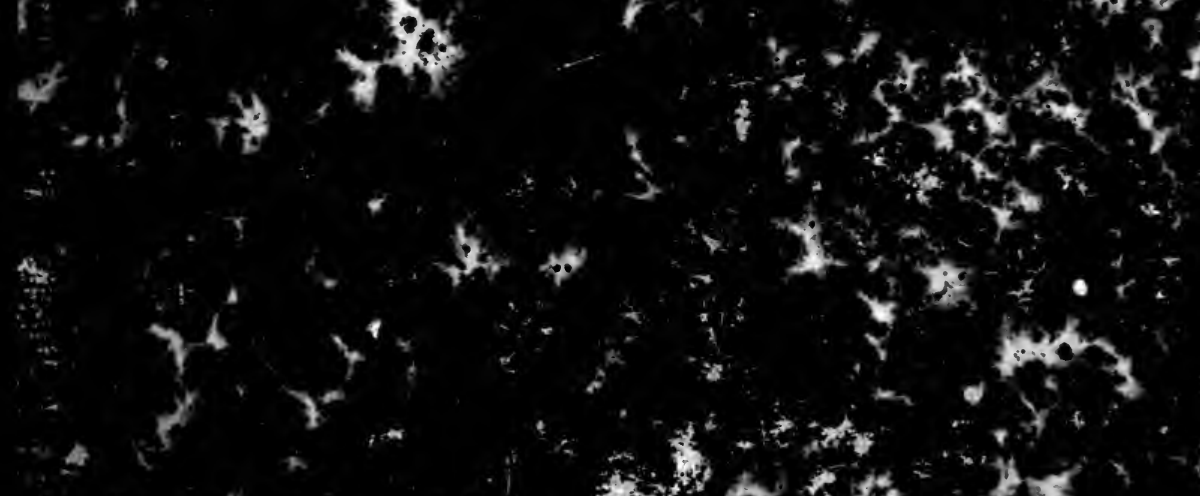

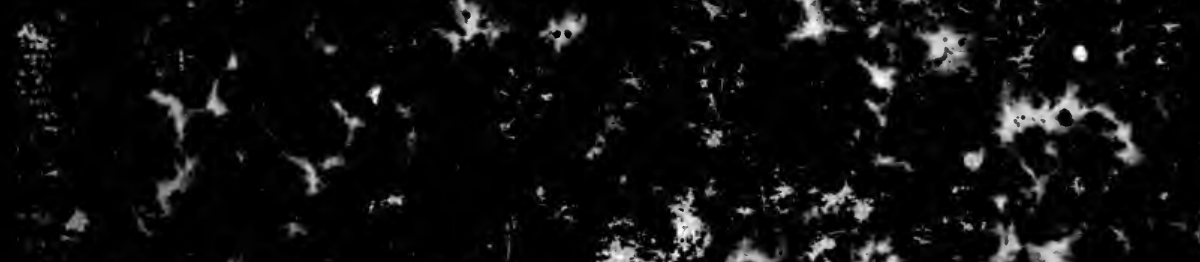

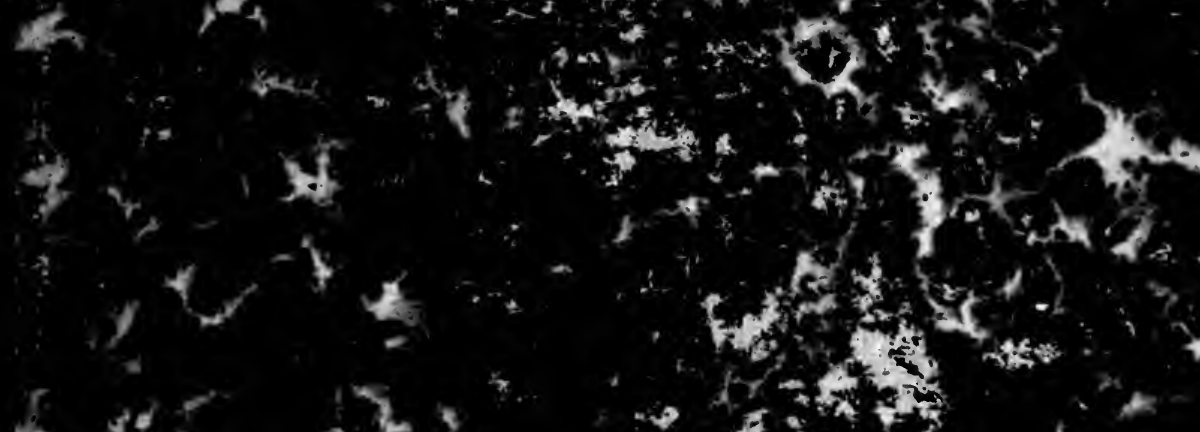

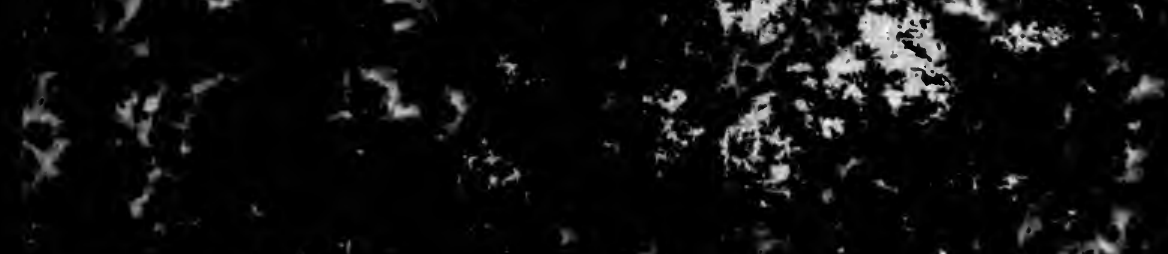

$$
\begin{aligned}
& \text { Hxis its }
\end{aligned}
$$

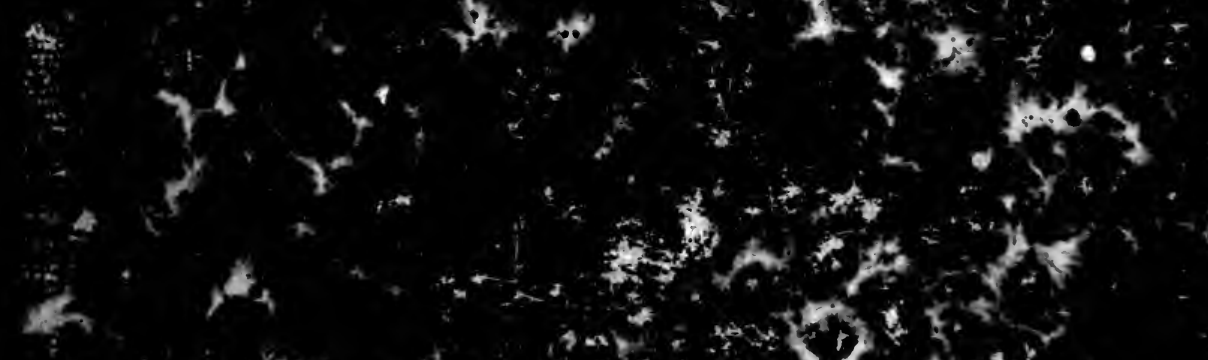

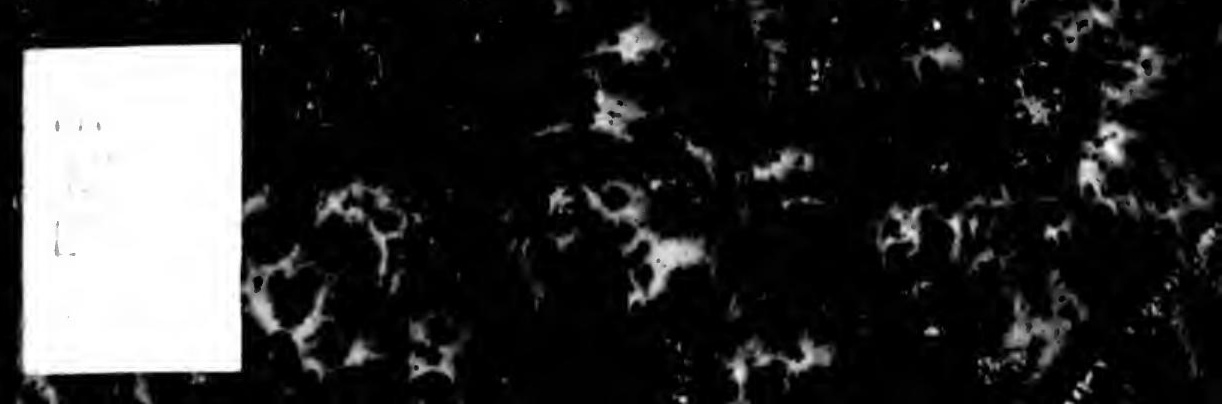





\title{
BETRACHTUNGEN ÜBER HOMERS ILIAS
}

\author{
VON KARL LACHMANN
}

MIT ZLSÄTZEA YOX NORIZ HALYT.

ZWEITE AUHLAGE.

BERLIN, 186\%.

DRUCK UND VERLAG VON G. REIMER. 


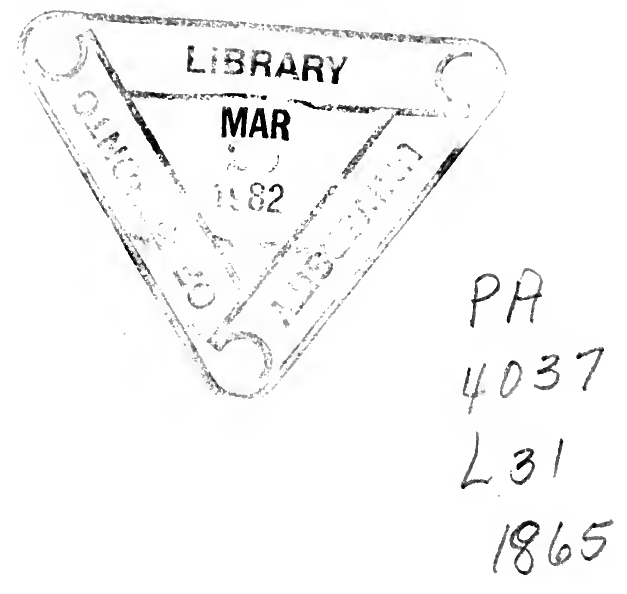




\section{ÜBER \\ DIE ERSTEN ZEHN BÜCHER DER ILIAS.}

(Gelesen in der akademie der wissenschaften am 7. december 1837.)

I.

Indem ich der akademie eine betrachtung der ersten butcher der llias vorlege, hoffe ich zwar zur entscheidung der frage uber den ursprung der homerischen gedichte etwas beizutragen, aber ich bin weit entfernt von einer etwa schon gewonnenen entscheidung auszugehn oder sie als das crgebnifs dieses aufsatzes zu versprechen. dem da nun einmahl die trägheit ein wesentliches stuck der menschlichen natur ist, wird es doch wohl erlaubt sein ilhr so weit nachzugeben, dafs man, so lange noch leichteres mit nutzen kann untersucht werden, das höhere den vorbereiteteren nachfolgern tiberlasse. ja ich weifs nicht ob die homerische frage nicht schon weiter gefördert sein k3nnte, wemn man, mit minderem aufwand von gelehrsamkeit und von theorie, nicht alles auf eimmahl aus den ersten grlinden zu erforschen versucht hätte, den ursprung und die ausbildung der troischen sagen, die entstehung von liedern ther die troischen begebenheiten, und die entstehung der beiden homerischen gedichte.

Ich will von der einfachen beobachtung ausgehen, die vielleicht schon viele gemacht haben und die gewils jeder zugeben 
wird, dafs manche stlicke in beiden werken in der form einzelner lieder gedichtet sind; ich will sagen, dafs, einstweilen zugegeben zwei auf einander folgende abschnitte seien ron einem dichter, oft nach dem ersten ein aufhören des gesanges und ein neues anheben roraus gesetzt wird. wähle ich unter vielen beispielen das nächste, so ist offenbar zwischen den zwei ersten bitchern der Ilias eine unterbrechung dieser art wahrzunehmen.

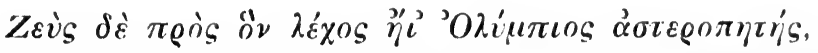

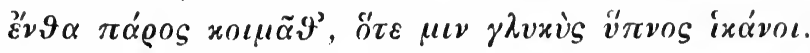

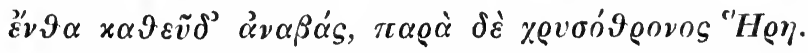

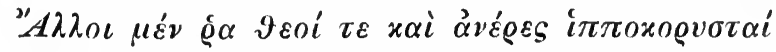

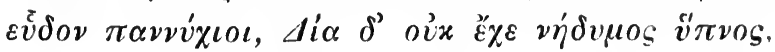

weder ist hier der gegensatz durehgeführt, 'alle giengen zu bett und schliefen, aber Zeus schlief nicht', sondern es heifst 'die götter giengen zu bett, und auch Zeus schlief. Alle götter' und menschen schliefen, Zeus aber nicht': noch war es zweckmäfsig, wenn doch dies folgen sollte, 'Zeus schlief nicht, sondern er rief den traumgott', vorher daran zu erimnern dafs neben ihm die goldenthronende Here lag, die von der berufung des traumes nichts wissen durite.

Und nun füge ich über diese form der epischen poesie, dals sie minder streng verknüpfte absehnitte sich gestattet, noch die bemerkung hinzu, dafs zu anfang der lieder auch scheinbar sehr enge verbindungen in gebrauch gewesen sein miissen; so dafs z. b. ein abschnitt der mit $\alpha \dot{v} \tau \dot{\alpha} \varrho \underline{\varepsilon} \pi \varepsilon \dot{i}$ anfieng, deshalb nicht eben streng mit dem vorher gehenden zusammen zu hangen brauchte. demn welche verbindung kam enger scheinen als die durch है $v \vartheta \alpha$ ? und gleichwohl fängt so die erzählung der Odyssee an,

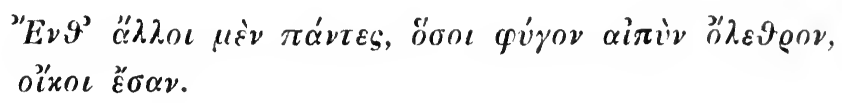

Wie weit sich nun im anfang der Ilias einzelne lieder vou einander absondern, wie sie ihrem inhalt nach gegen einander 
stehn, will ich, ohne von bestimmteren grundsätzen auszugehen, ohne fur jetzt nach einer ansicht über die ganze llias zu streben, fast ganz in der ordnung wie ich die untersuchung für mich gefithrt habe, aus einander setzen. ich bin selbst bei dem späteren oft zur betrachtung des fruheren zurück gekehrt: es wird mich daher nicht wundern oder verdriefsen, wenn bei fortgesetzter und umfassenderer forschung manches genauer und einiges anders bestimmt wird. nur ein rein negatives und polemisches verfahren sähe ich meinen beobachtungen nicht gern entgegen gestellt, weil dies in kritischen dingen immer nur zu abenteuerlichen tibertreibungen fuhlurt. 


\section{II.}

Bis zur auslieferung der Briseis, $A: 347$, liest man ohne sonderlichen anstols.

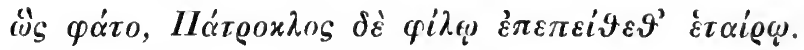

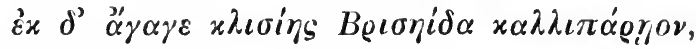

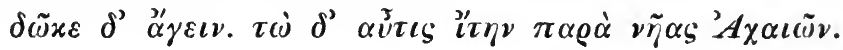

alles in der erzählung ist kunstreich gegliedert, aber auch vollendet in kürzerer darstellung der erfolge von v. 305 an, $I \eta \eta$ -

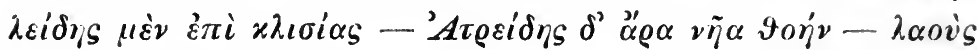
$\delta^{\prime}$ 'A A

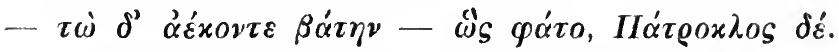

Nun aber folgen zwei fortsetzungen, die theils unter sich theils nit dem vorher gehenden nicht leicht zu vereinigen sind. die erste mag diejenige heifsen welche in die andere eingeschaltet ist, 480-492, die erzählung wie Odysseus die Chryseis zuruick bringt; die andere $348-429$ und $493-611$, Thetis bei Achilles und auf dem Olymp.

Die erste fortsetzung zwar ist nur bedenklich, wemn man sie mit der zweiten vergleicht, eben dadurch dafs sie in diese eingeschoben ist. nümlich in der zweiten heifst es 493

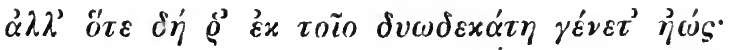

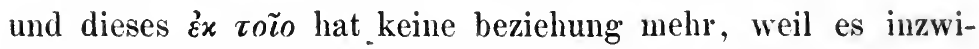
schen, in der ersten fortsetzung 475-477, nacht und wieder morgen geworden ist, ja 490 ff. sogar der verlauf mehrerer tage bezeichnet ist, wo es von Achill heilst

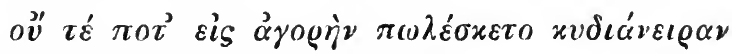

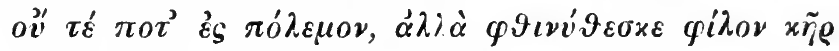

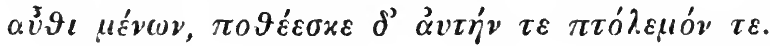


hingegen die zweite fortsctzung ist in sich im zusammenhang. gestern, sagt Thetis 424, sind die götter zu den Äthiopen gereist, am zwölften tage werden sie heim kehren: und richtig am zwölften morgen nach Thetis unterredung mit Achill, 498, kommen die götter in den Olymp zuriick. läfst man aber die erste fortsetzung gelten, so trifft Thetis voraussage nicht ein, sondern die götter kommen frühestens nach vierzehn oder funfzehn tagen wieder.

Also, da man einem dichter nie solche verkehrtheiten zutrauen darf, in unschuldiger zeit, die auf bestimmte anschauung hält, in dieser ordnung kann der erste dichter des anfangs die beiden fortsetzungen nicht gedacht haben. vielleicht nimmt man auch anstofs an der etwas steifen symmetrie in den an-

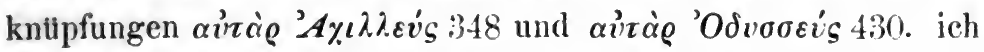
lege darauf für jetzt kein gewicht, und will lieber die manieren der epischen poesic erst lernen.

Setzen wir nun die erste fortsetzung unmittelbar an das erste lied,

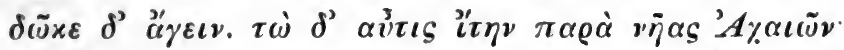

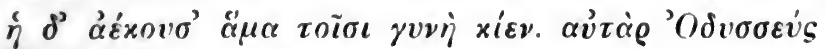

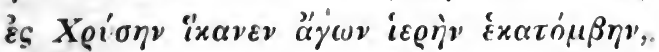

und lassen sie, wie gesagt, 492 schliefsen

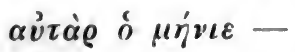

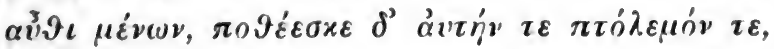

so palst alles genau zusammen, und der ausgang wird auf beiden seiten völlig zu ende gebracht, durch die auslieferung der Chryseis und das grollen Achills. die letzten verse aizà@ ó prive sind nothwendig hinzu zu fügen, damit die erzallung zuletzt wieder auf ihren anfang, den zorn des Achilles, zurick kehre. also der anfang des gedichts $A 1-34 \delta$ und die erste fortsetzung 431-492 haben entweder ursprlinglich zusammen gehört, oder der zweite dieser theile ist wenigstens sehr geschickt und im geiste des ersten hinzu gedichtet. 
III.

Hingegen die zweite fortsetzung $\boldsymbol{A}$ 348-429 und 493-611 ist eben so wenig als mit der ersten fortsetzung mit den haupttheilen der erzählung zu vereinigen. die vortrefflichkeit des gedichts erkenne ich vollkommen an: aber es kann nicht von demselben dichter sein, sondern er hat zwar das erste lied fortgesetzt, aber es ist ihm nicht ganz gelungen sich auch in den einzelheiten in die anschauung des ersten dichters zu versetzen.

Wenn die götter (423) seit gestern bei den Äthiopen sind, und Apollon nicht ausgenommen wird, so ist es wunderlich ihn von dort auf das achäische heer schiefsend zu denken, und Kalchas kann nicht sagen 96

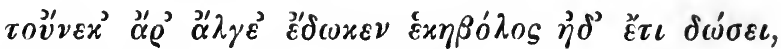

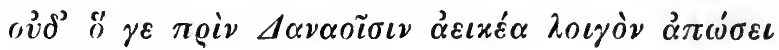

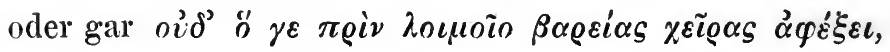

wenn man auch allenfalls zugiebt dafs Here und Athene 195 bei den Äthiopen den zank gehört haben und 474 Apollon bei

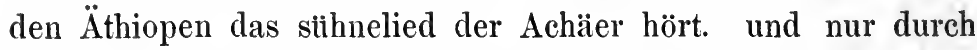
eine höchst gezwungene auslegung rechtfertigen die alten was 221 von Athenen gesagt wird,

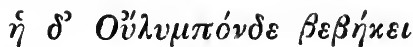

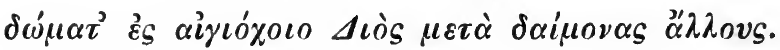

Ich habe den beiden fortsetzungen, der vielleicht echten und der von einem andern dichter, einerlei anfang zugeschrieben, 


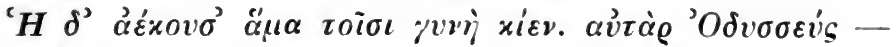

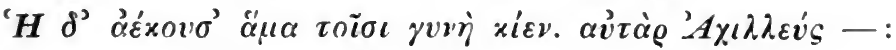

und so fällt das versstiick ganz weg 430

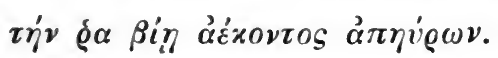

eine bemerkung die mir hr. Lehrs mitgetheilt hat, kommt mir

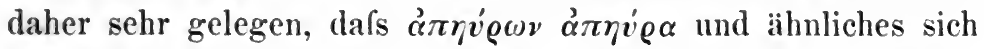
sonst nur am ende der verse finde. aber die gleichen anfänge beider fortsetzungen geben doch wohl der vermutung ein ibergewicht, dafs auch die erste nicht von dem verfasser des liedes ist.

In der zweiten nahm Aristarch an der $\dot{\alpha} v \alpha x \varepsilon q \alpha \lambda \alpha i$ i $v \sigma \iota s$ anstols, $A 370 \mathrm{ff}$.

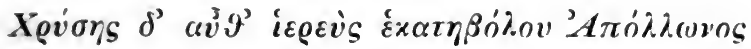

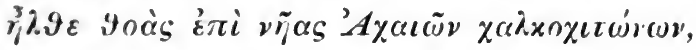

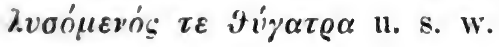

sie ist sehr sehön in einem andern liede, in einer fortsetzung, die so an einen andern beliebten gesang anmutig zurick erinnert. 
Im zweiten liede, wenn man dem dichter desselben nicht unrecht thun will, scheinen mir einige athetesen von bedeutendem umfang nöthig zu sein. ich will den zusammenhang nach den echten versen angeben.

B 1-52 Zeus sendet den traumgott an Agamemnon, der sich dann ruistet und am morgen die völker zur versammlung berufen läfst. $87-142,147-163,165-179,181-193,198-202$, 207-264 als sie versammelt sind, ermahnt er zur flucht, und sie widerstehn der versuchung nicht. Athene, von Here gesandt, rettet, indem auf ihren antrieb Odysseus die entfliehenden ermahnt und schilt. so kehren sie zur ruhe zurïck. Thersites, der noch lästert, wird von Odysseus bedroht. 333-483, 780-785 Nestor beruhigt die noch lermenden, indem er an Zeus glickverheifsenden blitz beim auszug erinnert, und heifst Agamemnon die völker scharen. nach dem opfer versammeln und ordnen sie sich zum kampf, Athene unter den feldherren, und ziehen aus.

Auch hier ist alles wohl angelegt, besonders auch die ge-

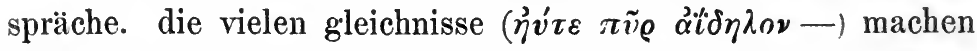
einen würdigen schlufs. auf das ausziehen gegen die Troer mufs eine schlacht folgen. aber das dritte buch in seiner einfachen darstellung pafst wenig zu diesem: es palst gar nicht, wenn man, wie ich es thue, die ristung der Troer streicht. diese aber, die einleitung zum katalog der Troer (786-815), ist gar zu dürtig, in der erfindung und in der schilderung des 
riistens, als dafs ich mich leicht entschliefsen könnte noch dieses stiick und den anfang des dritten buches $(\boldsymbol{\Gamma} 1$ bis 9 oder bis 16) hinzu zu nehmen. im folgenden ändert sich der ton augenscheinlich.

Das zweite lied zeichnet sich aus durch prachtvolle ausfuhrliche gleichnisse, $B$ 87. 147. 209. 394.455 ff. 780 . der

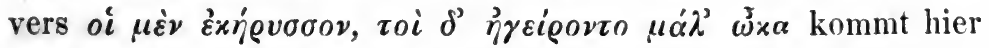
zwei mahl, 52. 444, sonst nicht in der Ilias. die darstellung hat etwas besonders alterthumliches, indem das innerliche, die gedanken und absichten verschwiegen werden, und der erfolg plötzlich hervor tritt. Zeus will den Achäern sehaden, darum heifst er sie zum kampf rüsten: er spricht aber nicht aus, wie ihnen der kampf solle verderblich werden. Agamemnon thut nicht nach dem befehl des gottes, sondern er klagt und reizt sie zur flucht: dafs er auf ihren mut rechnend das gegentheil

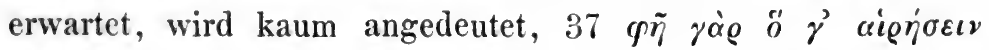

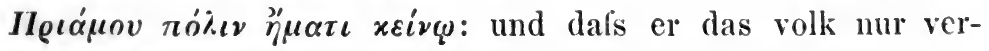
suchen will, steht nur als Odysseus vermutung da, 192

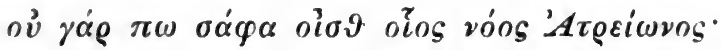

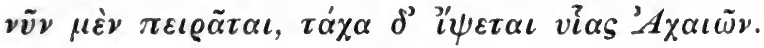

Die bezichungen auf das erste buch sind so sehwach, dafs der inhalt desselben dem dichter nicht sehr lebendig vorzuschweben scheint. niehts von der pest, nichts von Thetis bitte.

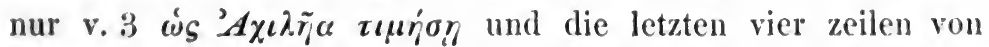
Thersites rede 2:39-2.42 gehen bestimmter auf Achilles beschimpfung und zorn. und wer weils ob diese vier zeilen echt sind? mit ihrer wörtlichen anspielung auf einen vers der zweiten fortsetzung des ersten liedes $A$ 356.507. Im achten liede $I 111$ ist die wiederholung desselben verses nicht unerwartet (s. XIII). die worte in der rede des Zeus. $B \quad 1: 3$

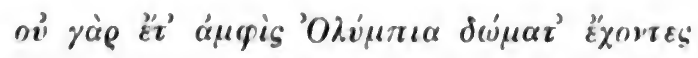

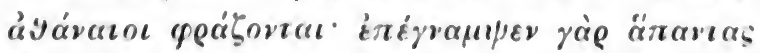

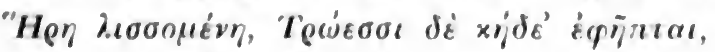

sehen jetzt wie eine luge in dem munde des gottes aus. ich 
werde später (IX) noch auf sie zuritek kommen. aber eine beziehung zwischen dem zweiten liede und der ersten fortsetzung des ersten ist unleugbar. die besehreibung des opfers, die sonst kiirzer gefalst zu werden pflegt, ist in beiden gleich ausführlich mit dem wiederholten $\alpha \dot{v} \tau \dot{\alpha} \varrho \dot{\varepsilon} \pi \varepsilon \dot{i}, A 458 \mathrm{ff} . B$

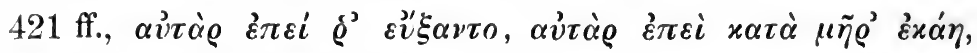

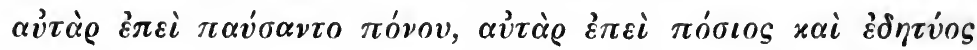

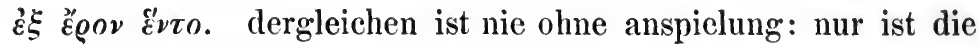
frage, ob hier das zweite lied an die erste fortsetzung erinnern will, oder diese an jenes. 


\section{V.}

Über die abkürzungen, die ich im zweiten liede nöthig gefunden habe, mufs ich noch einiges bemerken.

Wenn die beiden fortsetzungen des ersten an sich vortrefflich sind, so kann man dies von dem verworfenen sticke,

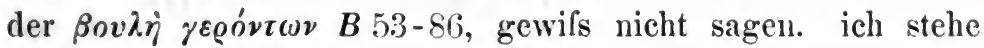
nicht an diese verse für schlechtes machwerk zu erklïren. die uberraschung durch die sache, dafs Agamemnon ganz wider des gottes geheifs die Achäer erst versucht, ist schon als auffallend bezeichnet worden: durch eine vorher gehende rathsversammlung der feldherren konnte sie freilich gemildert werden. aber der dichter wollte das nicht: denn wenn die ftuhrer des obersten feldherrn absicht wusten, so brauchten Here und Athene sich nicht $z u$ bemühen. und was hat denn der verfasser dieser erzählung vom kriegsrath weiter hervor gebracht als eine andre therraschung? und wo sie ganz unertriglich ist, im rath, statt in der sache. Agamemnon giebt nicht etwa seine gründe, wie sie in den rath gehören: 'wohlan,' sagt er 72-75, 'ob wir vielleicht die Achiler rusten! aber zuerst will

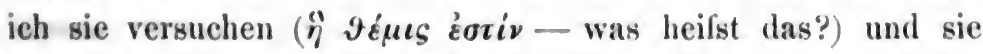
fliehen heifsen: ihr dann haltet sie zurttek.' ist darin wohl im mindesten mehr verstand, als wenn ihm nun Nestor antwortet 76-83 'wenn den traum ein andrer als der höchste der Achäer gesehn hätte, wttrden wir ihm nicht glauben. wohlan. ob wir vielleicht die Achlier rttsten.' ich Itbergehe was Aristarch sonst noch verstundiges wider die verse von Nestor ein- 
wendet (zu $B$ 75; vergl. zu 55): gegen das ibrige ist er offenbar zu nachsichtig gewesen. wie wortarm und unbeholfen ist der dritte von diesen versen!

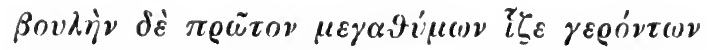

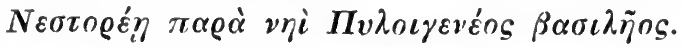

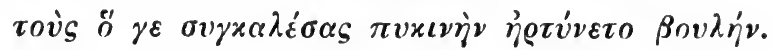
$x \lambda \tilde{v} \tau \varepsilon$, gí

dafs dann Zeus worte zum dritten mahl wiederholt werden, geht wohl auch iuber das mals des erträglichen.

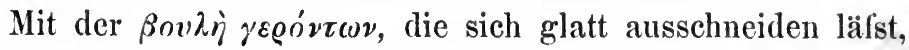
fallen nur zwei verse, und ebenfalls ohne spur nachzulassen, 143 und 194

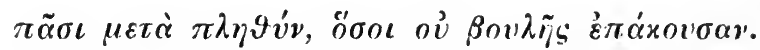

है

den zweiten dieser verse strich schon Aristarch mit den drei folgenden 195-197, aus guten gründen: weniger möchte ich ihm beistimmen, wenn er mit ihnen auch einen schon (IV) erwähnten verwirft, 193

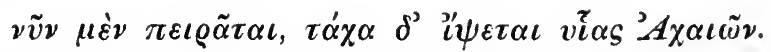

er thut es aber wohl nur, weil auf vias 'A $\mathcal{\prime} \alpha \iota \tilde{\omega} \nu$ nicht gut folgen konnte

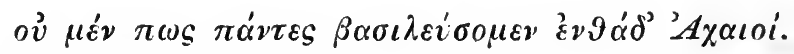

und doch muste dieser vers mit den zwei folgenden, wie er sehr richtig fühlte, hier stehen, bei der ermahnung der könige, nicht nachher in der anrede an das gemeine volk 203-205. ich will aber eher glauben dafs beide reden gleich unechte zusätze erhalten haben, von gleichem inhalt, 'die macht ist vom Zeus,' 194-197. 203-205.

V. 278-332 hoffe ich nicht ohne den beifall feinerer leser zu verwerfen. Odysseus hat das seinige gethan, er hat die fliehenden zuriick getrieben und den Thersites zum schweigen gebracht. dafs er danach eine lange rede hält, auf die kein 
mensch ricksicht nimmt, aufser dafs sie ihm beifall schreien, dafs er darin nieht einmahl, wie Nestor nachher 386 , auf die zur flucht treibenden zurlick kommt, dies widerstreitet einer vernünftigen ökonomie des epischen gedichts. olme zweifel ist es nur der versuch eines nachdichters, den helden hier noch zum dritten mahl auch im rath auszuzeichnen. auch dic Athene, welche bei seiner rede als herold die völker schweiget, 27:, ist nur eine schwächliche nachbildung der schönen stelle 446 , wo die göttin mit der ägis durch die scharen schreitet und ihnen mut und kampfbegier einflöfst.

Fallt num die rede des Odysseus weg, so missen entweder, wie ich bisher angenommen habe, die verse $265-27 \%$, ron der zuchtigung des Thersites, ebcufalls ausgelassen werden, oder aber v. 333-335, der beifallruf nach Odysseus rede. ich habe nichts dawider, wem jemand grinde hat lieber diese letzten drei verse zu streichen. mich leitet die bemerkung, dafs in der volkspoesie lächerliche scenen gern ins rohere ausgebildet werden: ich glaube daher, der dichter liels seinen Odysseus den Thersites nur bedrohen (bis 264), wortiber das rolk ihm zujauchzet (3938-3:35), und dies reizte einen nachfolger die strafe wurklieh vollziehn zu lassen (265-277).

Endlich der katalog der Griechen (B 4\$4-779) ist ein zu wichtiges stlick, als dafs es durch die vorher geherden prächtigen gleichnisse hätte diirfen verdunkelt werden. ich halte diesen katalog fiir ein besoldres lied, dessen stelle willkirlich ist, ob es gleich zu den liedern rom zorn des Achilles ausdrucklich gehört. mit dem zweiten liede hat dic nachahumug. des katalogs der Achïer, der troische, ebenfalls nichts \%u schatfen. von der einleitung zu demselben ist schon geredet worden (IV). 


\section{VI.}

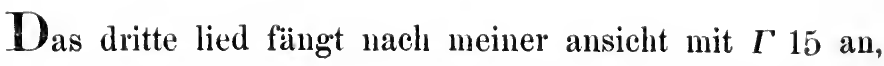

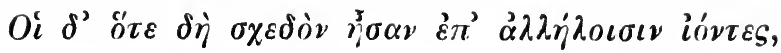

oder auch ohne weiteres, 16 ,

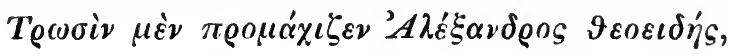

und es lälst sich, wie ich (VIII) zeigen werde, nicht weiter als bis an den schlufs des dritten buchs führen, wo Agamemnon nach dem versehwinden des Paris sagt 'offenbar ist Menelaus sieger. wohlan, ihr 'Troer, gebt uns die Helena zuritck.'

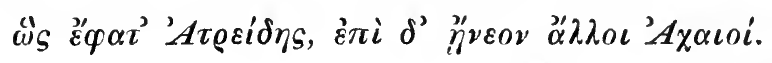

aber imnerhalb hat dies lied, wie ich glaube, bedeutende zusätze erlitten, und ich halte von den 461 versen des dritten buches nur etwa 170 und einige mehr für echt, 16-102. 111115. 314-382. 449-461. mit einem worte, Helena und Priamus gehören nicht in dies lied.

Erstens Helena. nachdem Menelaus dem Paris den helm abgestreift hat, heifst es weiter 379-382

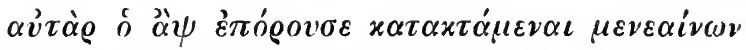

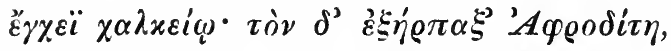

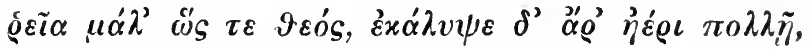

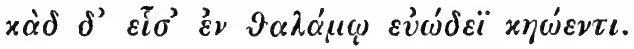

dieser erzählung vom verschwinden des Paris entspricht es 
vollkommen, wenn hierauf sogleich von Menelaus so fortgefahren wird, 449-454,

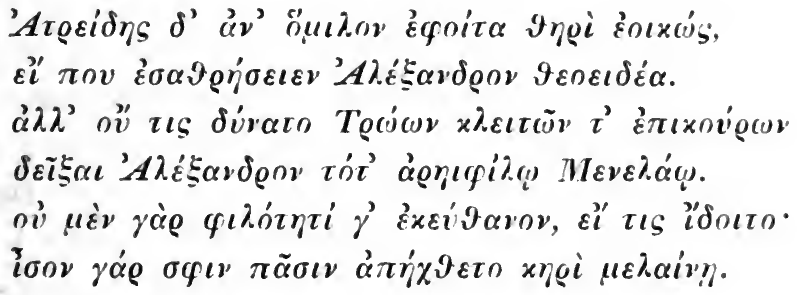

hingegen wird ganz das gefuhl der symmetrie verletzt, wenu von Paris noch in 66 versen 383-448 eraihlt wird. so verfehlt nur ein nachdichter das ebenmafs. und nicht minder störend ist die mit jenem abschnitt zusammen hangende teichoskopie 121-244. die unschicklichkeit der fragen an Helena in zehnten jahr des krieges kömite vielleicht der erste dichter dieses liedes so gut verschuldet haben wie ein interpolator: aber den ungeschickten ubergang von Aias auf Idomeneus, nach dem gar nicht gefragt war, 2:30, möchte ich ihm doch nicht zutrauen; und noch weniger die kindische abwechselung in den versen 171. 199. 228

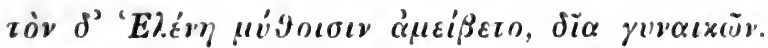

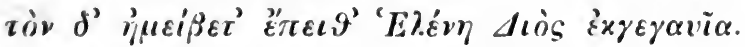

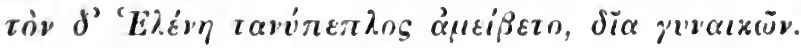

Aber mag, es doch um Helena sein, die ich hice gern ciner tieferen untersuchung therlasse; wenn ich nur therzeugend darthue dafs das auftreten des Priamus, auch aufser der teichoskopie, dem urspringlichen plan dieses liedes fremd war, 103-110. 116-120. 24i)-313.

Wo tinden die herolde den Priamus, als sie mit dem opfergerăth zu ihm kommen, 249? sein wagen scheint in der vahu zu sein: denn es wird sogleich angespannt, 259. 260. und dam aus dem skaischen thor gefahren, 2tii. die bestimmung des ortes, dafs die greise am skatischen thor sitzen, 1.44-14!? ist nothwendig fir die erzhlung vom bundesopfer, zwisehen 1 . 120) und 24a: wenu sie aber uach den absehnitten von Holena 
auf dem thurme sind, 15.3. 384, so sollte Priamus doch wohl herab steigen.

Ferner zu welehem zwecke wird der kïnig geholt? damit

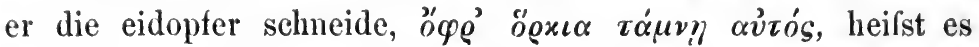
v. 105. das thut aber nieht er, sondern Agamemnon, 273

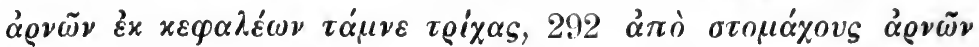

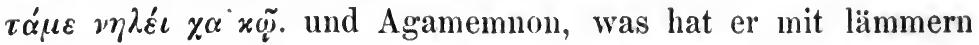
zu thun? nur ein lamm war für die Achäer geholt worden,

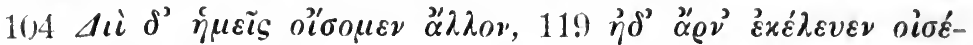

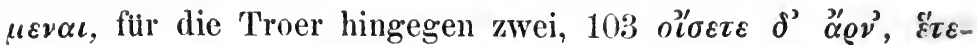

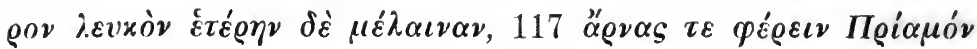

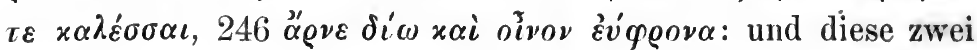

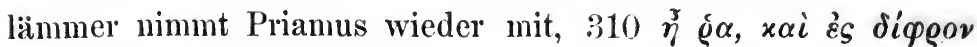

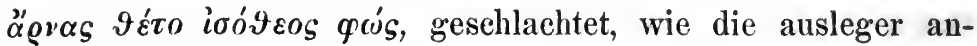
nehmen. dies alles ist eine abseheuliche unzusammenhangende erzählung, der mit gelehrten deutungen nicht zu helfen ist.

Wenn ich dagegen alles von Priamus auslasse, so ist das ganze im schönsten zusammenhang. nur ändert sich dann die fabel in einem nicht unwesentlichen punkte: das bundesopfer wird nicht vor dem zweikampfe dargebracht, sondern dies soll erst geschehen nachdem einer von beiden gesiegt haben wird, dabei ist der ausdruck immer, aber nur hier, 'die minne und eidopfer schneiden.' so sagt Paris 71

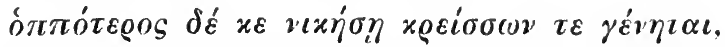

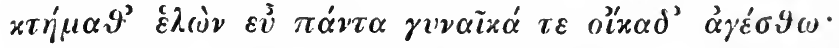

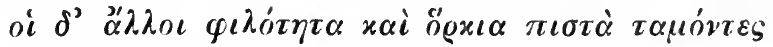

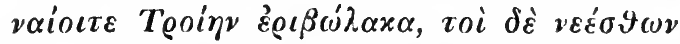

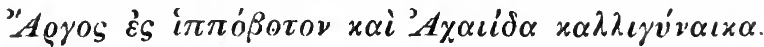

eben so Hektor statt der letzten drei verse, 94,

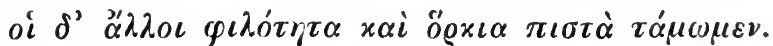
so beten die völker vor dem zweikampf, 320 ,

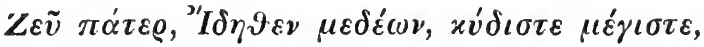

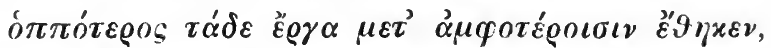

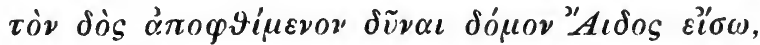

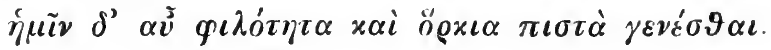


den zweifel kann ich für meinen zweck ungelöst lassen, ob der dichter des liedes am schlusse den Agamemnon nur sagen liefs

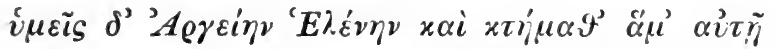

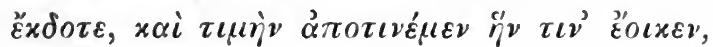

oder ob urspringlich schon, wie in dem eingeschobenen stiick 287 , darauf folgte 460

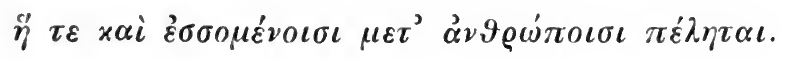

\section{VII.}

$\mathbf{W}$ ir haben bis hieher zwei mahl zusitze gefunden, die wir

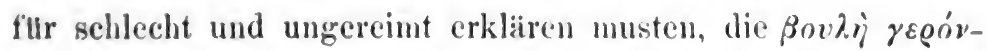
$\tau$ tov und die ögxı . beide stellen sehen nicht damach ans, als ob sie etwa nicht sowohl eingeschoben als durch anslassungen verdunkelt wiiren: doch wollen wir der kritik ja noch nicht die hände binden, und ihr vielmehr auch die annalme von lucken, wo sie nöthig sein sollte, vorbehalten.

Sonst will ich nur noch bemerken dafs wir im zweiten und in dritten buche der llias mit einfachen athetesen ansgekommen sind, gegen die von theoretischer seite selbst die strengsten vertheidiger der einheit des homerischen gedichtes nichts 
einwenden können. wer sich also von der verschiedenheit des tones in meinem aweiten und dritten liede nicht uberzeugt, und wer die rüstung der Troer ( $B$ 786-815 und etwa auch $\boldsymbol{I}$ '1-15) vertheidiget, der kann sagen, wenn er mir anch alle übrigen interpolationen zugiebt, das zweite und das dritte buch sind von einem dichter hinter einander weg gesungen. aber nicht so steht es mit dem ersten buche. dem wemn wir von diesem die zweite fortsetzung als ein widerstrebendes stick weglassen müssen, so fehlt zwischen $A$ und $B$ aller zusammenhang, wemn entweder

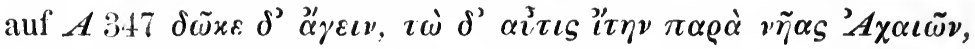

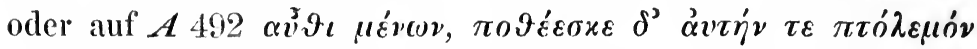

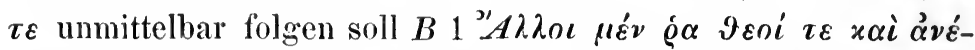

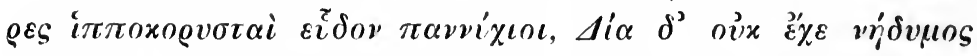
v゙rvos. wer also die annahme eines in den hauptabsehnitten beabsichtigten zusammen hangenden epischen gedichts fest halten will, der muls die zweite fortsetzung des ersten liedes mit aller gewalt vertheidigen. oder, da dies nun wohl schwerlich gelingen wird, jene zweite fortsetzung muls an die stelle eines verloren gegangenen celiten stiickes getreten sein. gegen diese ansicht labe ich theoretisch nichts zu erimnern: nur legt sie sich den beweis auf, dafs die echten stïcke unter sich iiberein stimmen, im inhalt, im stil, in der sprache, die unechten aber ihnen ungleich sind. ja vielleicht wird die erscheinung, auf die wir zunächst stolsen, manehen noch mehr zu dieser ansicht reizen, dann aber auch hofientlich zur beweisfithrung. 


\section{VIII.}

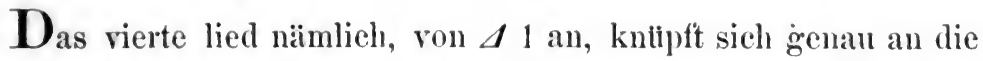
gesehichte des zweikampfes und an die entfihhrung des Paris, der sogar weder v. 10 noch sonst wo genamnt wird: und gleichwohl ist es keine fortsetzung des dritten liedes. denn ans dem dritten musten wir die öøx c hinweg sehaften: dieses aber hat

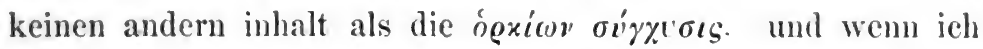
mich auch entschlösse die athetese der "gou anfzugeben, doch ist zwischen beiden stlieken niclit genug übereinstimmung. nach $\Delta 159$ reichten sie sich bei dem bündnifs auch dic hände,

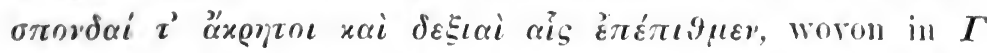
nichts vorkommt. indefs könnte man sagen dieser vers sei aus $B 341$ nur eingeschaltet. der bruch des bundes wirl in $d$ im-

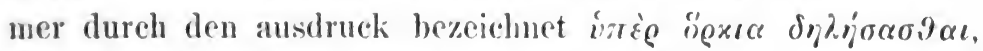
67. 22. 236. 271; in $T$ nicht so, sondern 117 diş rọxic $\delta \eta$ -

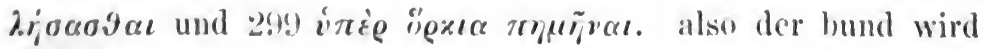
in $\Delta$ als abgeschlossen vorams gesetz, aber nieht von dem darsteller desselben in $\Gamma$ : mitlin contweder fehlt uns ein ganz andres lied oder stffck fur $\Gamma$, oder wenigstens statt der von mir verworfenen verse eine andre ausfithrung. alber man wird wohl lieber sagen ein andres lied: demn bei $d 1$ ist ein liedesanfang wie $B$ 1, da hier an den schlufs von $I$ durchans nicht wieder angekntpft wird, namentlich nicht an Agamennmons worte imeis J'A 'A

Das vierte lied also enthält den gobtterrath. Menelaus verwundung, das anrldeken der 'Troer, und die sugenannte zanaí- 
$\lambda \eta \sigma \iota s$ Agamemnons, - also den bruch des bundes und die vorbereitung zur schlacht. allein diese vorbereitung sehliefst A 421 ohne ibergang, ohne dafs man erfährt wohin sich Agamemnon begicbt: und erst $\boldsymbol{E} 38$ kommt er wieder vor. also bei $\Delta 421$ ist der schlufs des liedes, oder wenigstens ein abschnitt bei dem eine unterbreehung des vortrages voraus gesetzt wird. hier wirde man mit besserem grunde das funfte buch haben anfangen lassen, wenn es nieht dadurch tiber tausend verse bekommen hätte.

\section{IX.}

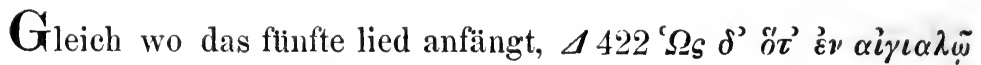
$\pi o \lambda v \eta \gamma \varepsilon \dot{\varepsilon} \iota$ $x \tilde{v} \mu \alpha \vartheta \alpha \dot{\alpha} \sigma \sigma \eta s$, zeigt sich ein ganz anderer uns aber bereits wohl bekannter eharakter der darstellung, nämlich der des zweiten liedes. ja, wenn man es recht bedenkt, auf $\boldsymbol{B}$ 483 oder 780-785 kann man, ohne eine störung zu bemerken, 4422 unmittelbar folgen lassen. denn die beziehung auf das vierte lied, auf die verwundung des Menelaus, ( $\boldsymbol{E} 206$

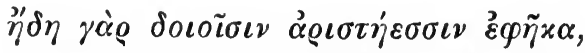

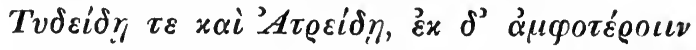

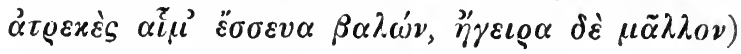


scheint mir nicht sehr wichtig, da sie in der langen und gewifs ursprünglich nicht ganz so langen rede des Pandarus vorkommt. dagegen stimmt eine bedenkliche stelle des zweiten liedes genau mit einer des fünften zusammen, in einer fabel die uns das erste buch nicht iberliefert. dort sagte Zeus $B$ 14, Here habe alle götter durch flehen bewegt zur gunst für die Achäer: und hier im fünften liede $E 832$ sagt Athene, Ares habe ihr und der Here versprochen gegen die Troer zu streiten und den Achäern beizustehn.

Ich erlaube mir bei diesem liede mich der rechte eines anfängers zu bedienen. wenn auch der hauptinhalt desselben wohl der kampf mit den göttern ist, so sind doch die begebenheiten so abwechselnd und mannigfaltig, dafs man, noch ungeubt und ohne auf das einzelnste der darstellung und selbst der sprache einzugehen, nicht hoffen darf mit einiger wahrscheinlichkeit die ursprünglichen und die etwa später eingefiigten bestandtheile des liedes zu unterscheiden. wer also nach mir sich an das schwerere wagt, dem mag auch ïberlassen sein zu entscheiden, ob etwa das zweite und las flinfte lied von einem dichter sind, oder ob nur einer streng der manier des andern folgt. er mag auch entscheiden ob es zu vereinigen ist dafs Athene im zweiten liede $B 446$ mit der aigis unter den Achäern geht und dafs sie im fünten $E$ 738 sie sich erst um die schulter wirft; ob tiberhaupt die riistung der göttimen und ihre fahrt ins heer hier im füften liede $E$ 711-792. $907 \mathrm{ff}$. einem später folgenden $\Theta 350$ fr. nachgeahmt ist, oder umgekehrt. ich sehe nur so viel, dals bei der jetzigen fassung der anfang von $Z$ noch zum funften liede $\%$ rechnen ist: demn nur nachdem eben gesagt worden ist, die götter seien in den himmel zurick gekehrt, kaun man den vers verstehen,

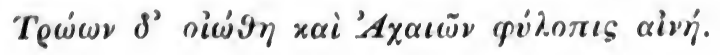




\section{X.}

Gleich mit dem folgenden verse aber, $\boldsymbol{Z} 2$

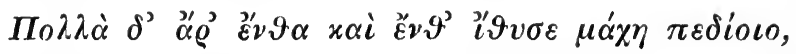
oder mit dem nächsten absatze, 5

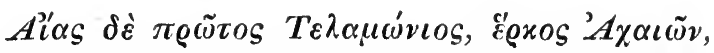

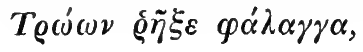

fängt ein neues lied an, das sechste.

Es schliefst sich nicht genau an die vorher gehenden begebenheiten. die unvollendeten óøxı aber wunderbar, bei dem zweikampf zwischen Hektor und Aias ist nirgend eine beziehung auf den des Menelaus mit Paris, auch da nicht wo Menelaus selbst sich zum kampf mit Hektor anbietet. also die erinnerung an das dritte und vierte lied zeigt sich eben nicht stark im sechsten. sehr wichtig scheint mir dafs Andromache $Z 435$ sagt, drei mahl sei schon von den feinden die mauer am feigenbaum versucht worden; wovon aber im fiinften liede nichts zu finden ist. Aristarch tilgte die sieben verse $Z$ 433-439, ö $\tau \iota \psi \varepsilon \tilde{v} \delta$ os $\pi \alpha \rho \dot{c} / 0 v \sigma \iota v$ die andern gründe, die er gegen sie aufsucht, halte ich nicht für erheblich.

Das ganze lied hat einen milden und anmutigen charakter. schilderung der kämpfe wird vermieden. die begegnung des Glaukus und Diomedes ist ein vorspiel zu Hektors besuch bei Andromache. die kurze aufzählung der kämpfe $\boldsymbol{Z} 5$-36 ist ganz 
wie die andere $\boldsymbol{H} 8-14$. Helenus veranlafst in $Z$ Hektors gang in die stadt, er auch in $\boldsymbol{H}$ den zweikampf. Nestor, der im fïnf.

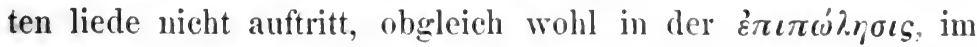
vierten, erscheint hier sowohl in $Z$, 66, als in $H, 123$. dies alles macht glaublich dafs $\boldsymbol{Z}$ und $\boldsymbol{H}$ ein zusammen hangendes lied sind, bis $\boldsymbol{H} 312$

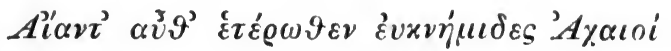

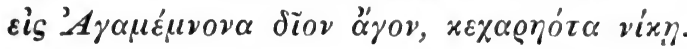

W as aber mun folgt, $H$ :313--Q25,, hat nicht mehr den mindesten \%usammenhang mit dem vorigen, ansgenommen etwa in

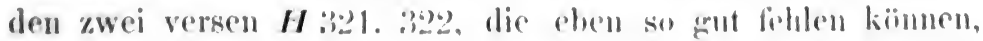
wo dias beim mahl mit dem rllekenstlick des stiers geehrt wird. $\boldsymbol{H} 3351$ wird in vorbeigehen der hundeshonch erwihnt. in allem ubrigen pafst dieses stllek nur soweit hieher, als das sochste lied mit dem einhruch der nacht endigte, hier aber die Achiser nach dem opfer vor nacht sich berathen, und die 'Truer rol' dem abēndessen. 
Die erzählung ist so kurz und ungeschickt, dafs man selbst die tage nicht sicher berechnen kann. $\boldsymbol{H} 381$ ist es morgen, 421 wird es tag, 433 noch nicht (wieder?) morgen, 465 geht die sonne unter, $\Theta 1$ wieder auf, 68 ist mittag. es eräugnet sich viel und mancherlei in noch nicht 500 versen; vier mahl essen $\boldsymbol{H} 313.370$. 466. $\Theta 53$ (das letzte mahl am morgen, nachdem eben $\boldsymbol{H} 476$ die ganze nacht durch geschmaust worden ist), vier mahl donner und blitz, $\boldsymbol{H} 478$. $\Theta$ 75. 133. 170, zwei götterversammlungen $\boldsymbol{H} 443 . \Theta 1$, eine reise des Zeus $\Theta$ 40 , er wägt die todesloose $\Theta 69$ und sendet den adler mit dem hirschkalb in den klauen $\Theta 247$, ein gespräch zwischen Here und Poseidon $\Theta 198$, ein rath der Achäer, ein rath der Troer und eine botschaft, die todten werden verbrannt, die mauer der Achäer wird in kaum zwanzig stunden gebaut mit thor und graben $\boldsymbol{H}$ 433. 465, Nestor verliert fast sein leben $\Theta 90$, die Troer werden fast in Ilios eingesperrt wie lämmer $\Theta 130$, Hektor ziindet fast die schiffe an $\Theta 217$ : aber nirgend kommt die scene zur klarheit, die darstellung zur ruhe. man kann dies stiick, wie es aller einheit ermangelt, nicht ein besonderes lied nennen, und gewifs mit recht hat es Hermann schon in der vorrede $\mathrm{zu}$ den hymnen s. vu als ein auffallendes beispiel des elendesten nachahmerstils aufgestellt. am richtigsten hält man es wohl fuir eine vorbereitung auf das folgende, die an die stelle des echten anfangs getreten ist. 


\section{XII.}

Denn wie wird nun mit einem mahl alles wieder anders und hell! mit den versen $\Theta 253$

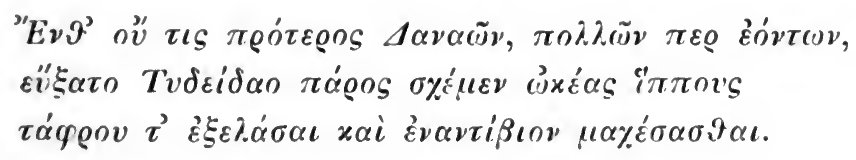

ton und darstellung zeigen dafs wir uns hier in einem andern liede befinden, das ieh das siebente nennen will. von dem rorigen wird hier allerdings einiges voraus gesetzt. der graben vor dem achäisehen lager ward in den vorher gehenden liedern nicht erwähnt: in dem verworfenen stlicke war er um die neu erbaute mauer gezogen, $\boldsymbol{H}$ 440. 449. der mauer erwälnt indefs auch das siebente lied nicht. die Achiier sind nach jener verworfenen einleitung $\Theta 213$ zwisehen den graben und die maner zurtick gedrängt: im siebenten liede rticken sic tiber den graben aus, $25 \%$, und treiben die Troer $\pi \rho \circ i^{\prime \prime} I \lambda \iota 0 \nu 295$, werden

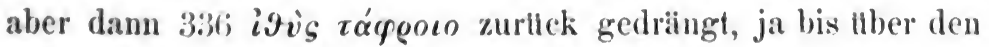
graben 343. anch finden wir 397 Zeus auf dem lda sitzend, wohin er sich im anfang des achten buches, v. 47, begeben hat. trotz diesen ubereinstimmungen wage ich mich auf das gebildete gefuhl jedes lesers zu berufen: es ist unmöglieh dafs ein dichter in so verschiedenem ton, so armselig und so vortrefflich, dic einleitung und das siebente lied kann gesungen haben. das aber ist klar, dafs das siebente lied jetzt keinen an- 
fang hat: die risstung der Here und Athene und ihr versuch den Achäiern zu helfen $\Theta 350$ ff., wobei auf den inhalt der zweiten fortsetzung des ersten liedes angespielt wird (372), gehört wohl auch noch zum siebenten: für den schlufs wird man $\Theta 484$ nehmen dïrfen, wo die göttinnen, von Zeus gescholten, still schweigen.

\section{XIII.}

W eiter können wir nämlich nicht gehen. denn $\Theta 485$ erfolgt der untergang der sonne so unpassend als möglich, ohne dafs erst die Troer heimkehren. es ist doch wahrlich nicht genug, wenn nachträglich in die erzählung eingeschaltet wird, Hektor habe sie von den schiffen an den flufs gefïhrt, 489

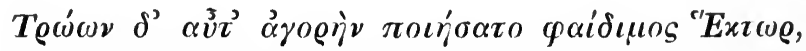

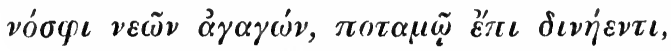

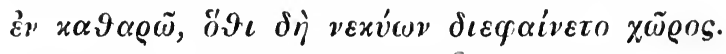

Es wird nicht nöthig sein dafs ich bei diesem achten liede, der gesandtschaft an Achilles, ins einzelne gehe: es scheidet sich bestimmt genug aus und trägt ïberall den stempel der nachahmung. nur das will ich bemerken, wie Homer, der doch 
ein halbweg verständiger dichter gewesen sein wird, sich hier so schmählich selbst parodiert, indem er den Aganemnon $I$ IT die Achäer, ernsthaft oder sie versuchend, zur flueht ermahnen lärst mit denselben worten in die $B 110$ die erste versuehung gefarst worden war. kleinlich ist auch $I 34$ die beziehung auf

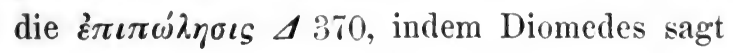

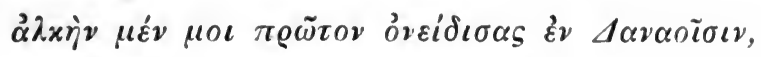

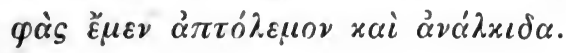

die mauer ist $I 349$ eben erst gebaut, wie in dem stitcke ror dem siebenten liede. alles scheint mir den ton späterer nachdichtung zu haben, die wohl auch schon auf das zusammen reihen der erzählungen in einer stätigen folge ausgeht. 


\section{XIV.}

Das neunte lied, $K$, die Dolonie, sondert sich von dem vorher gehenden und folgenden rein ab. im folgenden buche $\Lambda 1$ wird es zu spät morgen: denn bei dem ausgang der beiden helden $K 251$ ist er schon nah, auch haben sich beide $K 578$ schon zum frühmahl gesetzt. $\Theta 491$ versammelten sich die Troer

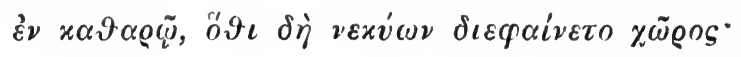

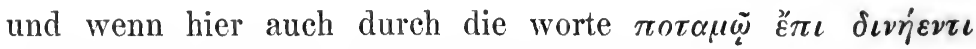
eine etwas grölsere entfernung bezeichnet wird, so kann es doch niemand loben dafs sich $K 199$ nun in derselben nacht die könige der Argeier jenseit des grabens auch wieder setzen

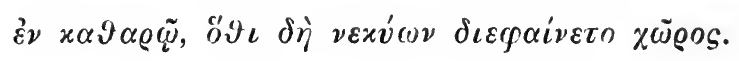

und wenn irgend iiberlegung und sparsamkeit bei dem aufbauen eines epischen gedichts waltet, wie kann ein dichter dazu kommen, in einer nacht wo die wachtfeuer der Troer ganz nah bei den schiffen brennen, beides und zwar nach einander unternehmen zu lassen, die aussendung der boten an Achill, und die der beiden helden die spähen oder den feinden schaden sollen? dafs aber Odysseus beide mahl mit muls, ist gar ungereimt oder doch höchst armselig. wenn also beide darstellungen wuirklich dieselbe nacht meinen, so sind es verschiedene sagen, unmöglich von einem dichter dargestellt, aber doch von dem anordner der Ilias hier richtig, wenn auch nicht ganz geschickt, zusammen gebracht. ist hingegen in der sage die ordnung der schlachten und der begebenheiten so fest nicht gewesen, so haben die beiden lieder vielleicht gar nicht dieselbe nacht gemeint. 


\section{XV.}

Da ich nur betrachtungen uber einen theil der Ilias versprochen habe, wird es mir wohl erlaubt sein hier beim elften buche abzubrechen, zumahl da untersuchungen dieser art sich nicht auf verlangen zu jeder zeit führen lassen, sondern nur in den besten stunden.

Aber im elften buche fangen ja gerade die versuche Hermanns an, wenigstens die ausgefithrteren und weiter greifenden, in seiner abhandlung de interpolationibus Homeri (opuscula V p. 52): sollte ich nicht sagen mutissen, ob sie mir eben so wahr scheinen als sie gewifs sinnreich sind? siunreich, und wohl uberlegt; so dafs es gleich erfreulich und elrenvoll sein würde, sie weiter zu bestätigen oder sie zu widerlegen, wer es könnte. ich aber mag mich zu dem nicht drängen was ich vielleicht nur unvollkommen ausfuhrte: mögen andere sehn ob sie recht thun blindlings zu folgen oder unbesehn zu widersprechen. genau genommen habe ich ja bis jetzo kein näheres recht zum urtheilen. denn da unsere wege doch etwas verschieden sind, da ich mehr als Hermann darauf aus bin die urspringlichen abschnitte aufzufinden und den umfang der einzelnen lieder zu bestimmen, so milste ich erst meine untersuchung selbständig gefuhrt haben. wenn sich anch allenfills ergeben sollte dafs in den folgenden bitchern nicht mehr wie bisher sich die einzelnen theile so bestimmt sondern liefsen, demnoch irst daun wenn von verschiedenen seiten her die versuche witrklich gemacht wären, könnten sie gegen einander als mafsstab dienen, und vielleicht eine wahrheit ergeben, die durch gegenseitige beschränkung bestimmt wïre.

Ich glaube mich daher nur berechtigt und verpflichtet das za vergleichen was Hermam uber einen von mir auch bereits behandelten abschnitt sagt. um mich gauz frei zu erhalten, 
habe ich absichtlich Hermanns aufsatz erst nach der schriftlichen abfassung dieser betrachtungen wieder gelesen: und es freut mich sehr dafs ich jetzt nur einen bestätigenden nachtrag zu liefern habe, iibrigens aber kein buchstab zu ändern war.

Hermann nimmt (s. 63) mit recht anstofs am anfang des achten buches, $\Theta 1-51$, wo Zeus den göttern mit harten drohungen untersagt Troern oder Achäern zu helfen. sehr unpassend, sagt er, fahren dann Here und Athene ganz offen im wagen unter die heere den Achäern zu hilfe. ich hätte diesen widerspruch, wie gewifs manchen andern, nicht ohne nutzen anmerken können, wenn er mir eben aufgefallen wäre. die fahrt der göttinnen ist in meinem siebenten liede, die götterversammlung in dem stücke welches statt des fehlenden anfanges zu diesem liede hinzu gedichtet ist. der verfasser desselben mochte denken, der widerspruch sei dadurch gehoben dafs er Athenen $\Theta 35$ zwar versprechen lälst sich des krieges zu enthalten, nicht aber des rathes den sie den Argeiern geben könne. aber in der erzählung von den göttinnen ist vom rath nicht die rede, sondern sie riisten sich mit waffen zum kriege 376. 388, und Zeus leidet nicht dals sie in die schlacht gehen.

Hermanns meinung ist nicht dafs die ersten 51 verse des achten buches zu tilgen seien (s. 68): aber er will sie vor $\boldsymbol{N} 4$ wiederholt wissen, wo sie ihm, glaub ich, urspriinglicher scheinen. dals sie sich dort sehr gut ausnehmen würden, ist keine frage: ob aber so starke verkiurzungen und umstellungen bei der einrichtung der Ilias würklich geschehen sind, darüber zu entscheiden ist nicht meines amtes: denn in den ersten zehn buichern habe ich zu dieser annahme keinc veranlassung gefunden. für den satz, auf den Hermann hier baut, dafs die rhapsoden an gleiche anfänge verschiedene erzählungen geknüpft haben, ist uns aber wenigstens ein bestätigendes beispiel begegnet (III), dafs die beiden fortsetzungen des ersten liedes ganz gleichen anfang hatten,

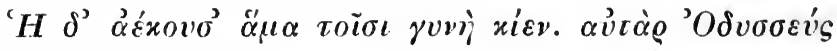

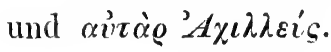




\section{FERNERE \\ BETRACITUNGEN ÜBER DIE ILLAS.}

(Gelesen in der akademie der wissenschaften ain 11. merz 1841.)

\section{XVI.}

Die sehriftliehe uberlieferung der homerischen gediehte im griechischen alterthum beruhte cinrig auf der arbeit des Pisistratus und seiner gefaihrten. dies erhellt aus der art wie die alten, zumahl vor der zeit der grammatiker, ihre zweifel an einzchen versen ausdrickten. wo ein ästhetisches bedenken war, wie der gegrundete verdacht einer gegen die weise des katalogs ausgefullten licke da wo von Aias, der mit zwölf schiften ron Salamis kam, nichts weiter gesagt ward als ( $B$ ins)

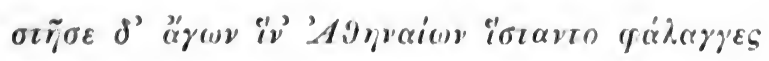

(denn einen andern als den isthetischen anstols nahmen hier gewifs erst die Alexandriner), oder wem in der véxues als mensehen der vorzeit, dic Odysseus noch haitte selin künnen, sehr unschicklich nur \% wei genannt wurden, in dem rerse ( $\lambda$ (i:31)

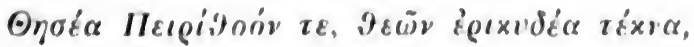

so schrieb man dic interpolationen, weil sie attische gesinnum verriethen, dem Solon oder dem Pisistratus zon. ist, ebenfills in der vexuca ( 2 6012. 6033), der dem (Odysseus erscheinende 
Herakles nur ein schattenbild, während er selbst unter den göttern wohnt, so dachte man bei dieser wunderlichen vorstellung an einen geistlichen mann unter den uberlieferten oder vermuteten helfern des Pisistratus, den Onomakritos, dem daran liegen konnte den in Attika zuerst göttlich verehrten heros auch in den Homer als gott einzufälschen. weil die Sikyonier etwas von einer stadt Donoessa zu wissen glaubten, hatte Homer, meinten sie, so geschrieben: Gonoessa ( $B$ 573) komme auf rechnung der attischen unkunde. aber das waren urtheile und vermutungen, nicht erwiesene thatsachen: niemand berief sich auf buicher die von der attischen überlieferung abwichen: und wenn die von Megara, wie erzählt ward, die attischen verse vom Aias umsangen ( $\dot{\alpha} \nu \tau \iota \pi \alpha \varrho \omega \delta \tilde{\eta} \sigma \alpha \iota$ nennt es Strabo, indem er den anfang davon giebt), so wollten sie gewils nur sagen, statt jener abgeschmackten zwei verse miisse man etwas schickliches und nach ihrer behauptung wahres setzen. wie sollte denn auch, in einer zeit der die kritik fern lag, mehrere mahle unternommen sein was von Pisistratus allgemein ausgesagt wird, dafs er die hie und dort zerstreute homerische poesie gesammelt

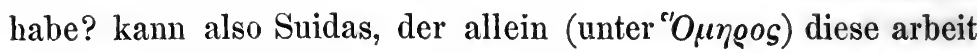
auch vielen andern aufser dem hauptsammler Pisistratus zuschreibt (

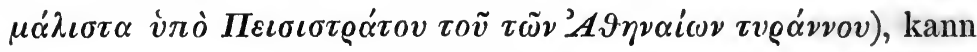
er anders als die gehilfen des Pisistratus milsverstanden und in viele andre, also sehr von einander abweichende, eben so ungereimt verwandelt haben, als in neuerer zeit von grofsen abschnitten der Odyssee behauptet ist, Aristoteles habe sie nicht gelesen, oder als gegen aristarchische athetesen anfuhrungen bei Platon oder gar bei Plutarch geltend gemacht worden sind?

In der nachricht iiber die arbeit des Pisistratus liegt aber nothwendig die aufgabe, deren lösung ich für einen theil der Ilias in einer der akademie vor drei jahren vorgelegten abhandlung versucht habe; wie ich sie jetzo, nach einem neuen anlauf, den ich ohne aufmunterung von freunden vielleicht nie gewagt hätte, auch bei den ubrigen biichern desselben gedichts glaube lösen zu können. dafs auch schon die alten gefragt 
haben ob die zusammen getragenen stïcke nicht hin und wieder noch zu erkennen seien, lehrt eine sehr bekannte stelle des Eustathius, deren inhalt man oft ohne nachdenken firr ein ïberliefertes gerucht von einer thatsache, statt für das verstaindige urtheil und die vermutung eines kritikers, genommen hat; (p. $785,42)$ die alten sagten, die Dolonie sei von Homer besonders gesetzt und nicht in die theile der Ilias eingereiht worden $(\mu \grave{\eta} \dot{\varepsilon} \gamma \varkappa \alpha \tau \alpha \lambda \varepsilon \gamma \tilde{\eta} v \alpha \iota)$, erst Pisistratus habe sie in die poesie gesetzt. unter den alten versteht Eustathius, wie jeder kenner weifs, die ihm vorliegenden ausziige aus alten grammatikern. in guten scholien wïrden wir dafür den namen eines Aristophanes von Byzanz oder fruhestens des Aristoteles finden: und der zauber wäre verschwunden, den das wort $\pi \alpha \lambda \alpha \iota$ i auf unkritische leser ausiibt. der urheber dieser ansicht von der Dolonie folgte natiurlich der hergebrachten annabme, dafs Ilias und Odyssee von einem einzigen dichter in stiicken verfafst worden seien, die der zusammenfiigung fähig waren, oder schon von ihm selbst zusammen gefïgt. wer vor der attischen sammlung derselben meinung war, schrieb die stlicke die er kannte und sich selbst in seinen gedanken in zusammenhang brachte, dem Homer zu, gewifs nicht mit der schïrfsten kritik. als die arbeit des Pisistratus verbreitet war, für deren sämtliche einzelheiten jene friheren nicht zeugen kömmen, verlor sich was etwa noch in anderer fassung umgieng, und die reiche thervollständige sammlung ward gern fill des einen dichters echtes werk angesehn. wemn aber wir, mit einem hoffentlich nachgrade feineren kritischen gefithl als wir es dem pisistratisehen zeitalter zutrauen, und aus grlinde'n die offen dargelent jeder nit eigenem sinne prllten mag, die cinzelnen stllcke wieder heraus erkennen und uns liberzeugen dals sie nicht alle ron einem und demselben dichter sein können, sollen wir da, ans blinder ehrfurcht vor dem alterthm, unser gefthl und unsere grithde lingen strafen, und riner mur auf alter, aber auf keinen beweis, gestutzten annahme zu liche eine erforschte und begrllndete thatsache verwerfen? es ist hicr nichts heiliges, keine rechtgläubigkeit, die von der stolzen höhe des sicheren wissens herab) 
griibelnden frevel und entweihung beklagen diurte. also griunde wider griinde! aber kein wehklagen, und kein anathema!

Zu soleh einer rechtfertigenden und vorbeugenden einleitung, ich gesteh es, habe ich in dieser versammlung keinen grund. ich weifs dafs ieh hier mit dem unschuldigen satze durchkommen werde, dal's es bei jedem buche, selbst wenn der verfasser sich nennt, erlaubt ist zu fragen ob es von ihm oder ob es von mehreren sei, und dals, sobald der zweifel nur einigen grund hat, vor dem erweise die annahme eines und des uberlieferten verfassers eben sowohl annahme ist als die entgegen gesetzte. hier darf ich gewil's unbefangen die friheren untersuchungen fortfiihren, und ich muls nur in voraus um verzeihung bitten wenn sie je schwieriger um so weitläuftiger werden sollten. 


\section{XVII.}

Man hat lïngst die unermefsliche dauer und den verworrenen thatenreichthum des tages bemerkt, der $\Lambda 1$ anfingt und bis $\Sigma 240$ währt, wo nach dem auftreten Achills der somnengott noeh wider willen zum Ocean geschickt wird, nachdem es vorher zwei mahl, $\Lambda 86$ und $I I$ 777, mittag geworden und nach $P 384$ einen ganzen tag um Patroklus, den lebenden und den todten, gestritten ist. im siebenten liede $\Theta 475.476$ ist das auftreten Achills auf einen spaiteren tag ( $\left.\eta_{\mu \alpha}^{\prime} \mu \tau \iota \tau \tilde{\nu}\right)$ angekindigt, nicht auf den nächsten: der ort wo un Patroklus leichnam soll

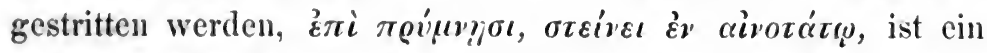
anderer als wo nachher wïrklich darum gestritten wird, nämlieh theils in der ebene theils an graben aufserhalb des schifflagers: und wemn ich recht verstehe, soll sich an einem tage der kampf un den leichnam und Hektors tod begeben. Aristareh hat den widerspruch getilgt, aber er erklïrt nicht wie ihn jemand so gedankenlos in das fertige in cinem sinne gedachte werk bringen konnte. die verschiedenheit des ortes fithrt oftenbar auf verschiedene dichter, die versehiedenheit der zeit wenigstens auf einzelne gesänge die sieh nieht \%u beklummern brauchten. gleichwohl milssen wir uns htten die einzelnen theile hier als so getrennt und unabbingig von einander zu hetrachten wie wir bisher die meisten gefunden haben: demn alle stimmen in einem unstande gleichmalsig uberein, der fur die fabel der llias so wichtig ist als der zorn des Achilles selbst, dafs die drei bedeutendsten helden, Agn- 
memnon Diomedes und Odysseus, fuir die dauer der kämpfe unbrauchbar werden. es gilt also zunächst den kühnen versuch, aus dem verwirten gebtische den stamm richtig heraus zu finden : und das können wir nur weun wir seinem edeln wuchse von der wurzel aus nachgehen. den bau und die art des zehnten liedes, das mit dem elften buch anfängt, muissen wir uns zur anschaumng bringen, um seine grenzen zu crkennen. einer kleinlichen betrachtung kann sich hier nichts ergeben. 


\section{XVIII.}

1 1-71. Eris, von Zeus ausgesandt, schreit den Achäern mut ein. alle riisten sich, voran Agamemnon, den Athenäa und Hera mit gerassel begleiten. sie rücken aus über den graben, zuletzt die zu wagen. die Troer stehn auf der höhe des feldes, unter Hektor Polydamas und dreien Antenoriden. die völker stiurzen auf einander und mähn wie schnitter.

Hier aber kommt unschicklich (denn nachdem Hermann in der vortrefflichen abhandlung de iteratis apud Homerum auf dergleichen gewiesen hat, darf es einem nicht mehr entgehen) ohne fortschritt ein neues gleichnils: die schnitter werden 72 plötzlieh zu wölfen. eben so unpassend ist die folgende ausschmilckung. 'Eris freute sich: denn sie allein war bei der schlacht, die andern götter safsen ruhig in ihren hïusern auf dem Olymp.' aber eben haben zwei göttinnen dem Agamemnon zu ehren gerasselt, nachher 437 schitzt Athene den Odysseus vor dem tode, auch ist Iris bei Zeus 185, und wie wir noch sehn werden (XIX) Apollon. 'alle,' heifst es weiter, 'tadelten den Zeus, dafs er den 'Troern sieg geben wollte.' alle, sagen die Alexandriner mit recht, sei nicht wahr. 'er aber ent-

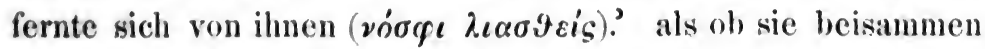
gewesen wären, sagen die Alexandriner. 'und setzte sich um die völker und die schlacht zu schanen.' vom himmel? fragen die alten; da er doch nachher nöthig findet von da zum Ida zu gehn. die kritiker thaten sehr wohl sechs verse $78-53 \mathrm{zu}$ streichen: nur hätten sie auch die sechs vorher gehenden 72 77 mitnehmen sollen. 
A 84-192. 195-207. Um mittag durchbrechen die Achäer die reihen der Troer. Agamemnon, der held welcher bis jetzt allein genannt ist, tödtet drei paare, zwei freunde, zwei Priamiden, zwei Antimachiden. die T'Troer fliehen; Hektor, von Zeus dem gedränge entriickt, und Agamemnon ihm nach, bis nah an die stadt. da geht Zeus vom himmel zum Ida und sendet die Iris zu Hektor. er soll weichen bis Agamemnon verwundet sei: dann wird der gott ihm kraft verleihn.

'Zu tödten,' heifst es weiter 193. 194 und wiederholt 208. 209, 'bis Hektor zu den schiffen gekommen sei und die sonne untergehe.' dies widerstreitet aber dem rathschlufs den Zeus später ausspricht, $O 232$ die Achäer sollen bis zu den schiffen fliehn, sich aber dann erholen. die alten verwarfen des widerspruchs wegen die verse welche diesen rathschlufs enthalten. solcher reinen willkür bin ich abgeneigt: aber wenn mir gelingt zu beweisen dafs die stelle die den rathschlufs des Zeus enthält zum zehnten liede gehört, so mufs ich hier die verse

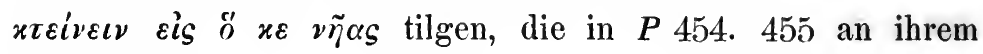
platze sind.

1210-496. Die Troer, von Hektor ermahnt, stehn den Achäern. Agamemnon tödtet die Antenoriden Iphidamas und Koon: aber von diesem durch die hand gestochen springt er auf den wagen und eilt zu den schiffen. Hektor, da er dies sieht, ermahnt die seinen und erschlägt neun anführer und vieles volk. die Griechen fliehn, bis Odysseus den Diomedes ruft. beide tödten drei paare. da macht Zeus die schlacht auf beiden seiten gleich. Hektor, nachdem Diomedes den Agastrophos zum tode verwundet hat, wirft sich auf die beiden helden. Diomedes trifft Hektorn ohne ihn zu verwunden. Hektor entweicht betäubt, springt auf den wagen und enteilt. während Diomedes den Agastrophos beraubt, schiefst ihn Paris, am grabmahl des Ilos stehend, mit dem pfeil in den fufs, so dafs ei, von Odysseus auf den wagen gebracht, zu den sehiffen fahren mufs. Odysseus ist allein ohne hilfe: von den Troern gedrängt erlegt er nach vier andern die Hippasiden Charops und Sokos, welcher letzte ihm in die seite sticht. auf sein rufen erscheinen 
zum schutz Aias Telamons sohn und Menelaus, der vierte und füfte Griechenheld, die wir nach der sparsamen und iberlegten art dieses liedes bald thätig zu sehn hoflen. aber Menelaus, nachdem er den rerwundeten zum wagen gefiihrt hat, lärst lange auf sich warten: Aias haut ein, und finf werden genannt die er sogleich tödtet.

Hier folgt ein zusatz, der mit jedem verse bedenklicher wird und anch schon von Hermann (opusc. V, p. 61) verworfen ist. $497 \mathrm{f}$. 'Hektor wufste daron nichts.' ganz richtig, obgleich wir es uns nach dem vorher gehenden 360 auch wohl selbst sagen. 'weil er entfernt stritt, auf der linken seite der

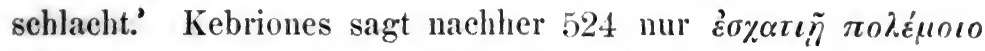

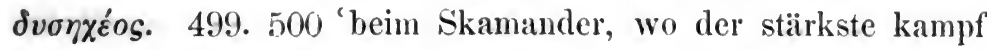
war.' nein: er ist am stärksten um Aias, sagt Kebriones 528. 501-503 'dort wo Nestor und Idomeneus waren.' aber dies lied nennt die helden nur wenn sie thätig sind, und beide werden uns hier gar nicht begegnen, Idomeneus ruhet bis $N 210$. 504507 'und die Achäer wïren nicht gewichen, wenn Alexandros nicht den Machaon in die schulter geschossen hätte.' dort beim Skamander, weit entfernt, auf der linken seite der schlacht? eben war er noch grade auf der andern seite, in der mitte des feldes 167, am grabmahl des Ilus 371, bei Odysseus und Diomedes, den er verwundete. und ist es wohl in der art dieses liedes, dals nun 508-520 auf Idomeneus rath Nestor und Machaon die schlacht verlassen ohne etwas nambaftes gethau \% haben?

1521-539. Der dichter des liedes läst den Kebriones, der das whten des Aias sieht, Hektorn rom andern ende her in seine nahe fahren. er springt hinab und beginnt den kampf.

Doch wohl mit Aias? o nein, sondern in drei oder vier versen 540-54:3 erfahren wir dafs Hektor den kampl mit Aias vermied. wenn doch alle interpolationen so deutlich und auf richtiges urtheil gegrilndet wären! dep interpolator hihlte was hier folgen muste und doch noch lange nicht kommt. anf den letaten dieser verse, welchen die handschriften nicht hahen, ohne zweifel weil ihn die Alexandriner tilgten, pafot der fol- 
gende echte wie die faust auf das auge. 'er mied den Aias: denn Zeus gönnte ihm nicht mit einem besseren manne zu streiten: Zeus sandte dem Aias flucht.'

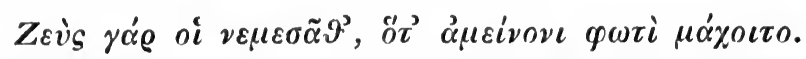

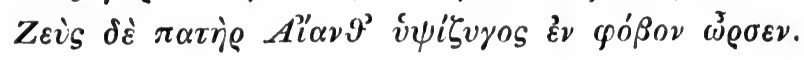

1544-557. Nicht Hektor vermied den kampf, sondern Aias floh, sagt der dichter, und setzt nach dem vortrefflichen gleichnils vom löwen hinzu, Aias sei ungern von den Troern gewichen: 'denn er fürchtete für die schiffe der Achäer.' wohl zu merken, er war ihnen also schon ziemlich nah.

Dals nun hierauf das zweite gleichnifs vom esel unschicklich folge, hat Hermann mit feinem und richtigem gefühl bemerkt. daran aber hängt ferner, um den Aias zu schuitzen, nicht etwa Menelaus, den wir erwarten, sondern Eurypylos; und zwar ohne sonderlichen nutzen: denn Paris, der also überall ist, verwundet ihn. Aias steht, da er zu befreundeten gelangt ist. dann wird an das frither verworfene stück von Nestor und Machaon angekniipft. wenn nun vor diesem, 596, wie Hermann meinte (opusc. V, p. 61), oder schon etwas frïher, 557, das lied schlösse, so wäre es unvollendet. Hektor hat nach Agamemnons abgang 284-309. 343-360 zu wenig gethan um das versprechen des Zeus $192 \mathrm{zu}$ rechtfertigen. Aias auf der flucht, oder thatenlos stehend, erregt erwartungen eines schlusses, der aber fehlt. endlich war Menelaus als thätig angekündigt, er hat aber noch nichts gethan. sollen wir abschliefsen, der erfolg fehle, oder geduldig noch weiter suchen? 


\section{XIX.}

I ch denke sagen zu dirfen, meine geduld ist nicht unbelohnt geblieben.

\$ $402-507 \mathrm{kommt}$ ein abschnitt, in dem wenigstens der name des Aias ohne grund voran steht: hier, wo uns der faden rils, palst er genau.

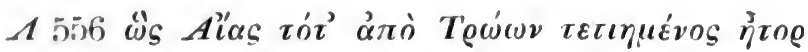

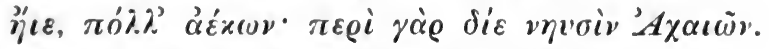

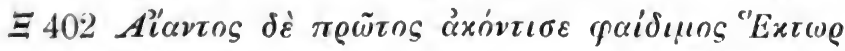

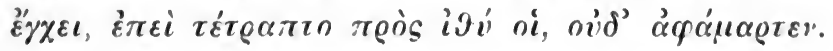

Hektors ruhm freilich verschiebt und sehmälert der tiberall griechisch gesinnte dichter noch, aber es handelt doch hier an wem die reihe zum handeln ist. Hektor trifft den Aias ohne wunde. Aias wirft einen stein auf Hektor, einen von den stitzsteinen der schiffe $\Xi 410$; der schiffe, fur die Aias filrehtete A 557. Hektor wird von seinen freunden gedeckt. der vers $\Xi 426$, welcher den auch sehon frther $A 57-5.9$ genamiten noch den Sarpedon und Glaukus beifthgt, die aber in diesem liede nicht beschaftigt werden, wäre hier sicher nicht zu finden, wenn der ganze abschnitt noch an der ursprtinglichen stelle stllnde. die freunde haben es nicht schwer den bethubten zu seinem wagen zu bringen, von dem er erst vor kurzem $\Lambda 538$ ge- 
sprungen ist, während Kebriones darauf blieb: die beiden verse also $\Xi 430.431$ sind wieder in beziehung auf anderes ( $\boldsymbol{M} 76$. $91 \quad N 790)$ aus $N 536.537$ eingeschoben, die uns sagen, Hektor habe hinter der schlacht einen wagen mit einem führer gehabt. wïhrend nun Hektor am furt des Xanthos ohnmächtig liegt, erfolgen fünf nach der art dieses liedes ausfihrlich erzählte kämpfe. Aias Oileus sohn, Polydamas, der Telamonier Aias, Akamas Antenors sohn, endlich Peneleos, Griechen und Troer einer um den andern, erschlagen jeder einen gegner. die Troer denken auf flucht.

Weiter können wir nicht: denn nun kommt sogleich $\Xi 508 \mathrm{ff}$. eine anspielung auf Poseidon, die wir eben so wenig verstehen als das darauf $O 4$ erfolgende erwachen des Zcus in den armen der Here. eilen wir zu der stelle wohin uns die andeutungen des letzten für sich allein wenig befriedigenden abschnittes führen, zur erweckung Hektors aus seiner ohnmacht.

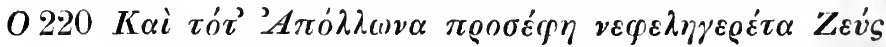

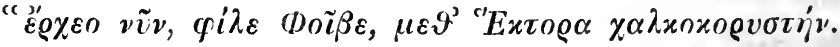

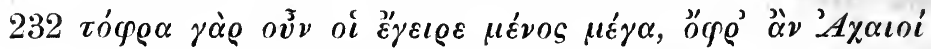

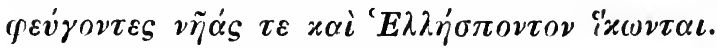

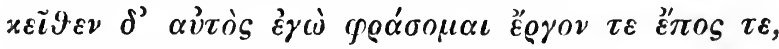

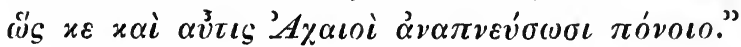

O 236-257. 262-269. 271-280. Auf diese rede des Zeus, aus der ich was sich auf Poseidon bezieht weggelassen, ermuntert Apollon den Hektor. die Griechen, bis dahin verfolgend, zagen beim anblick Hektors. dafs er trotz dem hemmenden graben wagen nachrïcken läfst, scheint mir bedenklich, zumahl da sie nicht wieder erwähnt werden: ich bin daher geneigt die verse 258-261 und 270 zu streichen.

Wenn ich nur aber wüste, was Thoas dann, da Hektor wieder erschienen ist, 281-305 für einen rath giebt. 'das volk

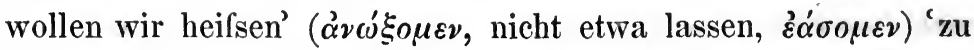
den schiffen fort gehen: wir besten wollen Hektorn mit erhobenen speeren bestehn.' der verfasser dieser verse mufs die vertheidiger sich an der mauer gedacht haben, wo sie stehn 
bleiben wollen, während die menge sich bei den schiffen sammeln soll: dieses ganze lied weifs aber nichts von der mauer. auch find ich nachher gar nicht dafs dic führer in der nähe des grabens bleiben, das volk aber bei den schiffen ist; aufser 344 , aber in einem abschnitte der mit unserm liede in allen umständen unvereinbar ist. und warum thut Thoas weiter nichts? und eben so wenig Idomeneus und Meriones, die hier unter seinen gefährten genannt werden. ich kann dieses stiick nicht für einen theil des liedes halten das wir eben betrachten.

O 306-327. Die Troer dringen ein, Hektor voran und Apollon mit der ägis. wenn sie der gott gegen die Achäer sehiittelt, fliehen sie. die ankündigung dieses wunders habe ich vorher aus einem andern grunde in der rede des Zeus 229 gestrichen. viel schöner ist die prachtvolle fiction bis hieher gespart.

Jetzo mitssen nothwendig einzelne kämpte folgen: aber dafs in den nächsten nur Troer siegen, ist unrichtig, weil ja der gott die iigis auch still hielt 318 und sie nicht immer schtittelte. das hieher passende und im geist dieses liedes gedichtete verzeichnifs kommt erst

$O 515$. Es siegen wieder, wie $\Xi 442$, fünf helden und wieder drei davon Griechen, Hektor Aias Polydamas Meges Menelaus. da reizt Hektor seine briider, vor allen den Melanippos, Aias dagegen die Achäer. sie umgeben die schiffe mit ehernem zaun, und Zeus erregt wider sie die Troer. Antilochus, aufser den fallenden der neunte griechisehe held, von Menelaus ermahnt, töltet den Melanippos, flieht aber vor Hektor.

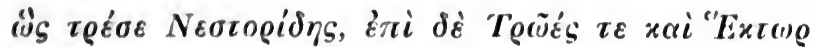

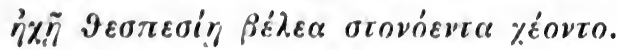

mit diesen versen (590) schliefsen wir, glauh ich, das zchute lied schicklicher als mit dem folgenden

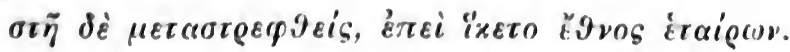

es ist erreicht was die aufgabe dieses liedes war. die drei helden sind verwundet: Hektor hat den ruhm die Achliter bis an 
die schiffe zurick getrieben zu haben. wer wollte von einem schon so ausgedehnten liede noch die erfüllung der worte des Zeus verlangen, er werde selbst einen neuen rath zur erholung der Achäer aussinnen (O 234)? zwar beziehen sich die nächst folgenden verse darauf und verheifsen bestimmter 601 eine $\pi \alpha \lambda i \omega \xi \iota \varsigma \pi \alpha \rho \dot{\alpha} \nu \eta \tilde{\omega} \nu$ : ich hoffe aber gleichwohl nachher (XXVI) zu zeigen dafs diese verse kein theil des zehnten liedes sind. 


\section{XX.}

Nur müssen wir erst wieder sammeln was bei dem bisherigen aufbau verschmäht worden ist: es sind zum theil treffliche und umfangreiche stiicke.

Zuerst finden wir, was sich wohl als ein elftes lied ansehen läfst, eine teichomachie, die das zwölfte buch fült; da es hingegen unmöglich war beim zehnten liede an eine mauer zu denken.

Die ersten verse des gedichts sind bei der zusammenfigung verloren gegangen, doch haben wir noch den eigentlichen anfang in den worten $\boldsymbol{M} 3$.

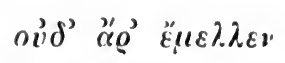

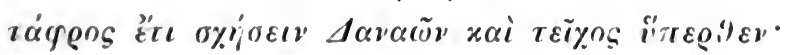

dem die erzahlumgr, wie nach dem troischen kriege Poseidon und Apollon die maner zerstört haben, sieht wohl einer einleitung ähnlich. die lage der Griechen ist num die (35)) dafs die Troer vor dem graben und der mater stehn, und sie selbst auf das schifflager heschränkt sind. dies wird auch spiater cinmahl × 70.447 als ein dauernder zustand dargestellt: in \%ehuten liede war nichts dem ahnliches, auch nicht in den verworfenen stlleken. dio Grichen sind also imerhalb der maner, anf und bei den thurnen: anch Aias der 'Telamonier M26is, der wo er in $A$ zuletzt vorkan sog sich von der flucht \%u seinen freunden gerettet hatte. Hektor, heifst es $\boldsymbol{M} .40$ recht in ton einer cinleitung, stritt wic zuror, gleich dem sturmwind. auf 
Polydamas rath versuchen die Troer zu fufs in fünf scharen die mauer zu brechen und die schiffe anzuzunden: Asios will zur linken seite der schiffe hinein fahren.

Hier aber ist eine schwierigkeit. den nun folgenden kampf auf der linken seite erkennt eine andre nachfolgende erzählung an: Asios und alle die hier $\boldsymbol{M}$ 139. 140 links stelenden kämpfen auch dort links $N$ 384. 506. 545. 560. nun aber heilst es hier $\boldsymbol{M}$ 118. 120, auf dieser linken seite sei das thor der mauer gewesen: hingegen in $N$ ist das thor nicht links 675.679 , sondern in der mitte der aufs land gezogenen schiffe 312. 681 . auch meint Polydamas nachher in unserem liede $\boldsymbol{M} 223$ thor und mauer müsse gebrochen werden: Asios fand es offen 121: woher weils Polydamas dafs es seitdem verschlossen ist 340 . 454? ich will grade nichts versichern: aber es ist wunderbar genug, dafs man hier alle die verse ohne schaden ausscheiden kann, in denen das thor erwähnt wird oder die Lapithensöhne Leonteus und Polypötes hervor gehoben werden, wie sie erst innerhalb der mauer die ihrigen ermahnen und dann sich von

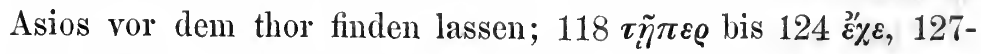
136. 141-153. 162-174. soviel ist sicher, dafs die erzïhlung von Asios unternehmen unvollständig ist. die durchaus lächerlichen verse $175-181$, die von den alten einstimmig verworfen wurden, sind offenbar an die stelle der echten getreten, in denen Asios wich, nachdem er einen oder den andern Achäer getödtet hatte: denn so etwas muste doch wohl hier erzählt werden.

Der zweite versuch Sarpedons an einer andern stelle der mauer, beim thurm des Menestheus, wohin Aias und Teukros zu hilfe geholt werden, und wie endlich Hektor dureh einen steinwurf das thor (an cinem dritten orte, nicht links?) öffnet, die Troer eindringen, und die Danaer zu den schiffen fliehen, dies alles ist unbedenklich. eine kleinigkeit nur mag bemerkt werden, dafs der vers 450

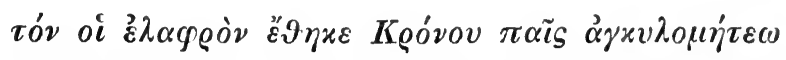

nicht beschwerlich ist, wenn man nur das vorher gehende oio

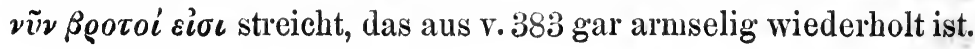


Das aber ist ja nicht zu vergessen, dafs in diesem ganzen liede sich nicht die leiseste andeutung findet, dafs den hier erzählten begebenheiten etwa unmittelbar eine schlacht aufserhalb des achäischen lagers voran gegangen sei. so hat man nicht nöthig die worte zu nehmen, falls sie auch echt sein soll-

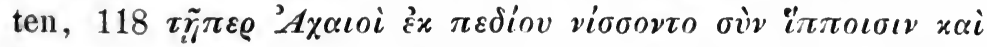
"้ $\chi \varepsilon \sigma \varphi \iota \nu$, sondern sie beschreiben nur das thor durch welches die Achäer aus und ein zu gehn pflegten. der zustand der einschliefsung gilt, wie gesagt, als ein dauernder. ob die rerwundung der drei helden als schon geschehen gedacht wird, liifst sich hier nicht entscheiden, da von namhaften Griechen iberhaupt nur die Aias Teukros Menestheus und die beiden Lapithensöhne vorkommen, und noch nicht handelnd 117 Idomeneus. erst ganz spät, beim sechzehnten liede (XXX), wird es wahrscheinlich werden dafs die voraus gesetzte einschliefsung der Achäer mit den verwundungen der drei helden zusammen hieng. ein bestimmtes versprechen des sieges, das Zeus Hektorn gegeben hat, wird von diesem ausdriicklich erwähnt 2:36: ob aber das auf welches Asios in den vorhin bestrittenen versen $164 \mathrm{ff}$. deutet dasselbe sein soll, und ob darin eine beziehung auf das versprechen des Zeus in $\Lambda 191$ liegen kamn, wird wohl so leicht niemand sagen. 


\section{XXI.}

V on ganz anderm charakter, weit reicher in darstellung und inhalt, ist das zwölfte lied, die schlacht bei den schiffen, im dreizehnten buche; das allerdings auch eine teichomachie voraus setzt, aber nicht ganz die uns erhaltene.

Gestern haben die Achäer unglück gehabt $N$ 745. die götter sind im Olymp, durch den rath des Zeus vom krieg abgehalten, 521-525. Zeus sah bisher dem streite zu 7: er hat Hektorn erregt 154 und ihn mit den Troem den schiffen nahe gebracht 1 , so dafs Hektor nun leicht bis ans meer zu kommen gedenkt 143. sie haben in masse die mauer überstiegen 50. 87. 737, nachdem Hektor das thor erbrochen hatte 124 und in thor und mauer gesprungen war 679 , und zwar da wo die mauer am niedrigsten war 683 , in der mitte des halbkreises der auf dem lande aufgestellten schiffe 312 , bei den schiffen des Aias und des Protesilaus 681. die wagen haben sie am graben gelassen 586. die Griechen sind theils im fliehen 56, theils haben sie sich zu den schiffen zurtick gezogen 84 .

Jetzt wendet Zeus (damit hebt das lied an) sein auge von den kämpfenden: 'denn er dachte nicht dafs einer der götter den 'Troern oder den Danaern helfen würde.' wie er das hoffen konnte, ist im zusanmenhange der Ilias bedenklich genug: aber in anfange eines liedes kann uns der dichter mit recht zumuten als begründet voraus zu setzen was sich hier nicht grüudlich ausftihren licfs, mochte es nun würklich ein anderer 
dichter schon gethan haben oder auch nicht. jeden auftauchenden zweifel unterdriickt die prachtrolle beschreibung von Poseidons fahrt über das meer.

Freilich kann aber nach diesem herlichen auftreten des gottes nicht wohl in demselben liede 345-360 die anmerkung nachgetragen werden, Zeus habe dem Achill und der Thetis zu liebe den Troern auf einige zeit sieg gewährt, Poseidon aber die Argeier heimlich zum kampf ermutigt, $\lambda \dot{\alpha} \vartheta \varrho \eta \dot{v} \pi \varepsilon \xi \alpha-$

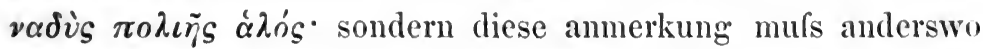
hin gehören, zumahl da itbrigens alles in diesem liede auf' das schönste und strengste zusammen hïngt.

Der kampf ist auf zwei verschiedenen punkten. Poseidon geht zuerst an den einen, in der mitte der schiffreihe; wo er die beiden Aias antreibt gegen Hektorn zu streiten 46, dam, von denen die sich zuriick gezogen hatten, den Teukros und den Leïtos 91. in der teichomachie waren Aias der ältere und Teukros zusammen zum thurm des Menestheus gegangen und stritten dort, Oileus soln aber war geblieben wo er stand $\boldsymbol{M}$ 331. 365. 400: sie miisten also seitdem ihre stellung verändert haben. auch haben wir dort nicht gefunden dafs, wie es hier 84 heifst, bei stürmung der mauer sich einige weiter zu den schiffen zurtick begaben.

Aufser beiden Aias und Teukros nebst den Lokrern $N 686$. 721 sind in der mitte die Böoten 685. 700, von denen Leïtos 91 genannt wird, die Athener (685. 689 unter Menestheus Stichios Pheidas und Bias 195. 690, die Epeer unter Meges Amphion nnd Drakios 691 (den Amphimachos verlieren sic 185), endlich die Phthier unter Medon und Podarkes 698. aber die zwei verse $92 \mathrm{f}$.

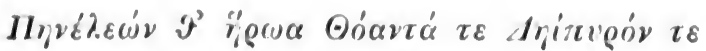

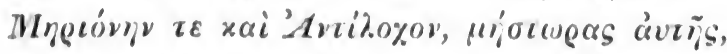

kinnen unmoghlich echt sein, weil aufser Peneleos keiner der helden hieher, in die milte, palst. Thoas nicht, als ein Ätnler: wie denn auch Poseidon nachher 21 i seine stimme ammimmt, indem er zu don andern, anf der linken seite, zehte oben da 
streitet und fällt auch Deïpyros 478. 576. der ganze vers von Meriones und Antilochus wiederholt sich dort 479. zwar von Meriones kamn man sagen, er geht erst mit Idomeneus auf jene seite 326. 329. aber vorher hat er sein speer auf Deiphobos zerbrochen 258, und Deiphobos ist ebenfalls auf der linken seite 402. nur will es sich wieder nicht fügen dafs 156-169 in Hektors nähe, der ja in der mitte war, das speer des Meriones auf des Deiphobos schilde brechen soll. ich halte daher diese erzählung 156-169 für einen unechten zusatz: der dichter hatte die sache, die sich auf der linken seite begab, nur angedeutet 258 ; wie auch 211 von dem ungenannten freunde des Idomeneus nicht erzählt wird wie und wo er verwundet sei.

Von den gegnern der Aias und ihrer umgebung, also in der mitte, wird bis v. 205 nur Hektor genannt, nachher 725 Polydamas und 790 Kebriones, die drei anführer der ersten schar in der teichomachie $M$ 88. die übrigen die unser lied $N$ 791. 792 aufzählt, fehlen in der teichomachie. hingegen die fünfte schar, Sarpedon und die bundesgenossen $\boldsymbol{M}$ 101, die dort beim thurm des Menestheus 332. 373 eine brustwehr brachen 397 und nicht zu vertreiben waren 419 , die sind hier wie vergessen; aufser dafs Hektor einmahl $N 150$ Troer und Lykier anredet und nachher 755 durch Troer und bundesgenossen fliegt. aber die ausführliche erzählung von Sarpedon wird hier nicht anerkannt; er muiste denn auf der rechten seite (308) gedacht werden, und die verse 149-155 wären mit den folgenden eingeschoben.

Nach zwei kämpfen, in denen Teukros den Imbrios und Hektor den Amphimachos erlegt 205, geht Poseidon zu den zelten, wo er den Idomeneus findet, welcher darauf mit Meriones beschliefst weder auf die rechte seite des lagers zu gehn 308, noch in die mitte wo Hektorn die beiden Aias und Teukros genug abwehren 312, sondern auf die linke seite wo hilfe am meisten nöthig sei 309. 326. der streit hier ist der hauptgegenstand des liedes 330-344. 361-678: die gefechte der einzelnen paare sind kunstreich an einander gekntipft. Posei- 
don bleibt ermahnend helfend und schitzend auf beiden seiten der schlacht würksam 239. 434. 554. 563. 677.

Hier erscheinen nun alle die Troer wieder, die im elften liede links standen. Asios, hier $N 385.400$ jener darstellung M 112 gemäls vor seinen rossen stehend; da hingegen die andern, wie Polydamas $1 / 76$ rieth, ihre wagen hinter der sehlacht liefsen $N$ 536. in Asios umgebung Önomaos Thoon Akamas M $140 \boldsymbol{N}$ 506. 545. 560 und die zwei andern führer der dritten schar M 94 Deiphobos $N 402$ und Helenos $N$ ót6. ferner die führer der zweiten schar $M 93$ Alkathoos $N 423$ Paris Agenor $N$ 490. 598. 660. von der vierten $M 98$ Äneas $N$ 459. gleichwohl ist die ubereinstimmung auch hier keineswegs vollständig. nicht nur werden hier drei mehr genannt, die aber fallen, Othryoneus $N 363$ Pisander 601 und Harpalion 643, dessen leiche sein vater Pylämenes folgt 658 , den im fuinften liede $\boldsymbol{E} 576$ Menelaus tödtete. von der vierten schar $\boldsymbol{M} 98$ fehlen im zwölften liede Archelochos und Akamas Antenors söhne: beide fanden wir im zehnten, Archelochos fiel vor Aias $\Xi 4633$, Akamas entgieng dem Peneleos $\Xi 488$. von den Griechen die auf dieser seite handeln und das leben verlieren, kam keiner thä-

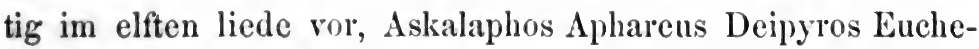
nor, eben so wenig die sich entfernen, Hypsenor Mekisteus Alastor, noch auch die vier bedeutendsten, Idomeneus Meriones Antilochus Menelaus, deren kampf gegen die tibrig bleibenden Troer, Äneas Paris und Agenor, 673 unterbrochen und in keinem späteren stlicke fortgesetzt wird. Hektor holt sich den Paris auf den anderen punkt, und hier wird ein kampf awisehen Hektor und Aias vorbereitet, dessen darstellung aber der dichter wohl nicht fir dies lied bestimmt hat. der drei im zehnten liede verwunleten griechischen heden geschicht nirgend erwåhnung. 


\section{XXII.}

Das dreizehnte lied, zu dem wir uns jetzo wenden, fuhrt uns ganz in den kreis der götter. den charakter dieses liedes zu erkennen mag mir wohl eine bemerkung von Hermann (opusc. V, p. 67) geholfen haben: die rechte dankbarkeit ist dafs man den anregenden gedanken bei sich lebendig erhält und ihn zur flamme entwickelt. die wendungen der schlacht oder die einzelnen kämpfe zu beschreiben behagt dem dichter wenig: ihm gefällt es das persönliche und sichtbare auftreten der götter zu schildern; so dafs ihm zum beispiel, da Poseidon die Achäer führt, das meer die schiffe und zelte bespülen mufs $\Xi 392$. die götter haben bei ilm etwas riesenhaftes. Here beim eide mufs mit der einen hand die erde und mit der andern das meer fassen $\xi 272$. Zeus schleudert die götter im saal umher und hält sie durch seiner hände kraft in furcht $\Xi 257 O 117.136$. 181. 224. wiederholt kommt die geschichte des Herakles vor $\Xi 250 O 18$, und die unterirdischen um Kronos $\Xi 274 O 225$, und das verhältnifs des Zeus zu seinen brtidern $N$ 345. 355 O 187.

Nachdem der umfang des liedes von der schlacht bei den schiffen genau erkannt worden ist, darf man es. nur sagen, so wird jeder leser von gebildetem geftihl selbst sehen dafs die verse $N$ 345-360 einen anfang bilden, an den sich schicklich $\Xi 153$ anschliefst. 'Zeus, auf dem Ida sitzend, wollte den Troern sieg verleihen, um Thetis und ihren sohn zu ehren, nicht aber 
um die Achäer im ilischen kriege ganz zu verderben. Poseidon durcheilte das achäische heer und unterstiitzte sie heimlich in menschengestalt. beide sah Here rom Olymp, und fafste ihren plan den Zeus zu betriegen.' nachdem dies gelungen ist, riicken Hektor und Poseidon mit den heeren gegen einander. die scene ist bei den schiffen innerhalb des grabens: eine mauer ist für dies lied nicht vorhanden.

Mit der sehlacht aber und mit dem wenig passend voraus gestellten namen des Aias (XIX) kommen wir $\underline{\Xi} 402$ an einen theil des zehnten liedes, an Hektors betiiubung. dieser abschnitt ist auch für das dreizehnte lied wesentlich, und es läfst sich wohl denken dafs der dichter desselben hier aus dem älteren die verse $\Xi 402-441$ benutzt hat: oder wenn er etwas seinem zusammenhange gemälseres gedichtet hatte, so haben die anordner der Ilias die bessere darstellung mit recht vorgezogen.

Die folgenden einzelnen gefechte hat aber der dichter in sein lied gewifs nicht aufgenommen: demn $\Xi 508$, wo uns das zehnte lied ausgieng, haben wir seine fortsetzung,

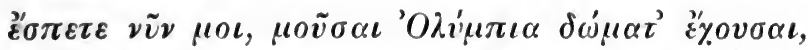

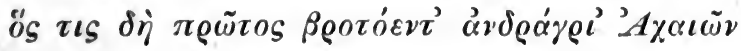

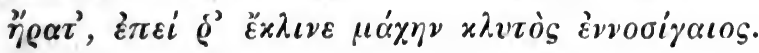

darauf läfst er ein kurzes verzeichnifs folgen, in dem die siegenden Achäer und die getödteten Troer zwar einiger mafsen mit dem zwölften liede liberein stimmen, aber doch durchaus nicht genau: denn Idomeneus Menestheus Meges Leïtos und andere fehlen hier, und Hippotion fällt $\Xi 514$, da dort $N 792$ nur Hippotions sohn rorkam.

Nun sind die Troer zurtick geschlagen und flltchten zu ihren am graben gelassenen wagen. nach den vier versen $O$ 1-4, die uns dies eradhlen, ist das ganze funtzchnte buch sehr unschicklich $\pi$ ahíw与s thberschrieben: demn es andert sich sogleich alles. der dichter, der nicht gern bei den menschen verweilt, läst den Zeus erwachen: Here mufs lris und Apollon zu ihm senden, Iris den Poseidon \%ur ruhe verweisen $O$ \$-219. 
dabei kommt 110 eine beziehung auf etwas vor, das uns im zwölften liede $N 518$ erzählt wird, auf den tod des Askalaphos, des solns des Ares. was dann Zeus dem Apollon befiehlt, das nahm der dichter aus dem zehnten liede $O$ 220. 221. 232-235. eine beziehung auf Poseidon und die ankïndigung der würksamkeit der ägis ward eingeschaltet 222-231: übrigens konnte von dem zehnten liede so viel als den zuhörern lieb war hinzu gesungen werden.

Was aber hier in den worten des Zeus folgt, 232 Hektor solle siegen bis die Achäer zu den schiffen und an das meer fliehen, dann wolle er selbst etwas zur erholung der Achäer ersinnen, das hat der dichter des dreizehnten liedes sich in einer ausfiihrung gedacht die unserer Ilias ganz und gar widerstreitet. Zeus sagt $O 62$, Hektor solle die Achäer vom graben zurïck treiben, dafs sie sich in die schiffe des Achilles sturzen. also ganz was im achten liede $I 650$ Achilles abwarten will, dafs Hektor zu den schiffen der Myrmidonen komme und sie anziinde. aber wenn er dann um sein zelt und schiff mit Hektor streiten will, so heifst es statt dessen hier $O 64$ 'dann,' also wenn die Griechen sich in die schiffe des Achilles flichten, 'wird er seinen freund Patroklus aufstehen heifsen. den wird, nachdem er aufser vielen andern den Sarpedon erlegt hat, Hektor vor Ilios tödten.' zu verstehn 'und die Achäer zu den schiffen zurïck drängen.' hierauf folgt erst.der neue rath des Zeus, 'alsdann, wenn Patroklus gerochen ist, will ich ein gänzliches und dauerndes zuriick schlagen $(\pi \alpha \lambda i \omega \xi \iota \varsigma)$ der Troer von den schiffen verhängen, bis die Achäer das hohe Ilion erobern durch rath der Athene.' wenn alles dies nicht gegen den ferneren verlauf der Ilias stritte, so hätten die Alexandriner wohl ihre zum theil recht schwachen verdachtsgründe über-

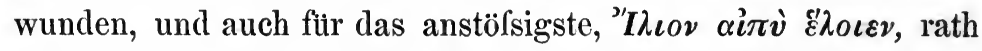

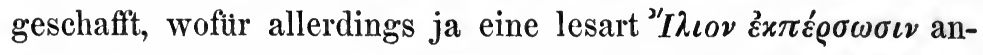
gemerkt ist, wenn sie auch immerhin nicht richtig dem Aristarch zügeschrieben wird, der hier nicht den guten willen hatte $\mathrm{zu}$ helfen (Lehrs Aristarch. p. 375). aber meinetwegen mögen die zweiundzwanzig verse nicht vom dichter des dreizehnten liedes 
sein: es mufs doch jeder zugeben dafs sie kein halb vernünftiger mensch hat in die fertige Ilias setzen können; wohl aber in ein einzelnes lied, das cinen andern fortgang der begebenheiten nicht ausschlofs, mochte dieser nun wiirklieh von andern so dargestellt sein oder nur in der fantasie des dichters liegen. Mit bei weitem mehr schein hielt Aristarch das verzeichnils der Griechenfreunde unter den göttern in den versen $O$ 212-217 für entlehnt aus der theomachie $Y 33-36$, weil dem Hermes und dem Hephästos für sich an dem untergange von Troja nichts gelegen habe. allein wer steht uns dafür dafs ein dichter der so viel mit göttern kramte, nicht seine gründe hatte auch diese götter sich bei der zerstörung der stadt thätig zu denken? 


\section{XXIII.}

Wir haben nunmehr von $\Lambda$ bis $O 590$ vier ihrem geiste nach höchst verschiedene lieder von gröfserem oder geringerem umfange nachgewiesen. ich bin weit entfernt die verschiedenheit dieser lieder als einen beweis der richtigkeit meiner ansicht von der zusammenfügung der Ilias zu brauchen: vielmehr sollen sie mir als probe dienen, ob meine beurtheiler werth sind gehört zu werden. wen die verschiedenheit unerheblich dünkt, wer sie nicht auf die erste erinnerung sogleich selbst heraus fühlen kann, wem diese vier atome (denn ich soll ja ein atomist sein), vier atome von zusammen mehr als zweitausend vierhundert versen, in ihrer jetzigen anordnung und verbindung als wohlgestalte theile eines künstlich gegliederten epos erscheinen, wer nicht begreift wie die sage sich vor mit und durch lieder bildet, der thut am besten sich um meine untersuchungen eben so wenig zu bekïmmern als um epische poesie, weil er zu schwach ist etwas davon zu verstehen.

Wenn ich nun aber dies mit wohl gegründeter iiberzeugung sage, so wird mir darum niemand die meinung zutrauen, dafs die Ilias gradezu aus den ursprünglichen liedern mit geringen zusätzen zusammen gefügt worden sei, dafs man die lieder nur eben glatt von einander schneiden und so das ganze verfahren anschaulich machen könnte. denn man sieht ja wohl dafs ich mit aller mühe lange nicht immer vollständige lieder zusammen bringe, wenn ich auch noch versetzungen ihrer theile 
und mehreren gemeinschaftliche stiucke annehme. und aufserdem würde jene meinung die hochmütige ungereimtheit enthalten, dals Aristarch und noch mancher unter den alten wie unter den neueren, auch Wolf nicht ausgenommen, das augenscheinliche nicht gesehn hätten. sie wïrden mir wahrlich nichts mehr zu finden ïbrig gelassen haben, wenn nicht überall in die lieder kleinere füllstiucke eingesetzt wären, die gewölnlich den triegerischen schein eines zusammenhanges bringen, mögen sie nun, was wohl nicht immer zu entscheiden ist, der verknüpfung wegen hinzu gedichtet oder vereinzelte bruchstïcke anderer darstellungen sein. dergleichen treten uns denn auch hier mehrere in den weg, und ich will mit den schlechtesten anfangen, die weiter nichts als das bestreben zeigen an vergessene helden zu erinnern. 


\section{XXIV.}

\$27-152. 'Dem Nestor aber,' den wir in den vier liedern nicht erwähnt gefunden haben, 'begegneten die könige, soviel ihrer ( $\left.{ }^{\prime} \sigma \circ \iota\right)$ verwundet waren, Agamemnon Diomedes Odysseus, die von den schiffen kamen, von denen die vordersten tief in die ebene hinein an der mauer standen.' Nestor, der, offenbar zu fufs, aus der schlacht kommt 43 , wahrscheinlich auch verwundet (denn 62. 63. 128 rechnet er sich zu den verwundeten), sagt ihnen 55 die mauer sei gesturrt (welches doch erst $O 361$ geschieht), es werde jetzt bei den schiffen gestritten. Agamemnon räth zu schleuniger flucht aufs meer, Odysseus tadelt ihn, Diomedes rühmt sich. auf Diomedes rath gehn sie die ihrigen zu ermahnen, Agamemnon voran.

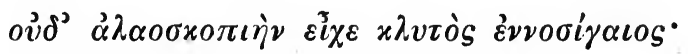

der gott erspähet die öffentlich gehenden von seiner partei, und geht in der gestalt eines alten mannes zu ihnen. nach einer rede 142, die einer folgenden 368 nachgeahmt ist und diese uiberbieten soll, schreit der alte mann, gleich dem verwundeten Ares $\boldsymbol{E} 860$, wie neuntausend oder zehntausend krieger, und giebt den Achäern kraft ins herz.

ב370-388. Dann mitten in der schlacht knuipft Poseidon an die eben beiläufig erwähnte rede den wunderlichen rath, sie sollen die besten schilde helme und speere nehmen. dieser rath, sagten die $\pi \alpha \lambda \alpha \iota$ i des Eustathius (p. 992, 34), beziehe sich 
nur auf die wenigen zuritck gewichenen, die unthätig standen. aber antreiben wollten die könige in dem ersten stïcke $\Xi 131$ die welche nicht stritten: und daran hätten sie besser gethan. das nächste, 'der tapfere der cinen kleinen schild hat, gebe ihn einem schlechteren manne und nehme den gröfseren,' ward als ganz lächerlich von Aristarch und schon von Zenodotus verworfen. die drei verwundeten könige (denn Nestor ist hier vergessen) führen die vertauschung der waffen so aus dafs die besten die besten bekommen. Poseidon schreitet, wie sonst niemahls, mit einem blitzgleichen schwerte voran.

O 367-380. Ein drittes stiick. nachdem das vorher gehende mit $\ddot{\omega}_{S}$ geendet hat,

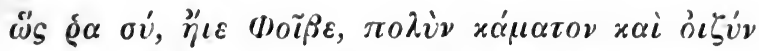

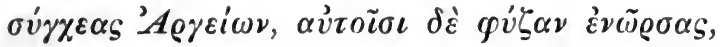

'also flohen sie,' wird wieder mit $\ddot{\prime}_{S}$ angehoben, 'also standen sie,

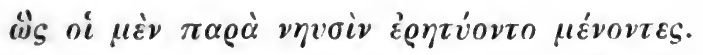

sie beten, und Nestor vor allen. Zeus donnert auf Nestors gebet. als die Troer den donner hören, stiirzen sie sich anf die Achäer.

O 658-667. Ein viertes gleichartiges stiick, schon aufser dem kreise unsrer vier lieder, bringt wiederum eine ermahnung Nestors, der aber daun samt den drei verwundeten völlig versehwindet.

Ich denke, wer diese vier stlicke mit bedacht liest ohne sich gleich durch die bessern umgebungen fortreifsen zu lassen, der wird mit so sehlechter poesie nichts wollen zu thun haben, und anch nicht wissen moggen woher sie kommt. 


\section{XXV.}

Ganz anders steht es mit einigen anderen stücken, die ein sinnreiches beiwerk $\mathrm{zu}$ einer teichomachie und eine vierte schlacht bei den schiffen enthalten, uns aber nicht vollständig uiberliefert sind.

1 497-520. Gleich der anfang fehlt offenbar, wenn auch die ersten der erhaltenen verse ungefähr so lauteten wie Hermann meint,

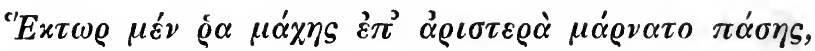

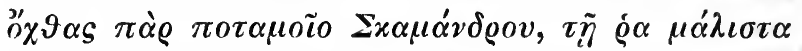

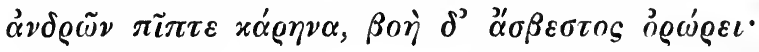

denn das $\tau \tilde{r} \varrho \alpha \mu \alpha^{\prime} \lambda_{\imath \sigma \tau \alpha}$ setzt bei dem zuhörer schon eine kenntnifs von der ganzen scene der schlacht voraus. sie ist noch nicht an der mauer: denn am heftigsten soll sie hier am Skamander sein. aber dafs hier die linke seite der schlacht genannt wird, stimmt doch damit überein dafs in den darstellungen der schlacht bei der mauer und bei den schiffen, sowohl im elften als im zwölften liede, die linke seite und die mitte einander entgegen gesetzt werden. diese übereinstimmung in der scene der sage macht wahrscheinlich dals auch hier etwas ähnliches folgen werde. unser abschnitt beschreibt die verwundung Machaons, den Nestor auf seinem wagen $\mathrm{zu}$ den schiffen führt.

A558-848. Nun mufs wohl der rückzug des Aias erzählt worden sein: denn an einer im jetzigen zusammenhang unpassenden stelle (XVIII) ist uns noch das gleichnils rom esel er- 
halten. - Ich möchte nämlich nicht gern sagen, die beiden gleichnisse vom löwen und vom esel seien zur beliebigen auswahl für die rhapsoden zusammen gestellt worden, weil in der

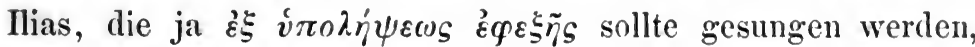
allzu wenig ist was man so ansehen kann. ich gebe einige soleher variationen zu, wie sie Hermann gezeigt hat, $B$ 459$468=469-473, B$ 474-479 $=480-483, \quad B \quad 780-785=\Gamma 10-14$, $\boldsymbol{\Gamma} 1-9=\Delta 422-445$ : aber sie sind auf der grenze des zweiten und funften liedes, und werden unter beide zu vertheilen sein. das gleichnifs B 144-146, das sich ausseheiden läfst, scheint mir ein tippiger ergufs der poetischen lust, etwa zugleich mit dem vorher gehenden $143^{n}$ vers (V) entstanden. - Dem Aias, der bald steht bald fliehet, kommt Eurypylos zu hilfe, wird aber, wie vorher Machaon, von Paris pfeil getroffen. indem ihn die freunde schiitzen, kommt ihnen Aias entgegen und wendet sich gegen die feinde. hier erwartet man dafs Aias etwas thue: statt dessen folgt der offenbar an die stelle der mangelnden erzählung gesetzte vers, 596 ,

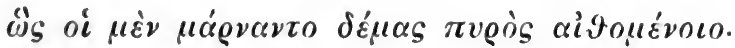

dann wie Achill den Patroklus abschickt nach dem verwundeten auf Nestors wagen sich zu erkundigen. dafs in Nestors zelt fur Machaons wunde nicht gesorgt wird, kann ich wiederum nur fir mangelhafte liberlieferung halten, da in eben diesem stucke nicht nur Achill und Patroklus nach dem verwundeten fragen 612. 630 und Nestor davon spricht 664, sondern auch Eurypylus von seiner verwundung weifs 835. in der rede Nestors ist die erzahlung (665-762, wie Hermann zuerst bemerkt hat, nieht in homerischem stil und darf wohl ohne bedenken fur einen zusatz gehalten werden. Patroklus, der dem verwundeten Eurypylus begegnet, fuhrt ihn, obgleich zu dem ungeduldigen Achill \%urltck eilend, ins zelt und sorgt fur ilı.

Wenn wir nun der spur der bisher erwahnten personen folgen, so finden wir $\Xi 1-21$; Nestorn, wie er den Machaon im zelt zurllek lafst und gerllstet hinaus tritt. da sicht er die Achäer voll den 'Truern gejagt, die maner int gestll\%t. er awei- 
felt ob er in die schlacht gehen soll oder (gott weifs zu welchem zwecke) zu Agamemnon. dies scheint ihm besser: jene setzen den streit fort. - Aber hier sind wir auf einer unrechten spur: denn es wird sich bald zeigen dafs auch nach den bruchsticken an denen wir jetzo stehen, die mauer noch nicht gestiurzt ist. wir wollen also dies schlechte stiick lieber zu den vorher (XXIV) durchgegangenen vieren zählen, unnützen episoden von schwacher erfindung. übrigens ist schwer zu sagen was nach der absicht des dichters auf diese verse folgen sollte. hatten sie nur den zweck auf das jetzo folgende vorzubereiten, wo dem Nestor die drei verwundeten begegnen, so mochte freilich der übrige zusammenhang den widerspruch, dafs Nestor dort nicht aus seinem zelte sondern aus der schlacht kommt, weniger fühlbar machen: aber die begegnung durch Nestors unveranlafsten entschlufs zu Agamemnon zu gehn vorbereiten konnte nur ein sehr ungeschickter dichter.

Suchen wir uns, indem wir dies stiuck verwerfen, vielmehr ein bild zu machen, wie bei den uns erzählten nebenumständen die schlacht sich miisse verhalten haben, wie sie der dichter darstellte oder vielleicht auch zum theil voraus setzte. zuerst ein kampf auf dem felde, in dem Agamemnon Diomedes und Odysseus verwundet sind, $\Lambda$ 660. 661; und zu gleicher zeit ein anderer kampf links am Skamander, wo gegen Hektor und Paris Machaon Idomeneus Nestor standen. Machaons verwundung. Aias flieht von dem ersten standpunkte der schlacht zum zweiten. Eurypylos tödtet eben daselbst ảen Apisaon und wird verwundet. Hektor mufs, da wo wir $\Lambda 596$ eine liucke vermuteten, in die nähe gekommen und von Aias auf eine zeit unthätig gemacht, dann aber von Apollon wieder in den streit gebracht worden sein. Patroklus abgesandt, in Nestors zelt, und mit Eurypylos.

O 281-305. Nun führt uns das nächste stiick das wir noch fiei haben, den rath des Thoas vor, das volk soll sich bei den schiffen sammeln, die besten sollen da wo sie sind, das heifst noch aufserhalb der mauer, bleiben und dem neu erstandenen 
Hektor sich mit erhobenen speeren widersetzen. daran schliefst sich wohl unmittelbar

O 328-366. 'Nun schlug ein mann den andern, beim zer-

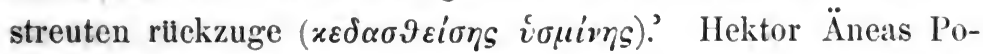
lydamas Polites Agenor Paris tödten jeder einen oder zwei, während die Achäer zum graben fliehen und hinter die mauer gehn 345. die Troer kommen zu wagen heran: Apollon mit der ägis vor ihnen ebnet den weg, indem er die matuer stürzt.

Den Apollon mit der igis, diesen theil der sage, fanden wir auch im zehnten liede, das aber von der mauer nichts weifs. die wagen schienen dort nicht zu passen (XIX), und eben so wenig in das dreizehnte, weun der dichter desselben etwa die verse des zehnten aufnahm (XXII). hingegen, mag der dichter dessen poesie wir jetzt eben betrachten, bei Hektors wieder erscheinen die darstellung im zehnten liede benutzt haben oder mag seine eigene uns verloren sein, die vorher verworfenen verse $O 258-261$ und 270 , in denen Hektor die streiter zu wagen nachricken läist, sind in seinem simne. nach dem elften und zwölften liede (XXI) liefsen die Troer, aufser Asios, ihre wagen am graben stehu: aber da ward auch nicht, wie hier, die mauer zerstört, ja nach dem elften $\boldsymbol{M} 12$, wie nach dem stlicke vor dem siebenten $\boldsymbol{H} 459$, stand sie bis nach der eroberung von Troja: es war nur eine brustwehr gebrochen, das thor gesprengt, und die mauer ward iberstiegen.

O 381-514. Gan\% anders hier, wo die Troer zu wagen ohne weiteres dureh die geebnete mauer gehn, xatà tzixos 384, und die Griechen sich von den auf das land gezogenen schiffen herab vertheidigen. - Patroklus, zu dem hier das lied zurluck kehrt, hat indessen, so lange die schlacht an der maner aufserhalb der schiffe war, bei Eurypylos gesessen, keineswegs aber unsere teichomachic in $M$ abgewartet, und unsere schlacht bei den schiffen in $N$, und den schlaf des Zeus in $\Xi$, sundern nur Hektors ohnmacht und sein neues auftreten. sobald er merkt dafs die 'T'roer auf die mauer dringen, eilt el zu Achilles, um ihn zum kampf zu reizen $O$ 402. es ist nattrlich und schön dafs seine fruhere absicht, dem Achill die ermahnende 
botschaft von Nestor zu bringen $\Lambda 839$, sich so gesteigert hat: das aber ist wenig wahrscheinlich, dafs Nestor $\Lambda$ 794-803 auch schon gesagt haben soll, Achill möge wenigstens statt seiner den Patroklus senden. gewifs sind diese verse nur aus der $\mathrm{Pa}$ troklie $\Pi$ 36-45 herauf genommen, wie auch vielleicht Zenodot meinte (schol. A 1 794). Aristarch verwarf nur die beiden letzten, ohne rechten grund; dagegen ich ihm und Aristophanes gern beistimme, wenn sie das geschwätz des Nestor $\Lambda$ 767-785 tilgten, in welchem die anrede des Peleus an seinen sohn mïssig erwähnt wird, wenn Achill nicht dadurch, sondern nur durch den zuspruch des Patroklus soll ermahnt werden. Nach dem abgange des Patroklus wird die beschreibung der schlacht fortgesetzt, die im ganzen noch unentschieden bleibt. ein hauptpunkt ist bei den schiffen des älteren Aias, so nah dafs Teukros, da ihm die sehne des bogens reifst, ins zelt gehen und sich rïsten kann. die Troer sind noch immer zu wagen. eins von den schiffen des Aias, bei dem Hektor kämpft, soll schon verbrannt werden: doch Aias erschlägt den der die fackel bringt. ob mit den ermahnungen Hektors und des Aias das lied endigte, lälst sich nicht entscheiden: bruchsticke eines besonderen liedes aber können wir diese so sehr eigenthümlichen abschnitte wohl nennen. es mag also das vierzehnte heifsen, weil sich in kunstmärsiger untersuchung seine besonderheit erst nach den ibbrigen zeigen liefs. 


\section{XXVI.}

I ch kann der geduld derer die an diesen untersuchungen theilgenommen haben zum trost sagen dafs das sehwierigste iiberwunden ist. wir werden nielt melir die noth haben die einzelnen theile der vielleieht nicht einmahl ganz erlaltenen oder ältere poesie sich aneignenden lieder von versehiedenen orten her zusammen zu lesen.

Bei dem zunächst folgenden funfzehnten liede, der Patroklie, kann man nieht zweifeln dafs es ron $O 592$ wenigstens bis an den sehlufs des folgenden buches reiche: ob noch weiter, wollen wir dam untersuchen, indem wir uns zunlichst innerhalb jener grenzen halten.

Das lied hebt mit einem besonderen eingang an, in welchem als rathschlufs des Zeus angegeben wird, er habe Hektorn den sieg geben wollen, damit er die schiffe anzindete und so die bitte der Thetis ganz erfullte: damn habe er eine $\pi \alpha-$

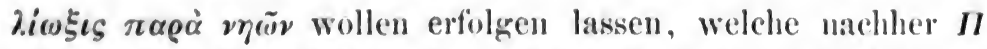
654 bestimmter auf Patroklus bezogen wird, der die Troer zu ilhrer stadt zurtick treiben solle. ob der dichter des zelnten liedes seinen :thnlichen rathschlufs des Zeus $O 234$ eben so gemeint hatte, liifst sich nicht sagen. der des dreizehnten setzte wenigstens noch dazu voraus $O 63$ dafs die Griechen sich in die sehiffe Achills stllren wlirden (XXII). in cinem russat\% zum vierzehnten fragte Nestor $A 666$ ob Aclill warten wollte 
bis die schiffe angezlindet wären; offenbar ohne zu wissen dafs er selbst im achten $\boldsymbol{I} 654$ gedrohet hat nicht eher zu streiten als bis seine schiffe bremnten. in unserem liede ist ihms genug dafs ein anderes schiff zu brennen anfängt: er will nicht dafs die Troer die. schiffe nehmen $\Pi 128$, und hofft, durch die hilfe die er den Achäern an Patroklus sendet, die rückgabe der Briseis samt geschenken zu erlangen $\boldsymbol{\Pi}$ 85. dafs aber die bitte der Thetis auf das anzunden der schiffe gieng (oder ist das nur das ziel welches Zeus siclı gesetzt hat?), haben wir bisher nicht erfahren. in der fortsetzung des ersteu liedes wünscht Achill A 409 dafs die Achäer in die schiffe gedrängt und getödtet werden, und Thetis bittet $A 509$, so lange mögen die Achäer besiegt werden bis sie ihren sohn ehren. wo sonst die bitte der Thetis vorkam, stand nichts bestimmtes $\Theta 372 O 77 N 350$. eben so wenig ward sonst gesagt dafs Achill um verderben der Achäer zu Zeus gebetet habe, wie hier in einem verse $\Pi 237$, der zwar mit zwei ihn umgebenden auch $A 454 \mathrm{zu}$ finden ist, aber doch wohl den obelos ohne grund trägt, zamahl da das gebet zu Zeus auch $\Sigma 75$ vorkommt, wo angemerkt ist $\varkappa \alpha \tau \grave{\alpha}$ tò $\lambda \varepsilon \lambda \eta \vartheta o ́ s$.

Zeus wird in diesem liede zuschauend $\Pi$ 644, aber nicht bestimmt auf dem Ida sitzend, dargestellt: denn // 677, wo es so scheint, werde ich nachher (XXVII) bestreiten. dafs also

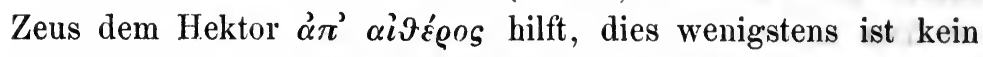
grund gegen die freilich bedenklichen verse $O$ 610-614. nirgend kommt vor dals die götter gehindert sind theilzunehmen. Athene entfernt das dunkel $O 668$, und Apollon ist unter den streitenden $\Pi$ 715. 726. 729. 788. freilich Apollon vom Ida gehend II 677 und sich auf die troische mauer stellend 700 und Here von Zeus angeredet $\boldsymbol{\Pi} 432$ kommen in zweifelhaften stellen vor. Achill warnt den Patroklus vor göttern die ihm leicht in den weg treten könnten, namentlich Apollon, der die Troer sehr liebe $\boldsymbol{\Pi} 94$. unmittelbar darauf kann er doch wohl nicht gut den Apollon anrufen, in vier albernen versen 97-100 die dem Aristarch mit recht erotisch zu sein schienen. 
Der graben des achäischen lagers wird $\Pi$ 369. 380 erwähnt. die mauer könnte $\Pi 370$ nicht wohl tibergangen sein; sie müste denn als völlig gesturzt gedacht werden. $O 736 \mathrm{sagt}$ Aias 'wir haben keine mauer zum schutz.' die Troer sind, und zwar ehe sie zum graben zurück geschlagen werden, zu wagen $\Pi 343$, auch Hektor selbst 367 ; welches unter den vorher gehenden nur zum vierzehnten liede pafst. ich werde aber nachher noch auf die mauer zurück kommen (XXVII).

Die handlung beginnt früh am tage: denn $\Pi 777$ ist es mittag: aber es mag doch wohl etwas schon vorher geschehn sein, wenn Patroklus $\Pi 44$ mit recht die Troer ermlidet ( $\boldsymbol{\varkappa \varepsilon -}$ $x \mu \eta o ́ \tau \alpha$ ) neunt. nur ist die frage, ob irgend etwas vou dem voraus gesetzt wird was wir in den vorher gehenden liedern gelesen haben. es ist der Troer erster versuch bei den schiffen der Achäer zu streiten; woran Hektor bis diesen tag von den greisen gehindert zu sein beklagt $O$ 722. die Troer gehn also auf die schiffe los. Hektor versucht durchzubrechen wo er das meiste rolk und die besten waffen sieht: aber die Achäer stehn fest wie eine mauer. bald jedoch fliehn sie vor Hektor, der einen einzelnen tödtet. 'und sie wurden,' die Achäer nämlich, 'der schiffe ansichtig' $O$ 653. das lälst sich durchaus mit den vorher gehenden liedern nicht vereinigen. doch denken wir uns auch die bisherige entfernung von den schiffen nicht allzu grofs: ja sie mussen wohl schon uber den graben sein, der sonst hier, wie $I I 369$ beim rllekzug, erwithnt sein mtiste. warmm die Achäier demnoch erst jetıt ihre schiffe sehen, erklärt sich sogleich: denn als sie nun von den vordersten schiffen gewichen sind, aber ohne sich zu zerstreuen bei den zelten stehn 657, heifst es auf eimmahl hi68, unerwartet, aber mit deutlicher anspielung auf etwas uns nicht erhaltenes, 'da stiefs ihnen Athene die wolke des dunkels von den augen.' das folgende, 'und sie bekamen licht sowohl von den schiffen als von der schlacht her,' wird damn in thbereinstimmung nit dem vorher $65 \%$. 656 g gesagten erklint, 'und num schauten auf' Hektorn und seine gefuhrten alle, sowohl die ohne zu streiten 
sich um die zelte zurtick gezogen hatten, als die noch mit den Troern bei den schiffen stritten.' Aias, der nicht unter denen bleiben mag die schon weiter zu den zelten gewichen sind, geht von schiff zu schiff und ermahnt die völker. das zurlick weichen zum lager, welches hier im anfang erzählt wird, fanden wir eben so vor der schlacht bei den schiffen angedeutet im zwölften liede $\boldsymbol{N} 84$ (XXI). auslassen kann man von unsrer erzählung nichts, aufser, wie gesagt (XXIV), Nestors unnitzes gebet $658-667$.

Der erneuerte streit, bei dem Hektor und Aias die hauptpersonen sind, ist besonders um ein schiff des Protesilaus $O 705 \Pi$ I 286. ist es nicht sonderbar dafs auch im zwölften liede $N 681$ Hektor bei den schiffen des Aias und des Protesilaus kämpft, und dafs er auch im vierzehnten $O 416$ mit Aias um sein schiff streitet? ärmlich allerdings, wenn alles von einem dichter wäre; selbst wenn man mit Aristarch in $N$ die schiffe des Lokrers Aias verstiunde, weil dort der streit in der mitte am thor der mauer ist, nach $\Theta 223$ und $\Lambda 6$ aber die schiffe des Odysseus in der mitte waren, und die des Telamoniers nach $\Lambda 7$ und $K 113$ an einem der äufsersten enden. aber ist es nicht vielmehr deutlich dafs alles nur drei verschiedene darstellungen derselben sage sind? und ist es nicht ganz naturlich dafs das schiff des Protesilaus, der zuerst ans land gesprungen war $B$ 702, auch eins von den vordersten $(\tau \tilde{\omega} \nu \tau \rho \omega \tau \varepsilon \dot{\varepsilon}(\omega \nu)$ sein muste und zuerst angegriffen und angezündet ward?

Eben so verbreitet mag wohl die sage gewesen sein, dals das schiff angeziindet worden indem Aias geflohen sei. so erklärt es sich dals wir davon in diesem liede zwei darstellungen finden, die sogar mit demselben verse anfangen, $O 727$ und $\Pi 102$. dies hat auch Hermann bemerkt. mir scheint es aber dafs der verfasser der ersten darstellung seine poetische lust ohne sonderliches nachdenken gebuifst hat. denn wie soll man sich das vorstellen? Aias gieng vorher vom verdeck eines

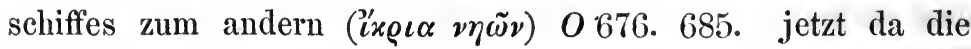
Troer auf Ein schiff aus sind und ihn die geschosse drängen, 


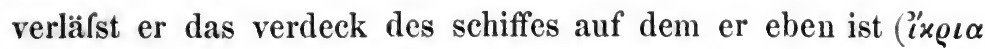

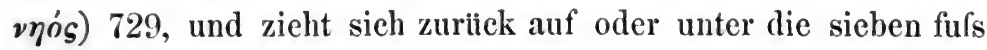
hohe oberste ruderbank ( $\vartheta \varrho \tilde{\eta} \boldsymbol{v} v \boldsymbol{v} \dot{\varepsilon} \varphi^{\prime}$ oder $\left.\boldsymbol{v} \varphi \varphi^{\prime} \dot{\varepsilon} \pi \tau \alpha \pi \delta ́ \delta \eta \nu\right)$. von da aus, oben herab von dem einen schiffe, wehrt er die Troer und ihre brände nicht etwa von dem einen schiffe sondern von den sehiffen $a b 731$, und verwundet zwölf von ihnen nicht etwa durch speerwürfe sondern durch stiche (ov̉ $x$ ) 746 . ich weifs hier keinen besseren rath als den, wie ich glaube, ganz genïgenden, dals man aus den versen 727-732 diesen einen mache,

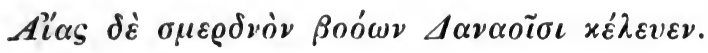

freilich mufs man damn 743 statt des plurals xoì schreiben, welches ja aber auch schon nöthig sein wïrde wegen des folgenden $\boldsymbol{\Pi} 1$

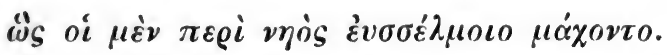

Der Patroklus des funfzehnten liedes hat nichts von den begebenheiten des vierzehnten mitgemacht. er bringt keine bestellung von Nestor, eben so wenig sucht er den Achill zum kampf aufzuregen, sondern er bietet sich selbst an. bei Eurypylos war er dort geblieben bis die Troer die maner stirmten und die Achäer flohen: diese näher drohende gefahr treibt ihn in diesem liede nicht, welches uberhaupt die mauer nicht kennt. er klagt nur dafs die drei besten helden verwundet sind: und das geburt ihm freilich zu wissen, weil es allgemeine sage war, wie es auch Achilles von Diomedes und Agamemnon weifs $I$ 74. wenn aber Patroklus dabei drei verse $I$ 24-26; ganz eben so spricht wie Nestor vorher $\Lambda$ 659-661, so kaum der vierte,

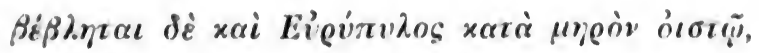

der in Nestors rede alle wahren zengen wider sich hat, auch hier, so echt er sein mag, nach dem jetzigen zusammenhange kaum bestehen. denn unter die ron welchen os heifat 


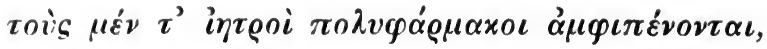

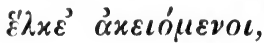

gehört Eurypylos eigentlich nicht, da Patroklus die ärztliche behandlung vollendet $\Lambda$ 844-848 und einem genossen nur seine unterhaltung aufgetragen hat $O 401$ : und die drei andern verwundeten haben sich auch schon lange auf die beine gemacht $\underline{\Xi} 28$ und den trefflichen waffentausch geleitet $\underline{\Xi} 379$. 


\section{XXVII.}

Einzelnes dürfte sich innerhalb des sechzehnten buchs noch gar manches finden lassen, des man lieber entibrigt wäre.

In der aufforderung des Patroklus an seine gefährten scheinen mir die verse $\Pi 273 \mathrm{f}$.

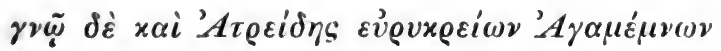

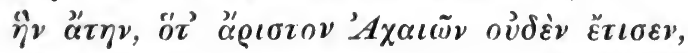

nicht so passend als $A 411$ in Achills munde, der den Achäern verderben winseht, während Patroklus sie zu retten geht.

Ob der dichter selbst oder nur ein nachbesserer dem Patroklus aufser den beiden unsterblichen rossen auch noch den sterblichen Pedasos gegeben hat, lï/st sich bezweifeln. wenigstens kommt er nur in zwei stellen vor, $\Pi$ 152-15.4 und 467 477 , die sich ohne schaden wegnehmen lassen, und in der zweiten ist 467 ov้z $\alpha \sigma \varepsilon v$ unrichtig fìr $\varepsilon^{\prime} \beta \alpha \lambda \varepsilon$ gebraucht (Lehrs Arist. p. 63-65). der $381^{\circ}$ vers whirde die auslassming sogar nöthig machen, wo dats nebenpferd doeh wohl mit ther den graben springt, sie heifsen aber alle

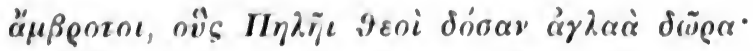

aber der vers hat hier keine alten zeugen fitr sich.

Als die Troer den Patroklus kommen sehn, wird ihnen das herz bewegt und die reihen wanken, weil sie ihn Mr 
Achilles ansehn: aber der grad der furcht welchen der aus $\Xi 507$ entlehnte vers II 283 bezeichnet,

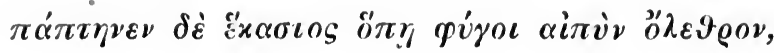

palst wenig dazu dafs sie gleich nachher 303 nicht etwa flichen, sondern sich nur von den schiffen zuriek zichn.

Wenn, wie ich vorher (XXVI) gesagt habe, die achäische maner in diesem liede nicht angenommen wird, und auch kein frihherer kampf bei den schiffen, so ist es schwer zu begreifen wie von Sarpedon $\boldsymbol{\Pi} 558$ gesagt werden kann, und zwar mit denselben worten dic das elfte lied $\boldsymbol{M} 438$ von Hektor hatte,

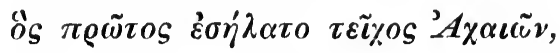

und von des Glaukos wunde $\boldsymbol{\Pi} 511$

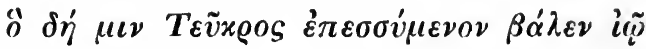

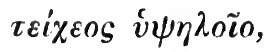

ebenfalls mit den kiinstlich wiederholten worten des elften liedes $\boldsymbol{M} 388$, wo es hiefs

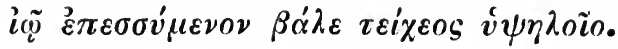

wird man nicht mit grofser wahrscheinlichkeit sagen können, die verse 509-531 und 555-562 seien nur willkürliche, zwar nicht schlechte, aber doch nicht genau passende, ausschmiickung? und wird es sehr verwegen erscheinen, wenn ich die fabel Sarpedons noch in einem punkte für aufgeputzt halte? nämlich wo von der entführung seines leichnams geredet wird. die beiden abschnitte, die sich darauf beziehn, fangen gleich an, und beide ohne irgend eine verknüpfung mit dem übrigen, II 432.666

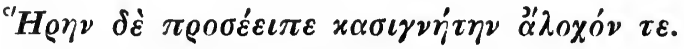

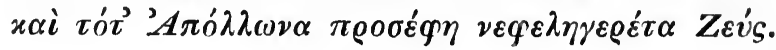

das gefithl des Zenodotus war wohl so unrecht eben nicht: nur hat er das erste mahl wenig geschickt geschnitten und 
das zweite mahl abgeschmackt verändert. man mufs in der ersten stelle die verse so verbinden, 431. 459.

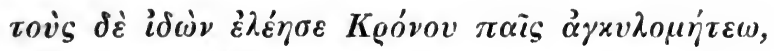

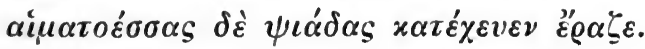

mit der tilgung der zweiten 666-683, die den Apollon brachte, wie zuvor der zusatz iiber Glaukus, verschwindet die schwierigkeit, dafs der gott nun erst vom Ida steigt, da doch später

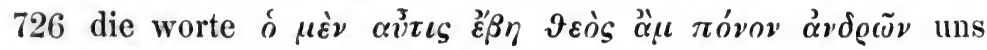
gebieten ihn jetzt in der schlacht zu denken, wo ihn vorher 94 sich auch Achill dachte. aber eben diese worte sind nicht minder gegen die erzählung 700, dafs der gott sich auf die mauer von Troja stellt und den Patroklus ermahnt von der stadt zu weichen. und ist denn nicht auch der ganze gedanke, der diesem abschnitte 698-711 zum grunde liegt, in dieser darstellung ungereimt? dafs ohne Apollons warnung die Achäer Troja erobert hätten 'unter Patroklos hand'; ohne dals ihm jemand half oder sich widersetzte, während Hektor am skäischen thore hielt und noch tiberlegte ob er streiten oder die Troer in die stadt zuriick ziehen sollte.

Beim tode des Patroklus ist das sechzehnte buch mit sich selbst vollkommen im einklange. wenn aber der sterbende zu Hektor sagt 'deiner zwanzig hätt ich ïberwunden,

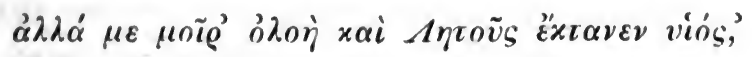

wozu soll da der zusatz 850

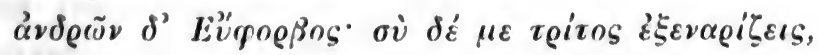

als nur den Euphorbus gan\% ohne grund und verdienst uber Hektorn \% erhöhen? dafs der name die thbrigen drei mahle viersilhig sein kann, mag bei genauerer untersuchung bedeutend werden: aber auszugehen von kleinen sprachbemerkungen, ist bei der beurtheilung so verlnderlicher poesie thorheit. 


\section{XXVIII.}

Nun aber wie vereinigen wir die erzählung vom tode des Patroklus in $\Pi$ mit der in $P$ ? dort hat ihm Apollon $\Pi 793$ den helm vom haupt gestofsen, der schild fällt ihm von den schultern 802 , der brustharnisch ist gelöst 804 , so dafs er nackt dasteht 815: er sagt selbst 846 , die götter haben ihm die waffen von den schultern genommen. dagegen in $\boldsymbol{P}$ will dem todten Euphorbus die waffen abnehmen 13. 16, Hektor zieht sie ihm würklich ab 125. 187, und zwar (Zeus sagt es selbst) 205 vom haupt und von den schultern. von diesem widerspruche reden auch unsre scholien (schol. $\boldsymbol{A} \boldsymbol{P}$ 125. 186. 205): wie ihn Aristarch gelöst habe, ist uns nicht iiberliefert (Lehrs Arist. p. 17). ich sehe zwei wege. entweder fängt mit dem siebzehnten buch eine fortsetzung an, die in dem einen punkte nicht genau ihrem vorbilde folgt: oder, wie wir schon mehrere ausschmückungen in diesem liede fanden, der dichter hat von Apollon nur erzählt dafs der gott dem Patroklus rücken und schultern geschlagen habe, und die verse $\Pi$ 793-805. 814. 815 . 846 sind nicht von ihm. ich bin mehr geneigt zu der letzten annahme, nach der Patroklus tod und der kampf um seinen leichnam für ein zusammen hangendes lied gelten; weil in der folgenden erzählung alle punkte der voraus gehenden mit strengster genauigkeit aufgenommen werden, weil ich in ton und darstellung zwischen beiden keinen unterschied wahrnehme, weil endlich auch in dem letzten theile noch ein oder zwei 
mahl fremdartige zusätze kommen, die denen im ersten theile nicht unähnlich sind.

Zeus hat beschlossen dem Hektor in Achills waffen ruhm zu verleihen, zumahl da er doch bald sterben wird $P$ 206: aber um doch auch die Achäer, die den leichnam des Patroklus vertheidigen, zu schützen, hüllt er sie in dunkel 269. nun aber, ein abschnitt 366-423, der weiter keinen zweck hat als zur vorbereitung uns ganz unnöthig zu sagen dafs Antilochus und Achilles den tod des Patroklus noch nicht erfahren haben, hebt mit einer ubertreibung an, von der ich nicht weils, soll sie auf das dunkel gehn oder auf die wut der streitenden; 'sonn und mond waren nicht sicher.'

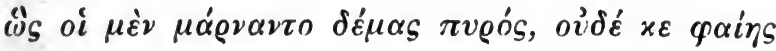

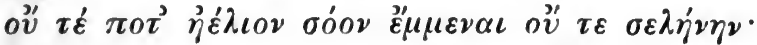

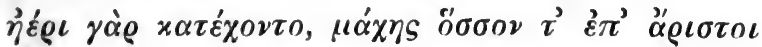

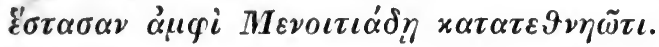

die letzten dieser vier verse geben den angemessenen sinn, wenn man sie, da uns durch eine liteke der Venediger handschrift hier die echten quellen fehlen, so zu schreiben wagt wie ich eben gelesen habe. das dunkel umhüllte die um $\mathrm{Pa}$ troklus strẹitenden: und zwar war das in der mitte, $\dot{\varepsilon} \nu \mu \varepsilon \dot{\varepsilon} \sigma$ 375. hingegen die andern stritten unter heiterm himmel nur

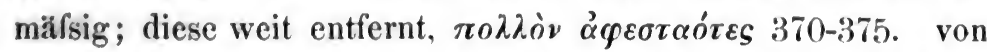
Antilochus und Thrasymedes wird noch ausdricklich wieder.

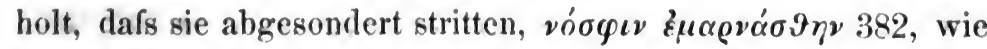
ihnen Nestor befohlen als er sie von den sehiffen in die schlacht sandte. 7.4 welcher zeit er ihnen den rath gab, wilste ich nicht zu sagen: bei dem plötzlichen erscheinen des Patroklus stritten sie mit allen andern $\boldsymbol{I}$ 317. dafs sie aber jetzt von dem leichnam, der in der troischen ebene liegt, entfernt gedacht werden, ist richtig. denn als nachher Antilochus geholt wird,

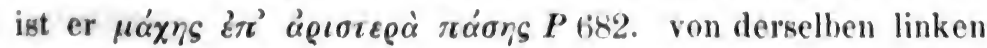
seite der schlacht her hat auch $P 116$ Menelaus, als ihn Hektor von dem leichnam des Patroklus vertrieb, den Biteren Ains zu hilfe gerufen, und es ist nur nicht ausdrttcklich gesagt dafs 
Aias, obgleich damahls das dunkel noch nicht verbreitet war, erst den tod des Patroklus von Menelaus erfahren hat, wie es $P 686^{\circ}$ auf besondre veranlassung uns von Antilochus erzählt wird. dafs aber Patroklus nach unserm abschnitt 404 noch weit entfernter, unter der mauer der Troer, gefallen sein soll, davon ist in der erzïhlung des funfzehnten liedes keine andeutung: ihm wiirde nur etwa der ausdruck passen, den das drei-

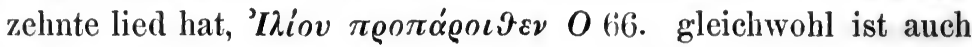
die andre darstellung nicht ohne zeugen: in $\boldsymbol{\Pi} 698$ verwarfen wir den versuch des Patroklus die mauer zu stürmen, und $\Sigma 453$ ward einen ganzen tag. am skäischen thor gestritten und die stadt fast genommen. aber das funfzehnte lied konnte von dieser ansicht aus nur ungeschickt und unpassend aufgestutzt werden. und sollte das wohl der verfasser dieser verse gewollt haben? bemerkte er nicht einmahl wie unschön er seinen zusatz mit $\ddot{\omega}_{S}$ schlofs, da das lied mit einem andern $\ddot{\omega}_{S}$ fortfuhr? $P 423$

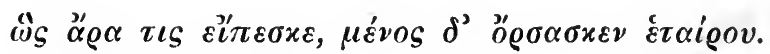
$\hat{\omega}_{S}$ oi $\mu \dot{\varepsilon} \nu \mu \alpha \dot{\varrho} \varrho \alpha \nu \tau o$.

ist es nicht wahrscheinlicher dafs der ganze zusatz aus einer andern darstellung entlehnt worden ist? mit der chronologie unserer Ilias steht er in schreiendem widerspruch, indem er 384 den kampf um Patroklus den ganzen tag dauern läist: aber in $\Sigma 453$ steht dasselbe, und vom funfzehnten liede habe ich schon (XXVI) bemerkt dafs es früh am morgen anfange.

Doch ich komme mir bald lächerlich vor, wenn ich noch immer die möglichkeit gelten lasse dafs unsere Ilias in dem gegenwärtigen zusammenhange der bedeutenderen theile, und nicht blofs der wenigen bedeutendsten, jemahls vor der arbeit des Pisistratus gedacht worden sei. diese ansicht im grofsen zu widerlegen habe ich mir nicht zur aufgabe gesetzt; um so weniger als man ja sagen könnte, des dichters kunstbildung sei vielleicht nicht fein genug gewésen um plan fortschritt und steigerung in der darstellung der gesamten fabel recht durchzuführen: sondern ich habe mich nur an das kleinere gehalten, 
das ein epischer dichter, dem der schein der wahrheit natiirlich tiber alles gehn mufs, unmöglich vernachlässigen kann. so will ich denn auch hier nur ein paar stellen mit frïheren vergleichen, um zu fragen ob sic aus einem munde haben kommen können. $P 306$ tödtet Hektor

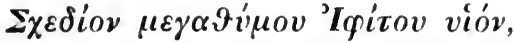

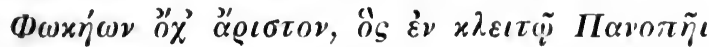

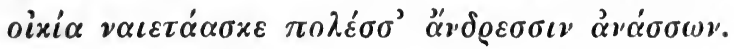

im zehnten liede $O 515$ erschlägt er

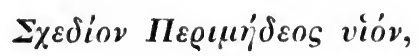

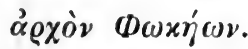

$P 347$

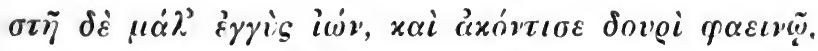

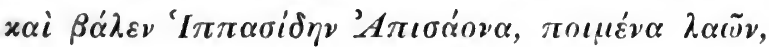

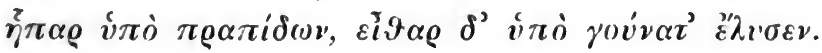

im vierzehnten $A 57 \%$

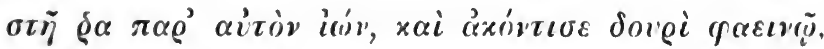

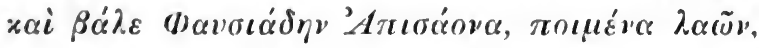

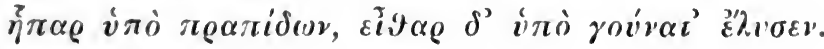
im zwölften $N 411$

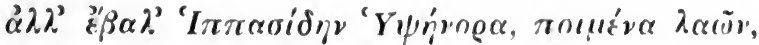

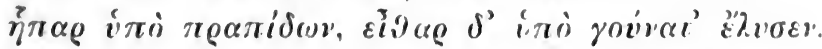

selbst das ist wenigstens auflallend, wem $P 2+$ Menelaus \% Euphorbus sagt, sein bruder Hyperenop habe ihn gresehmailıt

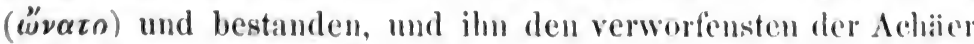
genannt oder doch dafür gehalten, ž́fato, wihrend er in drei-

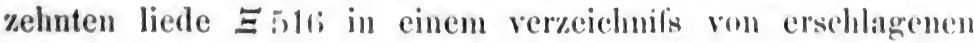
nur kurz erwähnt ward,

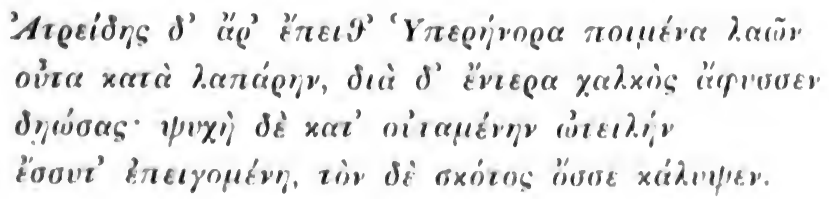


was soll man aber dazu sagen, wenn einige gar den Idomeneus, der $\boldsymbol{P} 612$ zu fufs in die schlacht gegangen ist, sich noch seit der schlacht bei den schiffen $N 329$ zu fufs denkeu? dort sind die Achäer sämtlich zu fufs: hier aber, wo nicht bei den schiffen gestritten wird, haben sie ihre wagen mit, $P$ 644. 698, nur Idomeneus nicht. wenn er, wie die geduldigen ausleger meinen, seit der erzählung, die ich in das zwölfte lied gesetzt habe, immer fort auf den beinen war, wie geht es zu dafs er nirgend vorkommt, sondern erst in der Patroklie $\boldsymbol{\Pi} 345$ ?

Allein ich darf nicht vergessen dafs in diesem liede noch zwei verse sind, die durch ein müssiges motiv anstofs erregen und auch von alten kritikern angefochten sind: schade nur dafs ihre verhandlungen noch in die lücke der Venediger handschrift fallen. $P$ 545. 546. Zeus ändert mit einmahl seinen be-

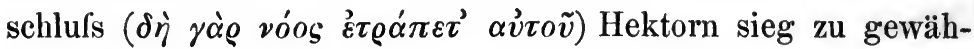
ren 206 bis er zu den schiffen komme und die sonne untergehe 454: Athene kommt nämlich vom himmel, von Zeus gesandt, um die Danaer zur vertheidigung des todten Patroklus zu entflammen. was braucht denn Zeus seinen sinn zu wenden? Athene hat ja freiheit unter die streitenden zu gehu, wie sie die göttin im ersten theile des liedes hatte $O 668$, und Apollon sie dort hatte (XXVI) und hier hat $P$ 71. 82. 118. 322. 582. und Zeus bleibt ja gleich nachher auf seinem sinne, indem er durch blitz und das schwenken der ägis den Troern sieg giebt, und den Achäern flucht 596. wenn er dann aut Aias bitte das dunkel zerstreut 649 , so hatte er es ja auch nur zu gunsten der Achäer ausgebreitet 270. 


\section{XXIX.}

Wie weit erstreckt sich das funfzehnte lied? soviel ich sehen kann, bis zum ende des siebzehnten buches. das folgende ist zwar (ich will es gern glauben, weil fast alles genau angekntupt ist) fortsetzung der Patroklie, aber nicht von demselben dichter. er hatte uns mit liebe und wärme erzïhlt wie die Aias den leichnam tragen und die Achäer bis an ihren graben fliehn. nun sind sie im achtzehnten buche schon bei den schiffen und am Hellespont 150, und die Troer erreichen den leichnam wieder 153. so trocken, 'sie erreichten ihn, und es war schwer ihn aus den wltren zu riehen 152, und die Aias komnten Hektorn nicht von dem todten verscheuchen' 164: aber kein wort mehr von dem tragen, so dafs uns das ganze ruhrende bild verschwimmt. der ausdruck 'sie kamen zu den schiffen und zum Hellespont' 150) ist auch ubertrieben. die 'Troer stehn, wenn wir die brtlichkeit uns bestimmter denken, nur am graben: denn Achill tritt gleich nachher von der mauer auf den jenseitigen rand des grabens 198. 215. 228, und von da wenden sie ihre wagen. aber was ist das? von der mauer 215? das funfzehnte lied kannte ja die mauer nieht (XXVI). die fortsetzung kennt sie; auch $Y 49$, wo Athene am graben aufserhalb der mauer steht. der kampf des Patroklus soll \ 4.33 am skaiscben thor gewesen sein: dafs dies nach unserer Patroklie 
nicht angeht, habe ich schon gesagt (XXVIII). wer den Patroklus getödtet hat, scheint dem dichter nicht klar geworden zu sein, oder die darstellung ist ihm wenigstens nicht ganz lebendig geblieben. Thetis sagt $\Sigma 454$ und das redende pferd sagt $\boldsymbol{T} 413$ Apollon habe ihn getödtet; wie freilich auch der

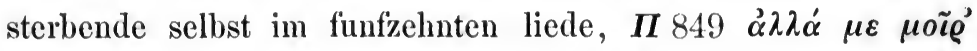

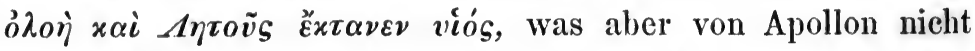
buchstäblich zu verstehen ist: der dichter des sechzehnten liedes selbst und Achilles sagen $\boldsymbol{X}$ 323. 331 er sei von Hektor getödtet worden. in übereinstimmung mit der Patroklie, aber im widerstreit mit den zusätzen (XXVIII), wird angenommen dafs Hektor ihm die waffen ausgezogen habe $\Sigma 83 X$ 323. nicht tadelnswerth scheint.mir dafs nach $\Sigma 14$ Achill dem Patroklus will verboten haben mit Hektor zu streiten, obgleich $\Pi 90$ Hektor nicht ausdriicklich genannt war: und ich denke, des von Barnes und Vofs aus Diogenes von Laertes in die ermahnung eingeschobenen verses können wir entrathen.

Wenn nur nicht alle folgenden biicher, gegen die Patroklie gehalten, geschweige gegen die noch edleren theile der Ilias, sich so ärmlieh und kühl ausnähmen, dafs ich das urtheil von Wolf (proleg. p. cxxxvi1) nicht recht begreife, der nur bei den letzten sechs büchern, also nicht auch, scheint es, beim achtzehnten, sich anders gestimmt fühlte. mir scheinen die fünf bïcher von $\boldsymbol{\Sigma}$ bis $\boldsymbol{X}$ so aus einem stiick zu sein, so überein stimmend in den begebenheiten nicht nur sondern auch in allen manieren, in dem gänzlichen verschwinden aller griechischen heroen aufser Achilles, in der masse von erscheinungen und würkungen der götter, in den vielen mythen, in der dürtigkeit der bilder und gleiehnisse, dafs sie eben so sehr einen einzigen dichter verrathen, als sie fuir fast alle der friheren, die deswegen nicht um jahrhunderte älter zu sein brauchen, dals ich es nur grade heraus sage, zu schlecht sind.

Ich gebe zwar gern zu dafs auch die Patroklie schon ihre besonderheiten hat, und dafs von dem auffallenden das die letzten gesänge haben sich auch in den friheren hie und da spuren finden: im ganzen wird aber die menge der einzelnen 
abweichungen den allgemeinen eindruck bestaitigen. so hat die Patroklie 'er sprachs und der andre antwortete' in einem verse zusammen, $P 33$

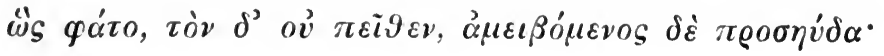

welches nun grade in jenen fünf biichern nicht vorkommt, aber im dreizehnten liede, auch keinem der besten, $\Xi 270$

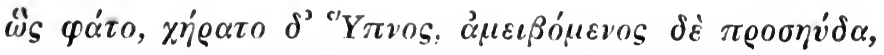
in der Dolonie, $\boldsymbol{K} 328$

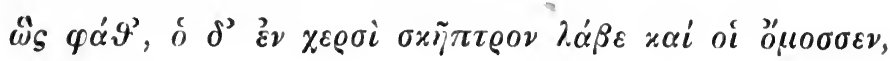

und in $\Omega$ zwei mahl, 200 und 424 ,

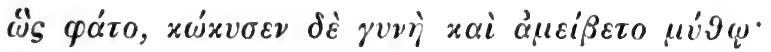

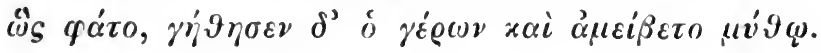

aber weit auffallender sind doch in den letzten biichern die reden die in einem einzigen verse bestehn, $\Sigma 182.392 \quad Y 42$ ? D) 509 y 707. 75:3. 76!) $\Omega$ 88: und niemand der gefühl für manieren hat, wird im vierzehuten liede die unnitzen verse $\Lambda 605-607$ ertragen,

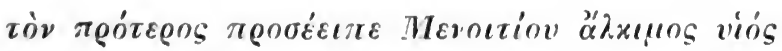

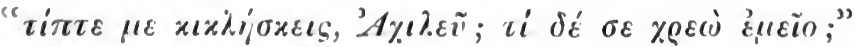

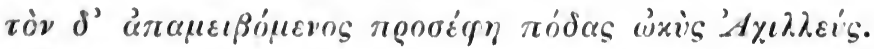

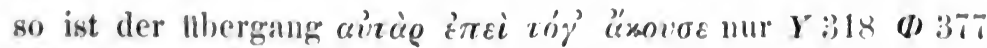
\& 161, sonst nicht in der llias, um die ich mich hier therhaupt allein bekllmmere: hingegen wem das gewïhnliche iे xai oder

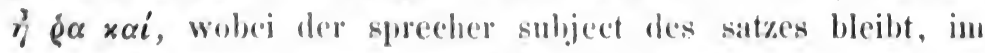
zweiten sechsten nenten und clften lierle gar nicht rorkommst. so ist von dem freilich ciurgen pĩ męi xacópryos (d) 361 dennoch, das sonst bei Homer unerhoirte qĩ abgerechnet, $\dot{\eta}$

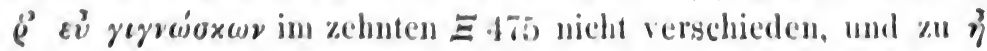




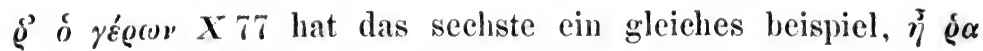

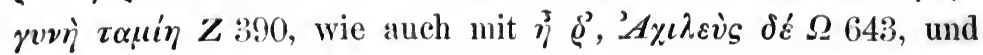

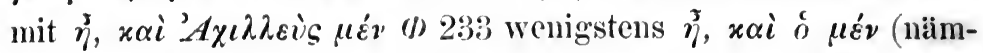
lich nicht der eben geredet hat) im neunten und im zehnten K $454 \Lambda 446 \mathrm{zu}$ vergleichen ist. so findet sich nirgend etwas ähnliches wie (D) 479, wo die rede der Here unmittelbar auf diese worte folgt,

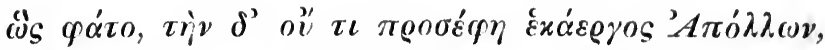

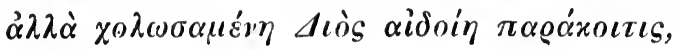

oder wie $\Psi 855$, wo gar mitten im verse directe rede anfärgt,

$$
\grave{\varepsilon} \varkappa \delta \grave{\varepsilon} \tau \varrho \eta \dot{\eta} \varrho \nu \alpha \pi \dot{\varepsilon} \lambda \varepsilon \iota \alpha \nu
$$

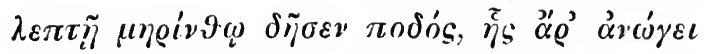

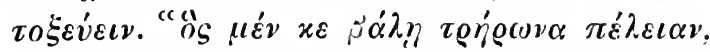

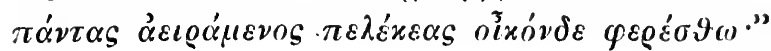

nur dafs man nicht sagen mufs, es fehle $\tau \alpha \dot{\alpha} \delta \varepsilon \lambda_{\varepsilon} \gamma \omega \nu$ : denn die verbindung ist ganz wie $\Delta 303$,

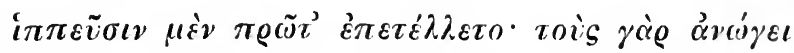

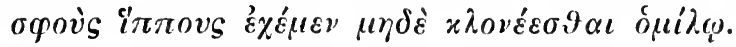

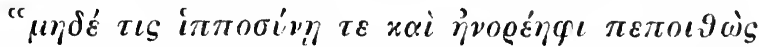

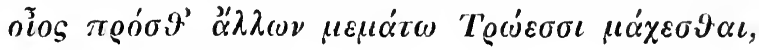
$\mu \eta \delta^{3} \stackrel{\alpha}{\alpha} \nu \alpha \chi \omega \varrho \varepsilon i \tau \omega . "$

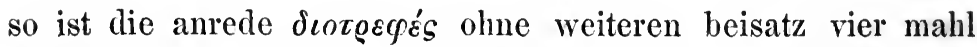
in den letzten biichern, $\Phi$ 75 $\Psi 594 \Omega$ 55ว3. 635, einmahl im

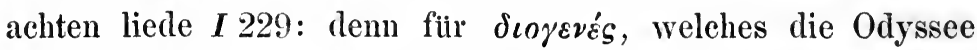

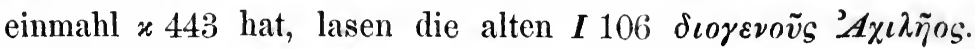

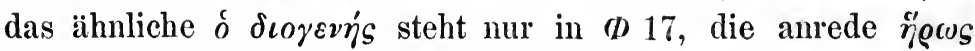
nur in $Y 104$ und in der Dolonie $\boldsymbol{K} 416$ : aber $\eta^{\prime} \rho \omega_{s}$ statt des namens und noch mehr 'ö $\gamma$ ' "̣̆os sind verbreiteter. so ist die $\dot{\varepsilon} \pi \alpha \nu \alpha \dot{\lambda} \eta \psi \iota \varsigma$ den letzten biichern von $\Sigma$ an zwar nicht eigenthitimlich, $\mathbf{\Sigma} 399$ 


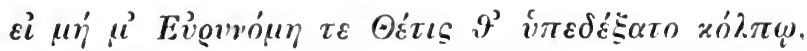

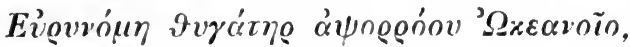

so $Y 372$ ( $86 \times 128$ \% 642; aber aufserdem doch, soviel ich weifs, nur im sechsten $Z 154$. $396 \boldsymbol{H} 138$, im achten $\Theta 531$, im elften liede $\boldsymbol{M} 96$, und in beiden katalogen $B$ (751. 837. 850. 870. doch dergleichen gesehickt und anmutig auszufithren ist eine kunst die ieh wenig verstehe.

Das vorletzte buch unserer Ilias hat der dichter desselben gewils nicht unmittelbar nach dem schlusse ron $\boldsymbol{X}$ wollen gelesen haben: demn es ist undenkbar dafs ein diehter diese verbindung wählen kann,

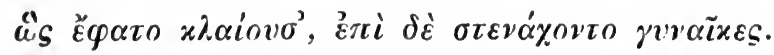

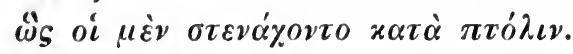

wie wir ähnliche schon zwei mahl rerworfen haben, $O: 367$ (XXIV) und $P 424$ (XXVIII). den vierten vers dieser art $Z 311$ hat bereits Aristarch getilgt,

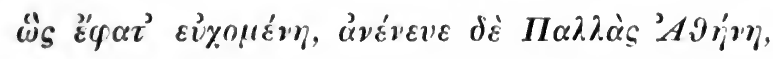

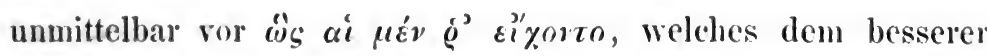
anstöfsig gewesen war nach der einzigen rede der priesterin. durch eine stärkere athetese, die aber nach meinen untersuchungen (XXVIII) eine mehrfache interpolation voraus setzen witrde, half Aristarch $P 424$ : aber warum schien ilın dort der

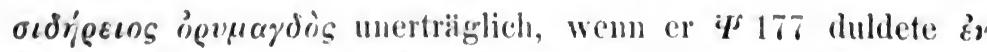

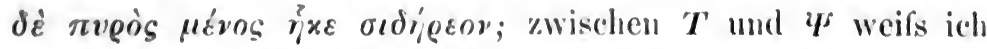
zur fernern bestätigung wenigstens eine kleinigkeit anzugeben. an welche der dichter, wenn er derselhe war, wohl gedacht und dem sehein des widerspruchs abgeholfen hätte. in $T 47$ hinken Diomedes und Odysseus noch von ihren wunden, und auch Agamemnon hat reine wunde noch. es vergeht ein tag is 109-225: dann bei den spielen springt Diomedes rom wagen

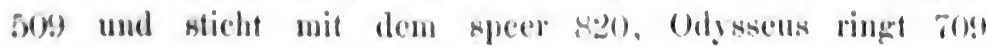


und liuft 755, Agamemnon steht auf zum speerwerfen 887. Nestor, der seit dem achten liede nur im vierzehnten vorkam (XXV) und in einigen der schlechtesten zusätze (XXIV. XXV), erscheint plötzlich nebst Idomeneus und Phönix in einem verse der eben so gut fehlen kamn $\boldsymbol{T} 311$ : aber in $\boldsymbol{\Psi}$ tritt er mit einer langen belehrenden ermahnung auf, 304.

Kleine zusätze von wenig gewicht werden sich auch in den letzten bitchern genug nachweisen lassen, wie der so eben erwähnte vers in $\boldsymbol{T}$, oder noch sicherer der störende $\boldsymbol{T} 374$ (Hermann de iteratis p. 8), den Aristarch gewifs als $\pi \varepsilon \varrho \iota \sigma \sigma o ̀ \nu$ gestrichen hat. ich darf nicht ausdrücklich bemerken dafs ich in der nachweisung kleinerer zusätze auf keine vollständigkeit ausgehe. allein Aristarch diirfte wohl einiges nicht mit unrecht getadelt haben was doch nicht für späteren zusatz erklärt werden kann. indessen gestehe ich, es wäre freilich zu viel verlangt dafs er trotz dem vorurtheil hier seinen Homer hätte aufgeben sollen. wer wird dem auch leugnen dafs in diesen bïchern viel schönes ist? ja ich will gern zugeben dafs der dichter des grofsen sechzehnten liedes in diesem mehrere ältere vereinigt hat: und in der that deutet der katalog der Troer $B$ 860. 874 auf eine andre darstellung des kampfes im flusse als die wir im einundzwanzigsten buche haben. aber der dichter hat den ailteren liedern in der iiberarbeitung so sehr seine eigne farbe gegeben, dafs niemand gern an die scheidung gehn wird, der, wie ich, darauf aus ist ausgefundene thatsachen zum künftigen gebrauch hinzustellen, die vielleicht noch im einzelnen, wo geirrt worden ist, richtiger bestimmt werden können, aber so wenig als möglich vermutungen, denen man eben so wahrscheinliche entgegen setzen diirfte.

So viel jedoch lätte. ich Aristarch wohl zugetraut, dafs er das letzte buch ganz verworfen hätte, und den schlufs des vorletzten von da an wo die fünf wettkämpfe beendigt sind. denn so viel waren nur versprochen $\Psi 621-623$, so viel gab Nestor als iiblich an 634-638, und was nachher folgt $824 \mathrm{ff}$. ist ungemein schlecht in der darstellung. das letzte buch aber, 
zu dem die veranlassung in der rede des Priamus $\boldsymbol{X} 412-428$ lag, fanden die alten schon in vielen punkten anstölsig. es ist durch die worte $\Lambda \tilde{i} \tau o \delta^{\prime} \alpha_{\alpha}^{\prime} \omega^{\prime} v$ ohne iibergang kunstlos angekniipft, selbst in der zeitbestimmung ungeschickt: denn dafs

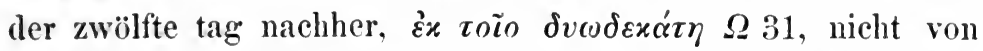
der 3. 4 ausdrieklich erwähnten nacht an gerechnet wird, sondern von Hektors tode zuriick, merkt man erst spät 107. 413 an äufserungen die sonst keinen sinn haben. 
XXX.

W enn ich mit meinen betrachtungen nicht gar zur qual meiner verehrten zuhörer iiber das ziel schielsen will, so mufs ich hier aufhören: denn in welchem verhältnisse die mir erkennbaren theile der Ilias gegen einander stehn, habe ich so kurz und bestimmt als ich es vermochte gesagt, und ich kann nur wiinschen, aber nichts dazu thun, dafs die geschichte der ältesten griechischen poesie diese untersuchungen in ihren nutzen verwende. wer nun aber etwa nach weiberart um seinen lieben Homer, seine liebe Ilias, seine lieben vorurtheile, jammert und sie fiir weit herlichere einzelne lieder nicht hingeben will, dem kann ich zum ersatz den entwurf einer andern Ilias, wenigstens bis zum auftreten des Patroklus, nachweisen. ich meines orts weifs es dem Pisistratus und seinen helfern dank, dafs sie uns nicht etwa eine ausfihhrung dieses entwurfs gegeben haben, sondern weit bessere und ursprïnglichere stïcke, die sich ohne ihren fleifs sicher nicht auf die folgezeit fort gepflanzt hätten. aber ich danke ihnen auch für die unschuld, mit der sie, gewifs absichtlos, in ihrer überlieferung die spuren anderer darstellungen und ansichten der sage gelassen haben.

Wie wir nämlich im dreizehnten liede eine andere anknïpfung der Patroklie vorbereitet fanden $O 63$ (XXII) als wie sie der anfang des funfzehnten giebt, eine andre im vierzehnten $O 402(\mathrm{XXV})$, und welche das zehnte $O 233$ andeutete blieb (XXVI) zweifelhaft, so weiset das sechzehnte lied wieder auf 
eine andre lage zurtick, die, wie sich gleich zeigen wird, auch im elften voraus gesetzt ward, und es giebt uns in einzelnen äufserungen so viel punkte der frïheren geschichte, dafs man daraus sieht, dem dichter schwebte ein ganz anderes bild der Ilias vor als wie es uns die pisistratische sammlung darbietet.

Agamemnon erziirnt den Achilles $\Sigma 111$, indem er ihm die Briseis, die jungfrau von Lyrnessos, raubt $\boldsymbol{T} 60.296$. die namen Lyrnessos und Mynes kamen nur im katalog der Achäer vor $B$ 690; dafs er sie bei zerstörung einer stadt gewonnen, im funfzehnten liede $\Pi 57$ und im achten $I$ 331. Achill betet zu Zeus, wie wir ebenfalls im funfzehnten fanden (XXVI), dafs die Achäer zu den schiffen gedrängt werden $\Sigma 76$. von der bitte der Thetis ist nicht die rede: doch missen wir annehmen dafs sie dem dichter bekannt war, wenn er würklich unser funfzehntes lied fortsetzte.

Von den schlachten in der ebene kommt nun zunächst etwas vor, das mit dem fünften liede stimmt; aber nichts von den zweikämpfen. Diomedes erbeutet die rosse des Äneas, den Apollon rettet; wie $E$ 323. 445). doch dies steht eigentlich nicht in sechzehnten liede, sondern in $\Psi$ 291. Athene reizt den Diomedes dals er den Ares verwunde, sie stöfst ihm selber das speer in den leib (D) 396; genau wie $\boldsymbol{E}$ 830. 856-858.

Dann wird der verwundungen des Diomedes und Odysseus erwähnt: beide hinken noch $T 47$, da nach unserm zehnten liede Diomedes in den fuls geschossen ist 1377 , Odysseus aber in die seite gestochen $\Lambda$ 437. Agamemnon ist von Koon gestochen $T 54$; aber nach 1252 in die hand, welche wird nicht gesagt: hier $T 25 \%$. 266 kann er mit den händen das messer ziehn und das sthmopfer schneiden. ob ihm das stehn sauer wird, ist bei den schwicrigkeiten der verse $T$ T nicht leicht $\%$ sagen. aber wie gan\% anders ist die lage als im zehnten liede! dic Achäer sind, genau nach dem gebet des Achilles $\mathbf{\Sigma} 76$, in die schiffe eingeschlossen und kömen nicht hinans 446: aber die maner, von der wir hier nicht erfahren wann sie gebaut worden sei (XIII), ist und bleibt unzerstirt $\mathbf{\Sigma} 215 \quad Y 49 . \quad$ also genau was wir bei dem elften liede voraus 
setzen musten $(\mathrm{XX})$. die Troer ibernachten fortwährend auf dem felde $\Sigma 259 T 71$. so ist es in unserm achten und neunten liede, aber nur während einer einzigen nacht.

In der letzten nacht vor dem auftreten des Patroklus eräugnet sich waś in unserm achten liede enthalten ist, die gesandtschaft an Achilles, an die vom neunten bis zum funfzehnten weder Achill noch sonst jemand wieder gedacht hatte. die greise der Argeier bitten den Achilles und nennen viel köstliche geschenke $\boldsymbol{\Sigma} 448$. noch bestimmter wird $\boldsymbol{T} 141$ Odysseus genannt, der auch im achten liede die gaben versprach. dafs die geschenke T 243-247 genau dieselben sind wie I 122-132, ist eben nicht zu verwundern.

Ich habe die verwundung der drei helden vor die gesandtschaft an Achill gesetzt, weil sich der dichter die folge so mufs gedacht haben: denn es heifst $\boldsymbol{T} 141.195$ in der nacht auf gestern, $\chi \vartheta \iota \zeta o ́ v$, seien dem Achill die gaben verheifsen, vor dem morgen an dem Patroklus kam. aber ich glaube, diese folge der begebenheiten war nur seine persönliche meinung, und wir dürfen wohl nicht schliefsen dafs er etwa fand, die gesandten hätten den Achilles um hilfe gebeten weil die bedeutendsten helden verwundet wären, sondern wir müssen daraus erkennen dafs er keine zusammen hangende darstellung vorfand, vielmehr einzelne lieder; aufser der Patroklie etwa vier, soviel er kund giebt; von denen er, nach dem zorn und dem kampf mit den göttern, das dritte und das vierte sich willkürlich ordnete. eins enthielt die gesandtschaft, während die Troer in der ebene übernachten; das andre" die verwundung der helden und die beschränkung der Achäer auf ihr lager. jenes mag wohl unser achtes sein, obgleich es der angenommenen ordnung widerstreitet $\Theta 532$ I 709; das andre vielleicht das im elften voraus gesetzte: das elfte selbst kann er aber nicht gekannt haben. im achten hat er $\boldsymbol{I} 650$ das tragische iuberschreiten des malses nicht gefunden, olne welches nach einer neueren ansicht die epische fabel nicht soll können begriffen werden (XXVI): ja ihm hat nicht einmahl eingelenchtet dafs den Achill, weil er die bitten verschmäht hatte, die Ate strafend begleitete $I 510$ : 
sondern dem Agamenmon, sagt er $\boldsymbol{T}$ 87. 270, sandten Zeus Möra und Erinys die Ate, um viel Achäer zu verderben, aber dem Achill giebt er keine siinde schuld, nicht einmahl dafs er zu lange geziirnt habe $\boldsymbol{T} 67$.

Der iibergang auf das erscheinen des Patroklus ist in der erzählung der 'Thetis $\Sigma 450$ sehr' sonderbar gemacht: 'Achilles verweigerte den greisen die hilfe, aber er zog dem Patroklus seine waften an und sandte ihn mit vielem volk in die schlacht.' iudessen das ist wohl nur eine kurze darstellung, und die begebenheit wird wie in der Patroklie gedacht: denn es ist $X 374$ ausdrüeklich gesagt dafs Hektor die schiffe mit feuer angeziundet hat, und daran war ja $\Pi 127$ die aufforderung des Achilles gekniipft. wie genan sonst das sechzehnte lied sich an die erzählung des funfzehnten schliefst, bedarf keiner besondern erörterung: die wenigen abweichungen habe ich vorher (XXIX) angegeben, $\mathrm{nm}$ zu zeigen dafs beide nicht einem dichter gehören können. 


\section{ÜBER \\ ZENODOTS TAGBERECHNUNG DER ILIAS.}

(Aus den berichten über die verhandlungen der akademie der wissenschaften, 1846 , s. 29.)

Hr Lachmann legte folgende beischrift eines basreliefs troischer scenen vor, welches neuerdings in Paris zum vorschein gekommen ist.

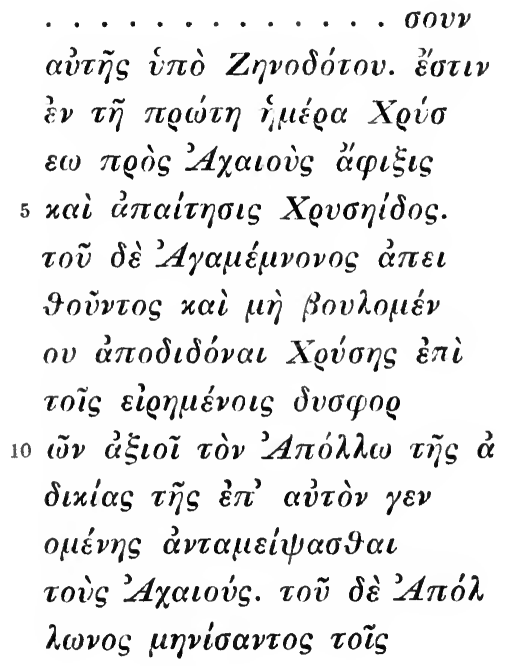




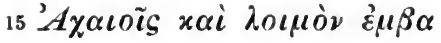

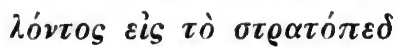

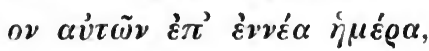

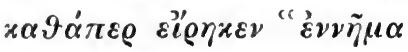

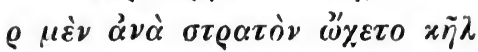

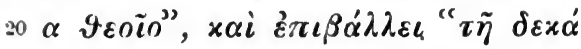

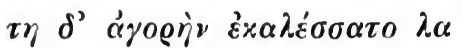

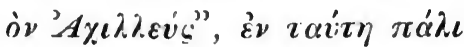

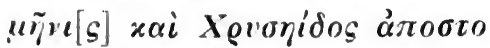

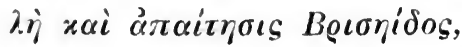

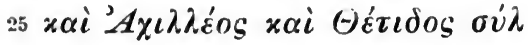

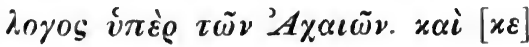

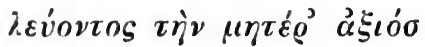

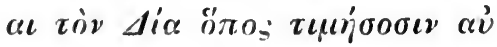

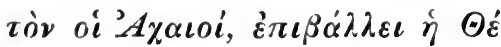

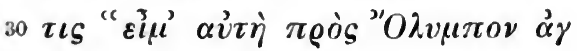

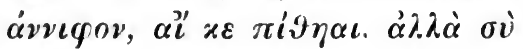

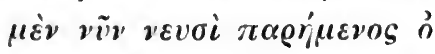

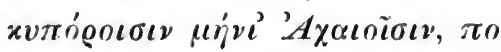
$\lambda \dot{\varepsilon} \mu \circ v \delta^{\prime} \alpha \pi \circ \pi \alpha i \varepsilon o \alpha^{\prime} \alpha \dot{\alpha} \mu \alpha \nu$.

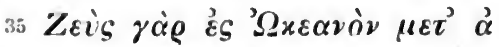

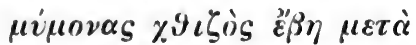

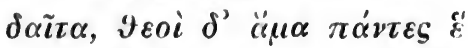

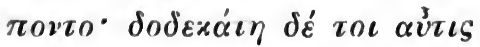

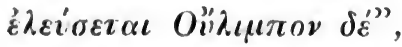

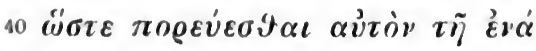

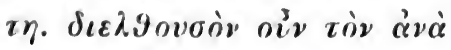

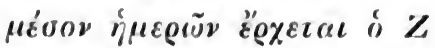

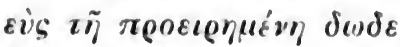

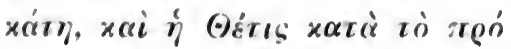

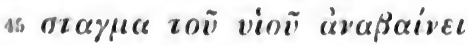

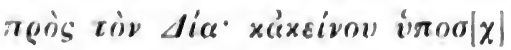

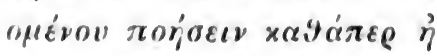

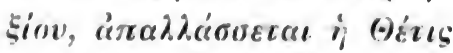

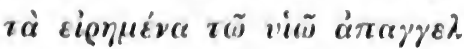

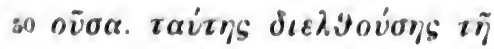




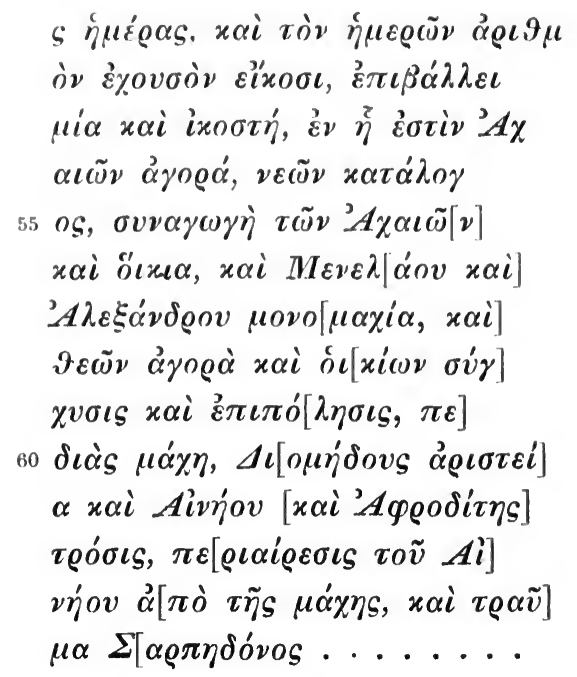

Die schrift ist, fast ganz eben so ergänzt, heraus gegeben von hrn Adrien de Longpérier in der Revue de philologie, vol. I, p. 441, und von hrn Bergk in einem Marburger programm auf den 21. december 1845. was schlecht geschrieben ist, sieht jeder selbst: nur das unbegreifliche $\dot{v} \pi \dot{\varepsilon} \varrho \tau \tilde{\omega} \nu$ 'A $A \alpha \iota \tilde{\omega} \nu$ (z. 26) widersteht einfachen versuchen.

Aus den ersten worten, über denen aber ein halbes dutzend zeilen abgebrochen sein soll, machen beide herausgeber eine

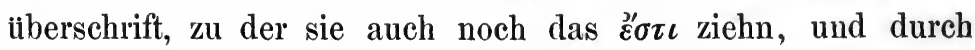
die sie den aufsatz für einen auszug der Ilias von Zenodotus dem Ephesier erklären. aber eine inhaltsangabe der ersten fünf bücher der Ilias haben wir hier nicht, sondern, für leser die sie schon kennen, eine berechnung der tage, mit anführung nur der verse die zeitbestimmungen enthalten. daher, und nicht durch absichtliches zusammenziehen, die kurze aufzählung vieler begebenheiten. die nächste ausführliche untersuchung würde auf die verse $\boldsymbol{H}$ 381. 421. 433. 465 gegangen sein; nach dem scholion zu $\Pi 202$, welches Aristarchs meinung zu geben scheint, die umgrenzung nur eines tages, des vierzehnten der $\mu \tilde{\eta} \nu \iota s$. dann müste ferner zu sehen sein, ob der sonnenaufgang in $\Theta$ vor oder nach der götterversamm- 
lung eintrat, v. 1 nach Aristarch, nach Zenodot vor dem 53". (gewifs hat erst Aristophanes oder Aristarch den jetzigen anfang von $\Theta$ bestimmt: aber es ist sicher falsch, erst ihnen, und nicht etwa Zenodot oder einem früheren, die kindische eintheilung beider werke nach den buchstaben des alphabets zuzuschreiben, da die gereiftere kritik die Odyssee bei $\psi 296$ schlofs.) dafs die abhandlung von Zenodot verfafst sei, haben beide herausgeber nicht versucht $z u$ beweisen. allerdings aber giebt die tafel Zenodots ansichten; nicht weil im anfang sein name steht, sondern weil Aristarch die gesamte darstellung bekämpft.

Zenodot verwarf die verse $A$ 488-490. 492: den $491^{\text {slen }}$ schrieb er gar nicht. warum, hat hr Bergk nicht richtig errathen, obgleich Aristarch die griunde der athetese widerlegt.

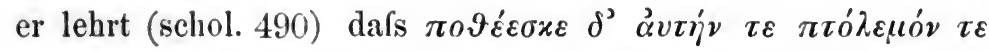
bedeute, die unthätigkeit sei dem helden schmerzlich gewesen: dem fruheren kritiker schien also die begierde zum kampf der drohung zu widersprechen, dals er nicht mehr streiten sondern heim kehren wollte. und őै $\tau c^{\prime} \pi o \tau^{\prime} \varepsilon_{S} \pi \delta^{\prime} \lambda \varepsilon \mu o \nu$, sagt Ari-

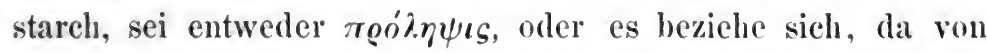
den dazwischen liegenden tagen iberhaupt nichts erzählt werde, auf kleine heerfahrten in die umgegend, die sonst Achill zu fuhren pflegte. dies scheint er so ausgefihirt zu haben, dafs er zeigte $\varepsilon i \varsigma \alpha \dot{\alpha} \gamma o \varrho \eta^{\prime} v$ sei grade so anstörsig oder gerechtfertigt

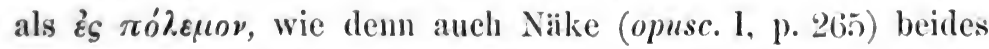
gleich unschicklich fand. ein ehronologisches bedenken nahm Kenodot an den versen nieht: sonst wiirde die tafel ihrer erwähnen. dagegen riggte Aristareh durch eine diple bei $A 475$ (s. schol.) die nachlissigkeit Zenodots, und der tafel, dafs der tag der ruckkehr des Udysseus von Chryse vergessen war. auch die schwierigkeit berihrt die tafel nicht, dats 472 die Achäer in Chryse zovinúgerı den Apollon besingen. das scholion erklärt 'den rest des tages, an dem gesehifit und das festmahl gehalten ward': es rerschweigt aber dafs auch die versammlung mit allen reden in diesen tag tiel, und die absendung des schifies, bei welcher zwanzig ruderer gewihlt und 
eine hekatombe geladen ward; freilich immer nur sehr wenig begebenheiten gegen die des tages von $\boldsymbol{B} 48$ bis $\boldsymbol{H} 293$.

Die iibrige rechnung der tafel findet hr Bergk untadlich und eben so gut als die gewöhnliche. das gespräch zwischen Thetis und Achill ist am abend desselben tages, an dem sich die könige zanken, des zehnten: die götter sind am neunten zu den Äthiopen gereist. dies mufs jeder annehmen, der die masse der Ilias fiur ein ganzes hält. nun sagt aber Thetis, am zwölften tage werde Zeus heim kehren: am zwölften, rechnet die tafel, nach der abreise, also am zwanzigsten, und am zwanzigsten läfst sie dann Thetis auf den Olymp gehen. hierin fand Aristarch zwei fehler. wenn mit Zenodot die verse 488-492 getilgt wurden, und nun ward 477-487 erzählt 'mit dem morgen', also am elften tage, 'kehrte Odysseus heim', so muste der unmittelbar 493 folgende 'zwölfte tag nach diesem' von dem elften ab gezählt werden, also nothwendig anders als in der rede der 'Thetis. dies bedeutete die diple bei 477. zweitens, da allerdings der zwölfte tag beide mahl gleich zu berechnen ist, so kann er das erste mahl freilich, in der rede der Thetis, sowohl von gestern, vom neunten tage ab, gezählt werden, als von heute: aber wenn nun der dichter selbst erzählend sagt 'am zwölften tage nach diesem', so kann er nicht von der begebenheit ausgehen, die nicht er selbst sondern nur eine seiner personen erzählt hat. dies sagt das allzu kurze scholion zu $A 493$, dessen verständnifs wir der tafel verdan-

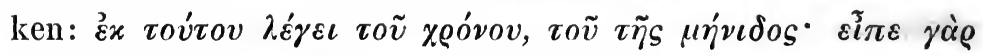

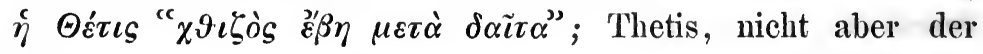
dichter.

Offenbar hat Aristarch, der den zwölften tag für den zwölften der $\mu \tilde{\eta} \nu \iota s$ nahm, grindlicher untersucht als Zenodot mit seinem elften, und nur bei Aristarchs ansicht darf man noch fragen ob sie genuige. zwar die meinung die hr Bergk p. 4 mit dem ausdruck argutatur rïgt (einem unschönen, wo es sich um freie aber achtungsvolle kritik der edelsten poesie handelt), hat weder der getadelte noch sonst jemand gehabt: aber der zweifel wird doch wohl erlaubt sein, ob es einem 
geschickten erzühler begegnen würde, dafs er zucrst drei zeiten angäbe, zwei mit zahl, die dritte vom täglich bis zum sechzehnten tage wiederholten, und er liefse damn eine zahl folgen die auf die erste zuriick wiese; 'am zehnten tage rath, zank, Thetis rede: am andern morgen kam Odysseus zuriick: Achill gieng inzwischen (nicht seitdem) niemahls zum rath und niemahls zur schlacht: nach diesem aber am zwölften morgen kehrten die götter heim.' es ist wahr dafs hieran Niike keinen anstofs genommen hat, sondern nur der, wie hr Bergk sagt. qui omnia dissolvit. vielleicht könnte nun dieser zugeben dafs sein gefuhl hier zu scharf sei, wemn es der bedenken im ersten buche der Ilias nieht mehr gäbe, und wenn nur nicht hr Bergk eine schwierigkeit des ersten buches dureh das letzte, ein werk aus einer weit späteren kunstperiode, reehtfertigen wollte. die stelle aus $\Omega$ ist in den betrachtungen tiber die Ilias (XXIX am ende) mit deutlicher beziehung angefuihrt, aber vielleicht nicht genügend erklärt. es wird erzählt 'die Aehäer zerstreuten sich in die schiffe, und afsen und schliefen damn: nur Achill weinte schlaflos, und am morgen schleifte er Hektors leichnam um das grab des Patroklus; so bis am zwölften morgen Apollon zu den göttern sprach.' da nach $\Omega+13$ der zwölfte tag nach Hektors tode gemeint ist, so mufs wer die jetrige Ilias gelten laifst allerdings mit dem seholion bei $\Omega 31$ rechnen wie Aristarch im ersten buche; nicht 'wic Yenodot,' der dort einen tag fruher zu zïhlen anfieng. alser die beiden letaten bitcher beginnen, ohne genauere bezeichnumg, also an vorher gegangenes ankntifend, jedes nit Hektors todesabend, und mit denselben worten,

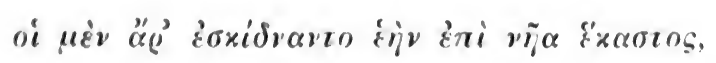

und

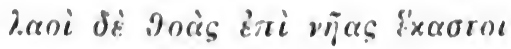
éoxidvavi' iéval.

keines von beiden bllehern pafst an den schlufis ron $\boldsymbol{X}$ : $\boldsymbol{P}$ hat keinen bestimmten schlufs, und nicmand weils was dic bedenk- 


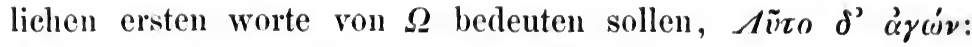
wie verwegen witrde es also sein, in diesen worten und in dem allerdings voraus gesetzten begräbnil's des Patroklus anspielungen auf unser dreiundzwanzigstes buch zu sehn! míssen wir dies aber absondern, so macht im letzten buche der zwölfte tag keine schwierigkeit, er rechtfertigt aber auch nicht den im ersten. 


\title{
ZUSÄTZE \\ VON MORIZ HAUPT.
}

\author{
Zu III. s. 6.
}

Den widerspruch zwischen $A 222$ und 424 zu heben hat Aristarch auf verschiedene weise versucht. er meinte, entweder misse 222 gestrichen oder allgemeine homerische formel, ohne individuelle bedeutung fir diese stelle, angenommen werden. ein dritter versuch der ausgleichung ist fiur "̈логлo im 424"

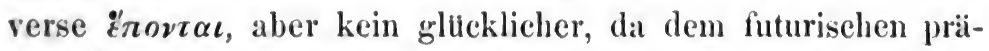
sens $\stackrel{\alpha}{\mu} \mu \alpha$ und der gedanke widerstrebt. auf der andern götter abwesenheit kommt es gar nicht an: miterfolgt kann sie miterwähut werden; gan\% llberflufsig wird ihrer gedacht, wenn sie erst bevorsteht. dafs Apollon am tage nach der götterfahrt \%u den $\ddot{A}$ thiopen seine pestpfeile in das heer zu senden fortfihrt und am gesange der in Chryse das opfer haltenden sich erfreut ist dem Aristarch nicht aufgefallen. dafs Athene ron Here vom Olymp herabgesendet wird und dahin zurllekkehrt hat ihn zu keiner athetese bewogen: nur 222, nicht auch 221 , gab er allenfalls preis, und zwar 195. 19; verwarl er, wohl nur weil diese verse sich wiederholen, aber 206. 209 nahm er 
gegen Zenodotus in seliutz, der hier aus derselben scheu vor widerholung tilgte. den widersprueh dieser stellen und des

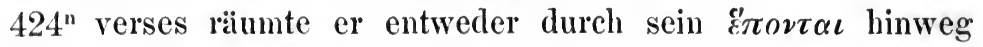
oder dureh erklärung; er hat nicht in beiden ausgaben Ė $^{\prime}$ ov $\tau \alpha \iota$ gesetzt oder es nicht mit entschiedenheit als das richtige behauptet, sonst wären seine bemerkungen über 222 unnutz. die erklärung dureh die er den widersprueh zu lösen suchte mufs wohl die in $B L$ überlieferte sylleptisehe von $\pi \dot{\alpha} \nu \tau \varepsilon s 424$ gewesen sein; nicht dafs sie seiner wirdig wäre, aber eine andere weise sich iiber den widerspruch hinwegzuteusehen wird man sehwerlich finden können. von den unmögliehkeiten die Vofs (krit. bll. 1, 183) als 'die wahre antwort' auf die fragen giebt $\mathrm{zu}$ denen diese stellen nöthigen, war Aristarch weit entfernt.

$\mathrm{Zu} \mathrm{dem} \mathrm{(s.} \mathrm{93)} \mathrm{aus} \pi \alpha \imath \eta \mu \varepsilon ́ \rho \iota \iota ~(472)$ gewonnenen grunde für die verschiedenheit der verfasser des ersten liedes und der ersten fortsetzung fiigt sich noch eine andere betrachtung. wemn der dichter des ersten liedes seine erzählung durch eine fortsetzung wie 430-492 weiter führen wollte, so konnte er es doch nur thun um die begebenheiten seines liedes durch Apollons versöhnung zum abschlufse zu bringen. aber gerade dies wichtigste wird mit ganz knappen worten abgethan, $\tau o \tilde{v} \delta^{\prime} \varepsilon^{\prime} x \lambda v \varepsilon$

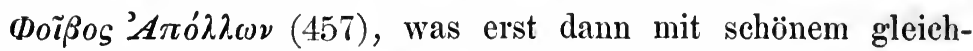
mals aus 43 widerholt wäre, wemn wie dort die erhörung

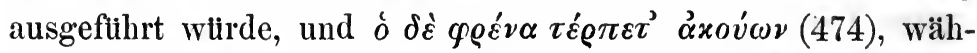
rend opfer und opfermahl weitläufig geschildert werden. dies ist einem fortsetzer zuzutrauen, der dem dichter dessen lied er weiter spann an künstlerischem verstande nicht ganz gleich kam und der sich in der beschreibung einer festlichkeit gefiel (wie die interpolatoren altdeutseher lieder in der schilderung von ritterfesten schwelgen), gewifs nicht dem dichter der sein lied (1-347) tadellos gliederte und abrundete. dieser dichter brauchte Apollons versöhnung nicht anzureihen; sie war aus der sage bekannt und von ihm selbst durch Kalchas worte hinreichend angedeutet. sein lied wollte nur als ein einzelnes aus der ganzen sage verständliches gelten: es ist nicht in der 
absicht eine lange reihe damit $\mathrm{zu}$ beginnen gedichtet; sonst würde Patroklos wo er zuerst vorkommt (307) nicht blofs patronymisch bezeichnet sein. dies fällt nicht auf im munde eines sängers der ein einzelnes stiick bekannter sage singt; ein berechnender dichter, der es auf ein langes umfassendes gedicht anlegt, wird anders verfahren.

Auffallend ist es wie viele verse der ersten fortsetzung sich an anderen stellen der homerischen gedichte finden. aus dem ersten liede sind 37. 38 hier 451.452 widerholt, was allerdings auch in éinem liede sehr schön wäre. 432 ist = Od. $\pi$ 324; und dabei kommt in betracht dafs $\pi 0 \lambda v \beta \varepsilon \nu \vartheta \eta^{\prime} s$ sich thberhaupt sonst nur in der Odyssee findet (auch $\beta \varepsilon \dot{\nu} \vartheta$ os nur $N$ 21. 32. $\Sigma$ 36. 38. 49 und in der zweiten fortsetzung des ersten liedes 358, in der Odyssee fuinfmahl). - 435. 436. $437=$ Od. o 497. 498. 499. - 453. 454. $455=$ II 236. 237. 238. 458 bis $461=B 421$ bis 424 . -461 bis $465=$ Od. $\gamma 459$ bis 462 . -464 bis $469=B 427$ bis 432 . $-470.471=$ I 175. 176 (Od. $\gamma$ 339. 340. $\varphi 271.272) .-475.476 .477=$ Od. $\iota 558.559 .560 . \times 185.186 .187$; wobei bemerkens werth

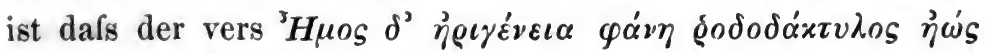
zwanzigmahl in der Odyssee steht, in der Ilias nur noch $\Omega 788$.

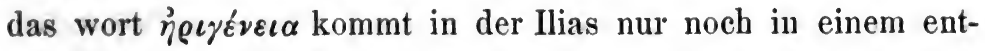
schieden späteren licde vor, $\Theta 5(18 .-481.482 .483=0 d$.

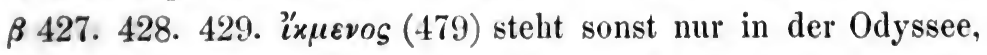
hier gleich in der nähe, $\beta 420$, in dem ganz ahnlichen verse

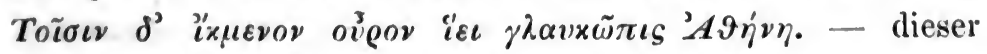
fortsetzer scheint also die hälfte seiner verse aus reminiscenzen und formeln zusammengesetzt zu haben und die s. 10 (IV am ende) hingestellte frage sich $z$ erledigen.

Der verfasser der zweiten fortsetzung wa nicht ohne gefuhl fur die darstellungsweise des gesanges den er weiter fuh-

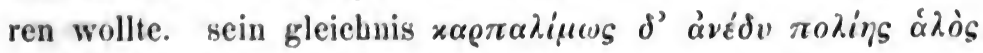

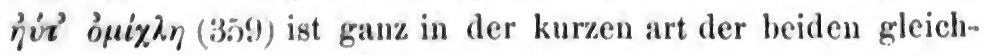

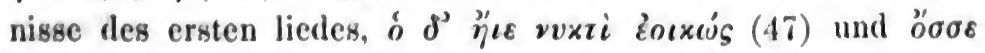

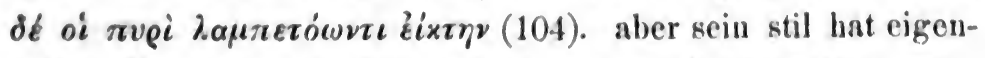
heiten die man zum theil als nenere ausdrucksweisen wird 


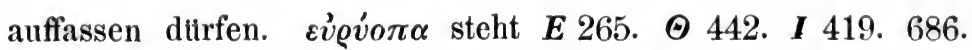
$N$ 732. $\Xi 203 . O$ 724. $P$ 545. $\Omega 296$ und siebenmahl in der Odyssee, $\beta$ 146. $\gamma$ 288. $\delta$ 173. $\lambda$ 436. $\xi 235$. $\varrho 322 . \omega 543$, immer als nominativus oder vocativus, immer vor Z $\boldsymbol{\varepsilon} \dot{v}$ s oder $Z \varepsilon \tilde{v}$, immer am versende, also ganz formelhaft unter fester bedin-

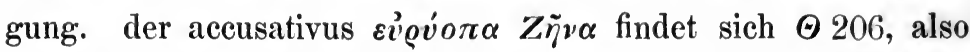
in einem verwerflichen stiucke, $\Xi 265$, also im dreizehnten liede das sich durch eigenthimlichkeit absondert, und $\Omega 331$, an allen drei stellen im versende. was wir $\boldsymbol{A} 498$ lesen, $\boldsymbol{E} \boldsymbol{v} \varrho \varepsilon v$

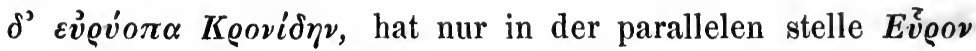

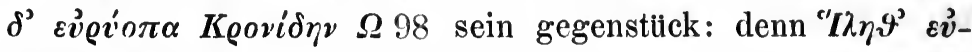

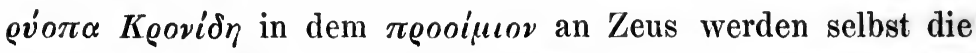
nicht rechnen denen sonst alles eins ist. ein anderes beiwort

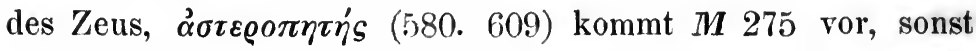
nur in einem schlechten stïcke $\boldsymbol{Z} 443$. ein drittes, $\boldsymbol{v} \psi \iota \beta \varrho \varepsilon \boldsymbol{\varepsilon} \dot{\varepsilon}-$

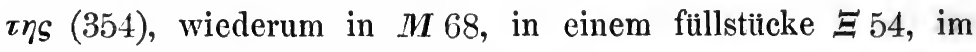

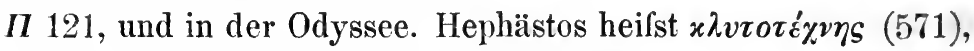

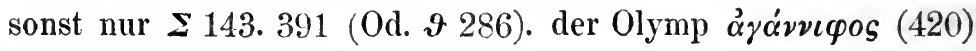
wie sonst nur wieder im $\Sigma 186 ; \pi \circ \lambda v \delta \varepsilon \iota \alpha_{s}$ (499), wie nur in demselben verse $\boldsymbol{E} 754 . \Theta 3$, also in dem absonderlichen fünften liede und in einem schlechten hinzugefigten stticke; $\alpha i y \lambda \eta^{\prime} \iota \varsigma$ (532) wie nur $N 243$ (und Od. $v$ 103). nur hier vor-

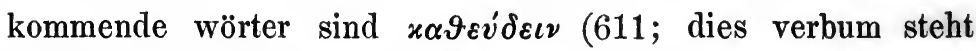
fünfmahl in der Odyssee; dafs es die Ilias sonst nicht kennt wird schwerlich zufall sein, da sie das einfache $\varepsilon v \delta \varepsilon \iota \nu$ dreifsig

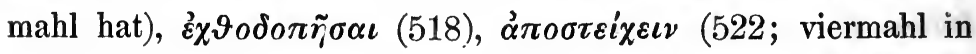

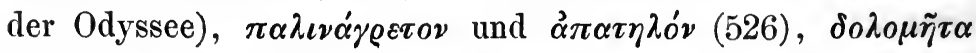
(540; auch die andere form $\delta o \lambda o \mu \tilde{\eta} \tau \iota s$ steht nur in der Odyssee), xolwós (575). nur hier (510) kommt die construction

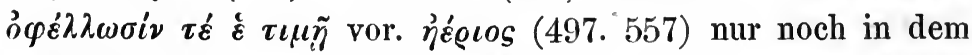
fillstiicke $\Gamma 7$ (und Od. $\iota 52$ ). $\delta \iota x \alpha ́ \zeta \varepsilon \iota \nu$ (542) nur noch $\Sigma 506$

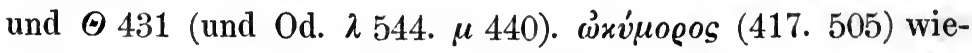
der $\Sigma 95.458$ (so in einem dreimahl gebrauchten verse der Odyssee, $\alpha 266$. $\delta 346$. $\varrho 137)$ und in anderer bedeutung $O 441$

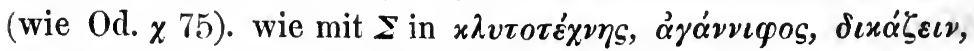

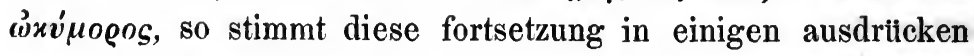




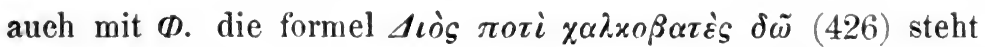
(D) 438. 505, und mit $x \alpha \tau \alpha \dot{~ i m ~ d r e i z e h n t e n ~ l i e d e ~} \Xi 173:$ x $\alpha \lambda x o-$ $\beta a \tau \eta \dot{s}$ sonst nur in der Odyssee, $\vartheta 321, \nu 4$. die formel $\eta^{3} \delta \dot{\eta}$

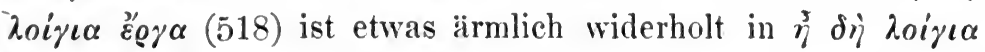

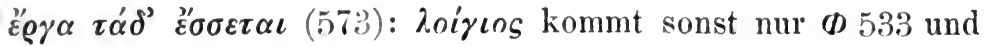
$\Psi 310$ vor. dafs endlich der vers 358 in $\Sigma 36$ steht verdient nach dem bei der ersten fortsetzung iiber $\beta \dot{\varepsilon} \nu \vartheta o s$ bemerkten beachtet $\mathrm{zu}$ werden.

zu s. 6.7 und 30 .

Der gleiche anfang der beiden fortsetzungen des ersten liedes,

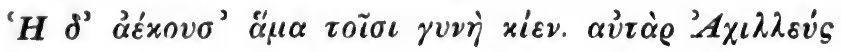

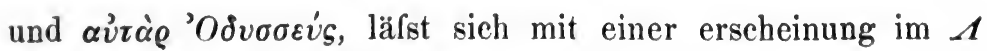
vergleichen. im $14^{n}$ liede war verbunden

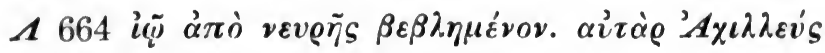

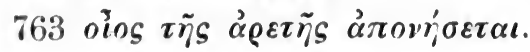

die unhomerische, den eiligen Patroklos wunderlich auf haltende

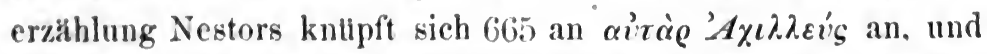
lenkt auf dieselbe weise wieder in den gang des echten stttekes ein, 762

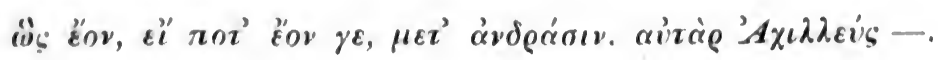


zu IV. s. 9.

Dafs die vier verse $B$ 239-242 unecht sind lälst sich noch deutlicher zeigen. auch 242 ist widerholt, aus $A 232$, und diese widerholung von worten des Achill, in ganz anderer beziehung, ist ärmlich in Thersites munde, dessen rede mit 238 lebendig und kräftig schliefst.

Thersites sagt kein wort von der pest; seine schmähsucht hätte aber gerade daran den erwïnschtesten anlafs zu vorwürfen gegen Agamemnon gehabt. das $\omega^{\prime}{ }^{~ '} A \chi \imath \lambda \eta \tilde{\eta} \alpha \quad \tau \mu \nu \eta \sigma_{\imath} \eta$ also des dichters ( $B 3$ ) spielt nicht auf das erste lied an, sondern nur auf die begebenheiten die dieses lied und gewifs auch andere (vergl. IX s. 21) erzählten.

Hermann (De iteratis apud Homerum) bemerkt mit recht dafs die beiden gleichnisse $B$ 144-146 und 147. 148 wegen zu grofser ähnlichkeit neben einander anstölsig sind: hinzusetzen kann man dafs sie wenigstens durch ein Oder verbunden sein mïsten. die ähnlichkeit geht bis auf den ausdruck, denn $\dot{\varepsilon} \pi \alpha \ddot{t}$ -

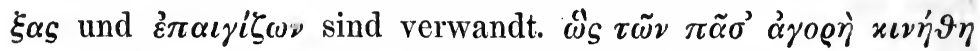
kann auf das erste gleichnis 144-146 folgen, das $x \iota \nu \eta^{\prime} \vartheta \eta \delta^{\prime}{ }^{\prime}{ }^{\prime} \gamma o \varrho \eta^{\prime}$ im nachsatze wieder aufnehmend; ich denke aber, dieses erste gewaltigere gleichnis (das aber $207 \mathrm{ff}$. ähnlich widerkehrt) wird das später hinzugethane oder statt des zweiten gesungene sein. so glaube ich dafs im elften buche das gleichnis vom esel ( 1558$)$ das ursprüngliche ist. nach dem schönen gleichnisse vom löwen (548) dies andere zu dichten oder jenes durch dieses 
zu ersetzen konnte keinem leicht einfallen. dagegen läfst sich denken dafs ein sänger die naive vergleichung des Aias mit einem esel für zu schwach oder für unwirdig des helden hielt und sie durch eine prächtigere ersetzte. ebenso scheint es mir auch am schlufse des zweiten liedes gegangen zu sein, dessen tubermälsige bilderfülle Hermann mit recht störend findet. 474-479 sind die heerführer mit hirten, Agamemnon mit Zeus Ares und Poseidon verglichen; gleich darauf (480-483) wird er zum stiere der herde. nach dem ersten dieser beiden gleichnisse konnte wohl niemand auf das andere gerathen. dieses scheint also das ursprüngliche $\mathrm{zu}$ sein, dessen schlichte einfalt ein anderer sänger durch ein glänzenderes zu überbieten suchte. die sammlung, die was an sich schön war sich nicht gern entgehen liefs, vereinigte beide. dafs die verse 469-473 an die vorhergehenden sich übel anschliefsen ist von Hermann bemerkt worden. aber dies gleichnis von dem fliegengewimmel hat in seiner einfalt fuir mich gerade etwas urspritingliches und es sollte wohl durch das zierlichere $459 \mathrm{ff}$. iiberboten werden. nach 458 giebt es mir keinen anstofs; auf ein bild für den waffenglanz des heeres kann sehr wohl ein anderes für die menge desselben folgen. beide beginnen mit ’̧úve. wie nun, wenn hierauf der dichter ein drittes gleichfalls mit $\eta \dot{v} \tau \varepsilon$ anreihte? 480-483, vom hervorragen Agamemnons. das dreifache

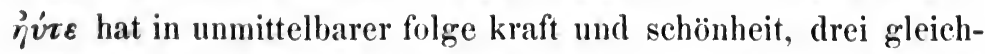
nisse fïr drei verschicdene dinge sind nicht zu tadeln, und wenn auch der dichter hier an ende seines licdes sicherlich des tuberflufses an bildern zum theil zu entledigen ist, an ausgefuhrten gleichnissen hatte er seine freude (87. 147. 209. 39:3), und dies unterscheidet ihn wesentlich ron dem dichter des ersten liedes, der in ungefähr gleicher verszahl nur zwei kurze unausgefthrte vergleichungen hat. 


\section{zu V. s. 11. 12.}

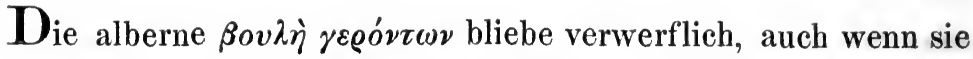
in der sprache gar nichts auffälliges hätie. aber aulser $\ddot{\eta} \vartheta \dot{q} \mu \iota s$ żoxiv (73), das in seiner formelhaften bedeutung hier ganz un-

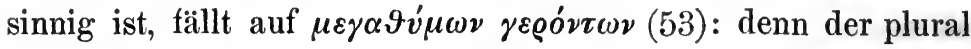
von $\mu \varepsilon \gamma \alpha \dot{q} \vartheta v \mu o$ s ist sonst nur epitheton der völkerschaften, der Achäer $(A$ 123. 135. $\omega$ 57), der Troer $(E$ 27. 102. $\Theta 155$. K 205. $A$ 294. 459. $N$ 456. 737. P 420. $\Psi$ 175. 181), Abanter (B 541. $\Delta$ 464), Aetoler (I 549. $\Psi$ 633), Epeier ( $\Lambda$ 732. 744. $O$ 519), Kaukonen $(\gamma$ 366), Kephallener (B 631), Paphlagoner

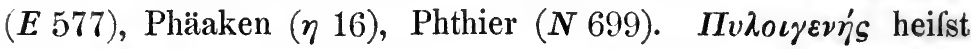
Nestor nur hier, und das wort steht sonst nur $\Psi 303$.

\section{zu s. 12.13.}

W enn Odysseus hier (zu anfang der rede) von den Achäern

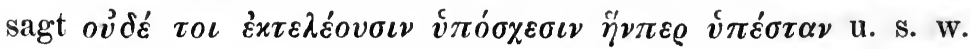
(286), so ist es fast lächerlich, wenn Nestor, als èr zu reden beginnt, mit gewaltigem anlauf doch gerade nur den gedanken ausspricht den schon Odysseus geäufsert hat, $339 \pi \tilde{\eta} \delta \dot{\eta} \sigma v y_{-}$

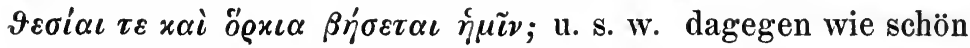
diese verse, wenn des Odysseus gerede wegfällt! wie aber der 
nachdichter seinen anfang aus dem der rede des Nestor genommen hat, so ist er auch sonst in seiner erfindung von Nestors rede abhängig. weil Nestor $350 \mathrm{ff}$. von Zeus siegverheifsendem blitze ermutigend spricht, so läfst er den Odysseus etwas ähnliches vorbringen, die geschichte von der schlange und den sperlingen.

\section{zu VII. s. 18.}

Gegen die freigegebene annahme éines dichters fiir das $2^{\text {e und }}$

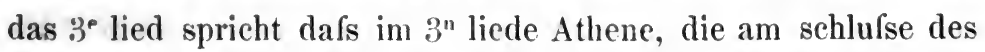
$2^{\text {n }}$ mit zum kampfe auszieht, ganz verschwunden ist (denn die flichtige andeutung $\Gamma 439$ steht in einem unechten stiicke) und

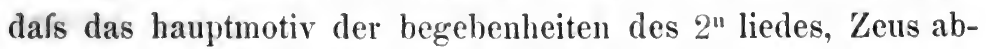
sicht den Achill zu räichen, hier ganz zurück tritt.

\section{zu VIII. s. 19 z. 20.}

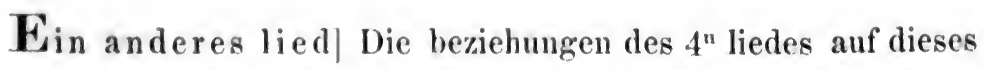
verlorene, die aus dem vorhandenen $3 "$ liede sich nicht erklärten, veranlafsten die interpolationen in $\boldsymbol{\Gamma}$. dies streben nach vereinbarung zeigt auch $r$ 439: denn ohne $\Delta ; \mathrm{ff}$. hätte der interpolator diesen vers schwerlich gemacht. 


\section{zu IX. s. 21.}

Der späte ursprung des $5^{n}$ liedes kann nach den beobachtungen von Geist, Disquisitiones Homericae (Giefsen 1832, wieder abgedruckt in Jahns archiv für philologie bd 1) nicht zweifelhaft sein, wenn auch nicht alles dort vorgetragene richtig oder richtig gefafst ist. aber in diesem späten liede lassen sich einige stellen als noch spätere zuthaten nachweisen.

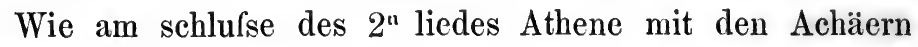
auszieht, so ist sie auch im $5^{n}$ liede, der fortsetzung des $2^{n}$, im heere, $\Delta 438.515 .541 . E 1.29 .121$. nachdem sie den Diomedes gegen Aphrodite angereizt hat, enteilt sie, $\dot{\alpha} \pi \dot{\varepsilon} \beta \eta$ 133: aber 290 lenkt sie Diomedes speer; sie ist also nicht etwa zum Olymp zurückgekehrt. aber 418 ist sie auf einmal auf dem Olymp: wie sie dahin kommt ist nicht gesagt. 'Athene und Here reizten stichelnd den Zeus' heilst es 418: aber Here redet kein wort. dies ist um so ungeschickter, da 419 steht roĩo

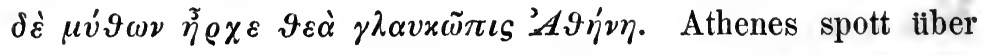
die verwundete Kypris ist ziemlich frostig; und nicht geschickt in den worten, denn nach $\tau \iota \nu \grave{\alpha}{ }^{\prime} A \chi \alpha \iota \alpha^{\prime} \delta \omega \nu 421$ ist dasselbe $\tau \iota \nu \grave{~ '} A \chi \alpha \iota \iota \alpha \dot{\alpha} \delta \omega$ unbehilflich. auch mufs ja Athene, wenn sie überhaupt zugegen ist, Kypris klage 376-380 wohl mit angehört haben: vor Kypris erzählung nähme sich der spott besser aus als jetzt, nach der heilung der verwundeten. auf Athenes spott lächelt Zeus und sagt zu Kypris sehr unbedeutendes. streicht man 418-431, so ist alles untadellich. die verwundete Aphrodite flieht zum Olymp; ihre mutter Dione tröstet und 
heilt sie -417. darauf wendet sich der dichter wieder $\mathrm{zu}$ dem von der Aphrodite verlassenen Aeneas, 432.

506. 507 wird erzïlt wie Ares, den Troem zu helfen, die schlacht mit dunkel umgiebt und (so geht es 508 weiter) die troischen scharen uinwandelt ( $\left.\pi \alpha^{\prime} \nu \tau \rho \sigma^{\prime} \dot{\varepsilon} \pi \sigma \iota \gamma^{\prime} \mu \varepsilon \nu \rho \varsigma\right)$, nach Apollons auftrag, der ihm geheifsen den Troern den mut zu erregen, nachdem er gesehen dafs Athene sich entfernt. Apollons geheifs an Ares steht 455-459. aber von einer entfernung Athenes ist dort kein wort gesagt, anch nicht dals Ares die Troer ermutigen solle; er soll den Diomedes aus der schlacht entferneu. un dies zu thun (denn so mufs man es verstehen) ermuntert Ares die Troer in Akamas gestalt, 461-470. er thut also schon dort was er hier noch cinmal thum soll, und was auch Hektor schon gethan hat, der von Sarpedon angefeuert

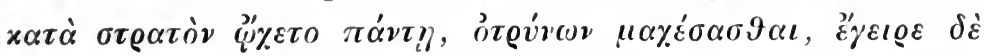

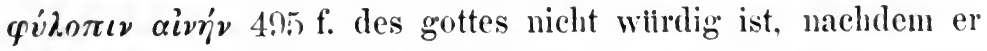
die Troer wunderbar in nacht gehitllt, dies iberflülsige thun. und ist jetzt, wo der angriff begommen hat, zeit zu unwande-

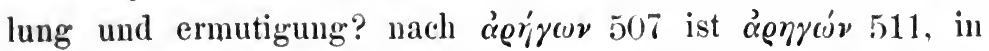
gauz matten flickworten, unschön. endlich aivós 512, in be-ziehung auf Doißov' 'A ó $_{\lambda} \lambda$ covos, ist zwar nicht unverständlich, entbehrt aber epischer klarheit. ich halte 508-511 für spätere einschiebung, und glaube dafs im echten liede 512 nicht aitós stand, sondern Goïßos.

Mit 711 beginnt ein gespräch Heres und Athenes, auf dem Olymp, wie man allmähllich merkt. Here gewahrt dafs die Achäer weichen. sie fordert $A$ thenen auf' sich mit ihr den 'Troem entgegenzustellen. darauf schimt sie mit Hebe ilmren wagen an; Athene wafinet sich und wirft die ägis um sich (die sie $B .44$; schon trägt). hierauf fahren beide zu Zeus auf den gipfel des Olympos. Here fragt den Zeus ob er erlaube den Ares aus dem kampfe zu entfernen, 757-7633. \%eus bejahende antwort wird mit seltsam knapper rede, 765.766 , abgethan. hicrauf fahren beide göttinnen hinab \%ur erde, \%u der stelle wo simois und Skamandros sich vereinigen. Here sehimt die rosse ans. die dann, in geworlk eingehullt (damit sie nicht gestohlen 
werden?) weiden. - warum die göttinnen den wagen verlassen sieht man nicht ein (Ares ist ja auf seinem wagen in der schlacht, bis er ihn der verwundeten Kypris abtritt, 363), oder warum sie zur niederfahrt vom Olymp des wagens sich bedienten. - sie eilen zu fufs dorthin wo um Diomedes das dichteste gedränge ist. Here ruft, mit ungeheurer stimme, dem Stentor gleich, den Achäern mut zu, 784-792. weiter thut sie nicht das mindeste, und man wundert sich billig dafs sie sich deshalb vom Olymp herab bemuiht hat und die erwartung, welche die lange beschreibung des anschirrens der rosse und die ganze vorbereitende erzählung erregt hat, teuscht. was von 793 an bis 906 folgt ist tadellos, bedarf aber, wenn Athene im heere ist, wo wir sie suchen, gar nicht des vorhergehenden stuckes. in diesem stücke nun ist $E$ 733-737 $=\Theta 384-388$,

$$
E \text { 745-752 = } \Theta 389-396 .
$$

in $\Theta$ ist alles in schönstem zusammenhange und gleichmafse der erzählung, so dafs Aristarchs urtheil (schol. $A$ zu $E 734$. $\Theta$ 385. 390) keine billigung verdient. auch die folgenden beiden verse 753.754 sind fast buchstäblich entlehnt aus der zweiten fortsetzung des ersten liedes $\boldsymbol{A}$ 498. 499. dort stehen diese beiden zeilen in festem zusammenhange der erzählung; hier ist vorher gar nicht gesagt dafs die göttinnen zu Zeus wollen. - die rïckkehr der göttinnen zum Olymp ist in drei oder vier versen, $E$ 907-909. $Z$ 1, eilfertig und dürftig, und nach der langen beschreibung ihrer wagenfahrt ohne alle symmetrie abgethan. die am Simois und Skamandros weidenden rosse sind ganz vergessen. $\boldsymbol{E} 908$ ist $=\Delta 8$, und entlehnung wahrscheinlich, da thene sonst nirgend ' $A \lambda \alpha \lambda x \rho \mu \varepsilon v \eta$ 's heilst. dals nun keine götter mehr in der schlacht waren ist $Z 1$ durch das

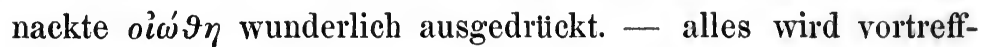
lich, wenn man 711-792 und 907-909. $Z 1$ hinweg nimmt. der zusammenhang ist dann von 703 an klar und ungestört. Hektor und Ares, viele tödtend, drängen die Achäer immer mehr zurück. da eilt Athene, noch immer im heere anwesend, zu Diomedes, regt ihn auf und begleitet ihn. er verwundet den Ares. Ares enteilt zum Olymp, wo Zeus ihn schilt, aber durch 


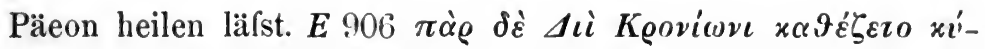

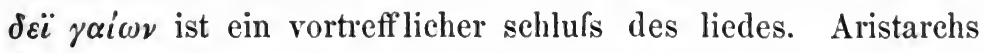

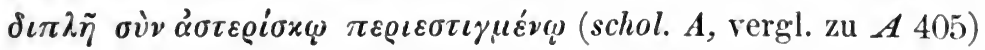
rührt aus irriger bedenkliehkeit her. $x \dot{\delta} \delta \varepsilon \ddot{i}$ yaicuv ist allgemeiner ausdruck göttlicher herrlichkeit. $A 405$ kam gestrichen werden, nicht ohne vortheil für die satzrerbindung.

Nach diesen athetesen besteht das $5^{\mathrm{e}}$ lied aus folgenden versen, $\Delta 422-E$ 417. 432-507. 512-710. 793-906.

Entfernt ist hiermit die stelle rom Stentor, deren seltsamkeit schon die alten bemerkten. die welche in den katalog verse uber ihn einschalteten, fühlten, indem sie ihn für einen Griechen hielten, sehr richtig dafs in dem langen gediehte, das sie als einheit betrachteten, ein solehes einmaliges vorkommen ohne beziehung anstörsig wäre. ein herold Nestors, wie die scholien BL zu B 96 angeben (auch mit Thootes irrend, der M 343 Menestheus herold ist), kann Stentor nicht sein: ein blofser herold wilrde schwerlich $\mu \varepsilon \gamma \alpha \lambda \eta^{\prime} \boldsymbol{t}(u \varrho$ genannt werden. die ihn fur einen Thraker erklärten und eine sage von ihm kannten, mögen recht haben; denn auf' Thrake führt die $\Sigma \tau \varepsilon v-$

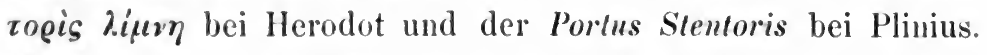
aber der in $L$ aufbewahrte einwand $\alpha \lambda \lambda^{\prime} z^{\prime} y^{\prime}{ }^{\prime}$ ' $O \mu \eta^{\prime} \varrho \omega$ tois

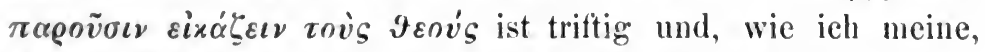
Aristarchs wllrdig, der seine diple hier nicht vergats. 


\section{zu X. s. 22.}

Wenn der dichter von den unvollendeten ó oxioıs wuste ( $\boldsymbol{H}$ 69), so war es doch allzu wunderlich dafs er da wo jeder es erwartet ihrer gar nicht erwähnte und so ein wirksames und naturliches motiv für reden des Aias und des Menelaos mutwillig oder nachlälsig aufser acht liefs. ich denke $\boldsymbol{H}$ 69-72 sind eingeschaltet, um eine anspielung auf früheres anzubringen, die man mit recht aber nicht an rechten orte vermilste. 73 ist dann $\delta \varepsilon ́$ zu streichen. der zusammenhang wird so (67. 68. $73 \mathrm{ff}$.) viel besser.

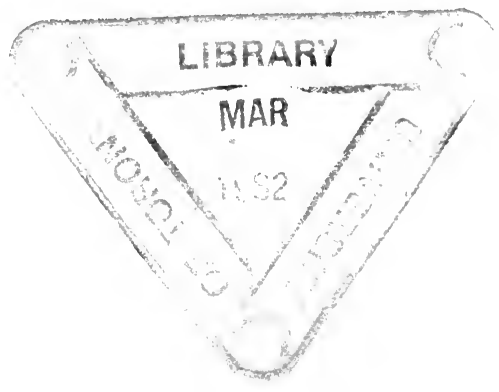





\section{PLeAse do NOT REMOVE}

CARDS OR SLIPS FROM THIS POCKET

\section{UNIVERSITY OF TORONTO LIBRARY}


$8 \%$

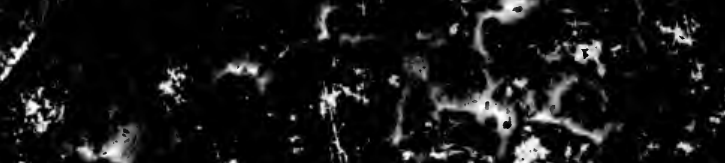

$30+2$

$+\infty=1+t^{2}$

$x^{2}$

atom (t), $x^{4}$

$x_{x}$

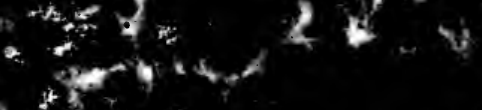

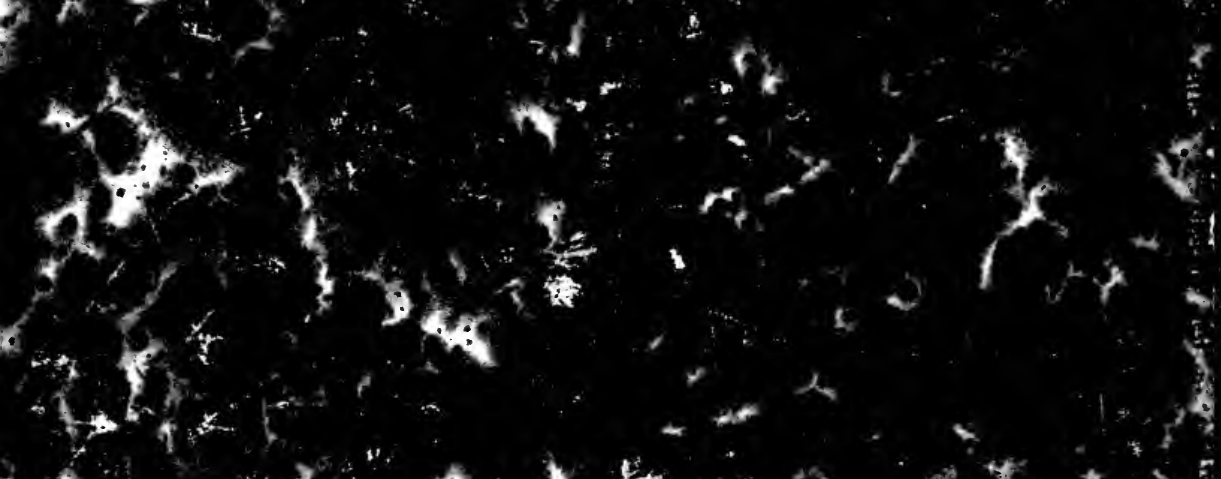

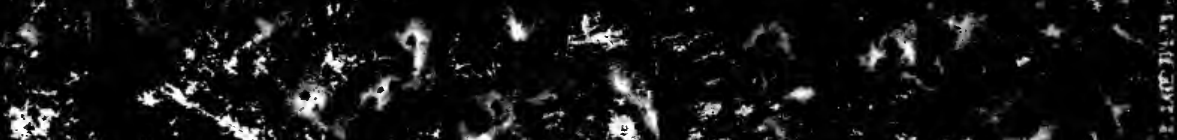

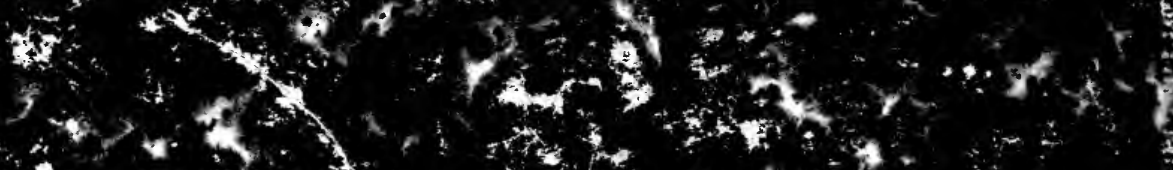

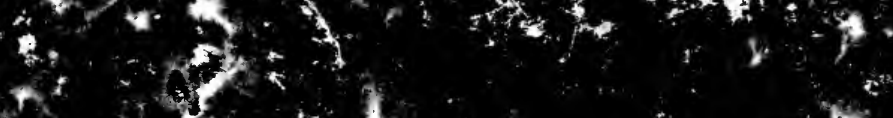

$x^{2} x+x$

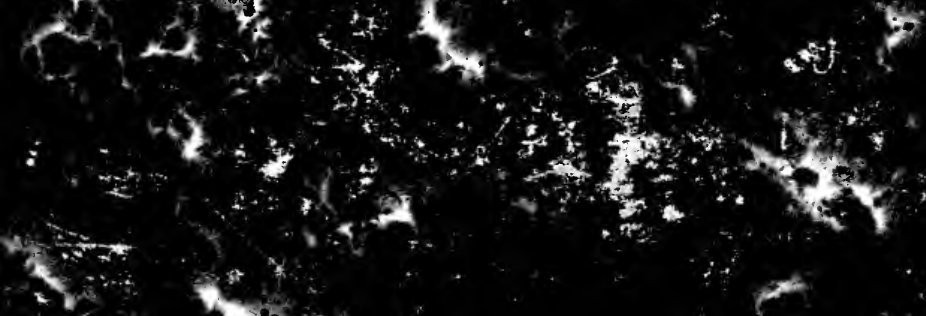

3

\&

+.

4,3

200 .

क $4 x=*$

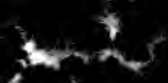

a.

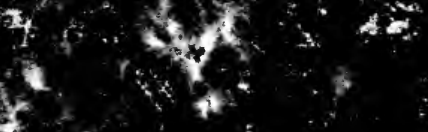

$x_{2}$

$-1+2+\infty+2$

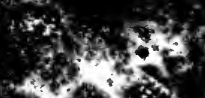

$\therefore$ औ.

80

$8+\cdots$

$+\infty$

4. $x^{3}, t^{3}, x^{3}$

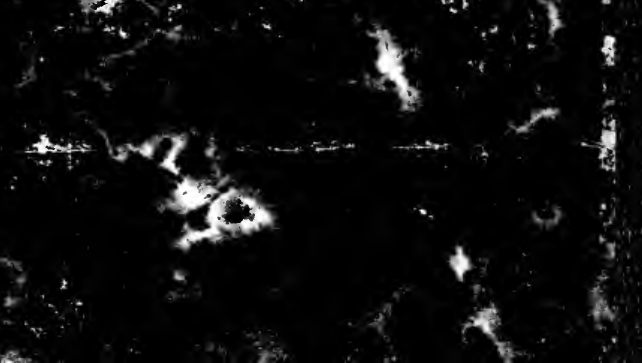

